\title{
Business Intelligence
}

Master

Cynthia El-Jaick Maranhão

TOPSIS VERSUS AHP: MÉTODOS MULTICRITÉRIO APLICADOS EM UM ESTUDO DE CASO

Monografia de Final de Curso

$22 / 12 / 2016$

Monografia apresentada ao Departamento de Engenharia Elétrica da PUC/Rio como parte dos requisitos para a obtenção do título de Especialização em Business Intelligence.

Orientadores: 
Dedicatória

Dedico aos meus pais pelo apoio e incentivo ao meu crescimento profissional e pelo eterno apoio em todas as minhas conquistas. 
Agradecimentos

Agradeço aos meus colegas de turma que mantiveram um clima de união e de motivação desde o início, proporcionando apoio nas horas em que cada um mais precisava.

Agradeço aos professores pela paciência em face das perguntas incansáveis: "Ok, mas, e na prática? "

Agradeço ao meu orientador, o professor Jesus Domech More, pela disponibilização de seu tempo, apoio ao tema proposto e sugestões dadas para melhoria do meu trabalho.

Por fim, agradeço a minha família que sempre valorizou o estudo e a busca por conhecimento, estimulando estes valores aos seus filhos. 
Believe those who are seeking the truth. Doubt those who find it.

—André Gide 


\section{RESUMO}

O presente trabalho tem como objetivo apresentar os métodos multicritério para classificação e seleção de projetos. Foi feita uma revisão bibliográfica dos principais métodos existentes, porém o estudo foi mais aprofundado nos métodos: AHP e TOPSIS, demonstrando-se a praticidade do seu uso no dia a dia e no auxílio à tomada de decisão. A fim de implementar as técnicas e realizar uma comparação entre as metodologias, foi escolhido um estudo de caso real chamado "Projeto Preparatório para o Gerenciamento dos Recursos Hídricos do Paraíba do Sul". Foram identificados seus prós e contras desses métodos na análise e ponderação dos vários critérios, bem como na classificação desses mesmos critérios e na seleção de projetos de investimento.

Palavras-chave: AHP; TOPSIS, tomada de decisão, multicritérios 


\section{ABSTRACT}

This paper aims to present the multicriteria methods for projects classification and selection. A bibliographical review was made of the main existing methods, but the study was more thorough in the methods: AHP and TOPSIS, demonstrating the practicality of its day-today use and in aiding decision-making. In order to implement the techniques and make a comparison between the methodologies, it was chosen a real case for this study, called "Preparatory Project for the Management of the Water Resources of Paraíba do Sul". Its pros and cons were identified in the analysis and weighting of the various criteria, as well as in the classification of these criteria and in the selection of investment projects.

Keywords: AHP; TOPSIS, decision-making, multi-criteria 


\section{LISTA DE TABELAS}

Tabela 1 - Técnicas de Decisão Analisadas . .14

Tabela 2 - Distribuição das publicações por áreas de estudo (MCDM) ..............................15

Tabela 3 - Distribuição das publicações por áreas de estudo (TOPSIS) .............................15

Tabela 4 - Distribuição da Nacionalidade dos Autores .................................................16

Tabela 5 - Família ELECTRE e seus problemas de decisão .............................................25

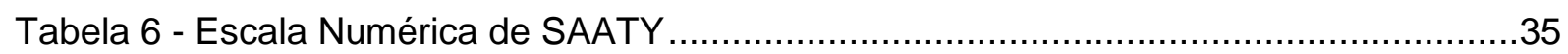

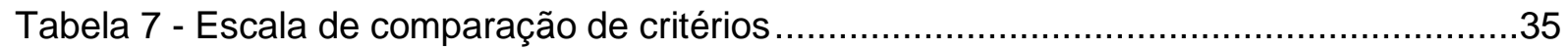

Tabela 8 - índice de consistência aleatória (CA) em função da ordem da matriz ..................35

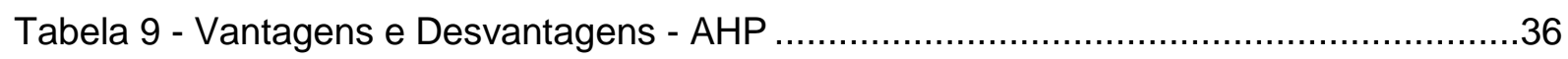

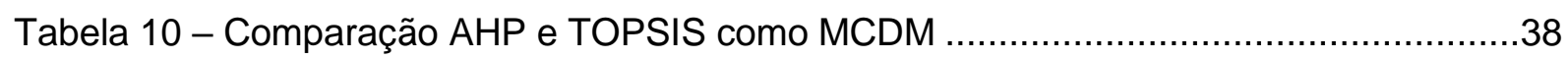

Tabela 11 - Comparação das principais características entre AHP e TOPSIS .....................38

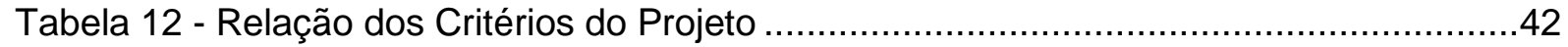

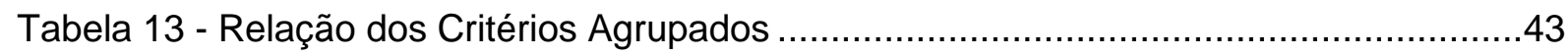

Tabela 14 - Relação do Critérios Classificados por AHP - Normalizados...........................47

Tabela 15 - Comparação Resultado do PPG x Estudo de Caso .........................................59

Tabela 16 - Resultados Absolutos e Normalizados ..........................................................64 


\section{LISTA DE FIGURAS}

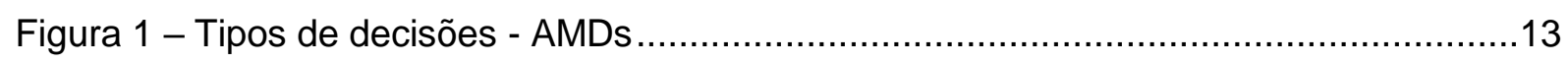

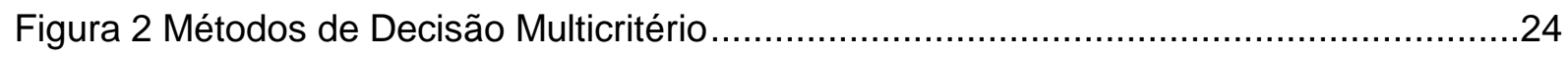

Figura 3 - Tipos de função de preferencias para critérios ...........................................27

Figura 4 - Estrutura hierárquica genérica de problemas de decisão …..............................29

Figura 5 - Estrutura hierárquica genérica de problemas de decisão ANP .........................30

Figura 6 - Estrutura de Avaliação da Avaliação de Performance .......................................31

Figura 7 - Capa do projeto utilizado como estudo de caso ...........................................39

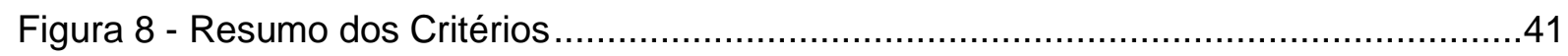

Figura 9 - Avaliação e peso dos critérios ...............................................................44

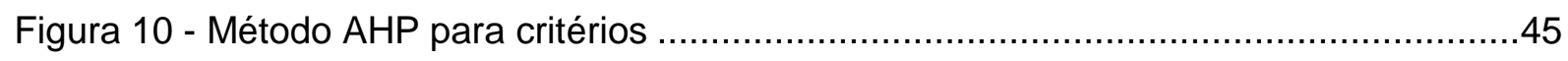

Figura 11 - Exemplo do cálculo normalização AHP ...................................................46

Figura 12 - Cálculo do peso por município ..........................................................

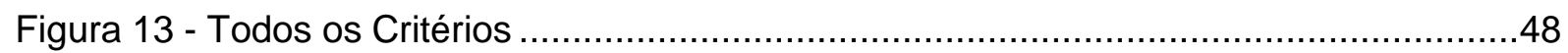

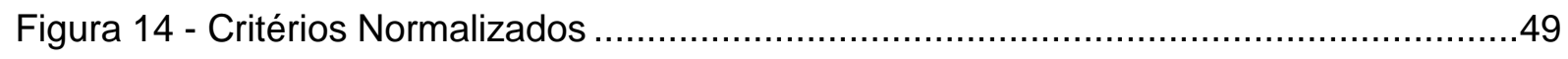

Figura 15 - Entropia, Diversidade e Peso …........................................................ 50

Figura 16 - Divisão do Valor Normalizado pelo Peso ....................................................50

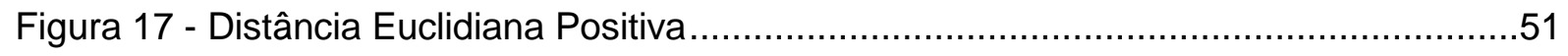

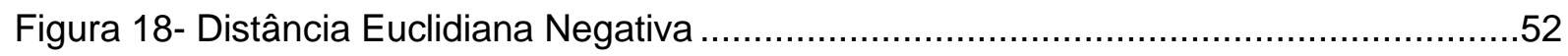

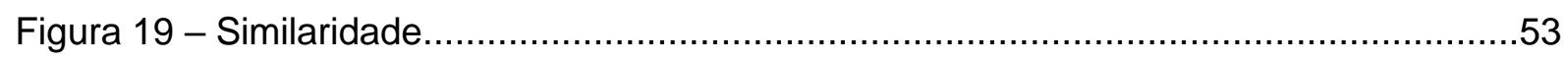

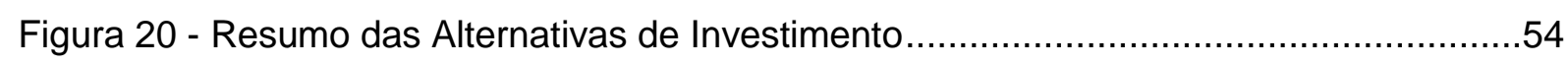

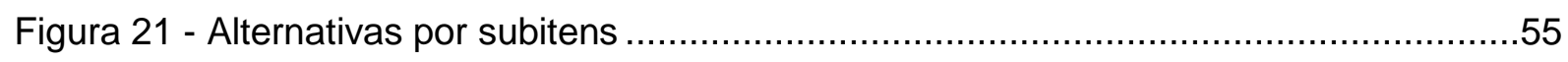

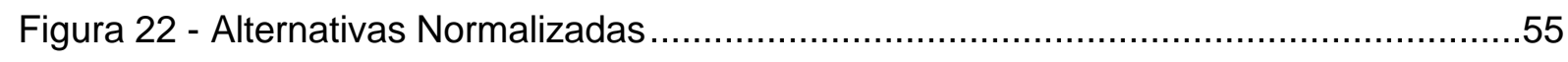

Figura 23 - Cálculo dos Pesos para os subitens .......................................................56

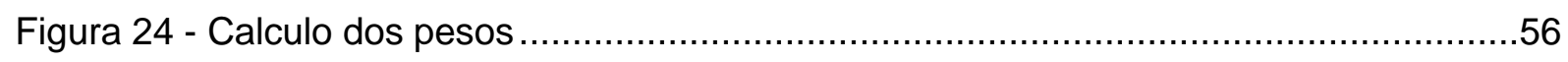

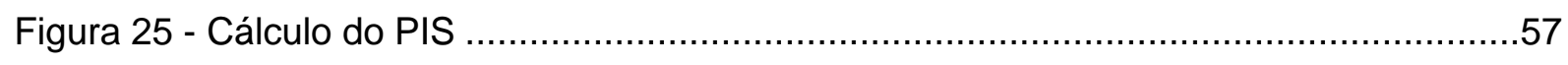

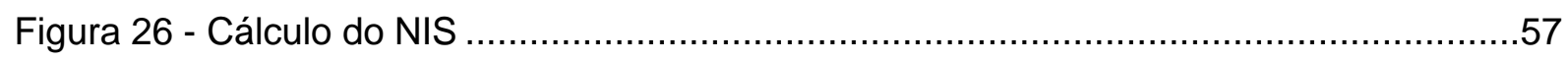

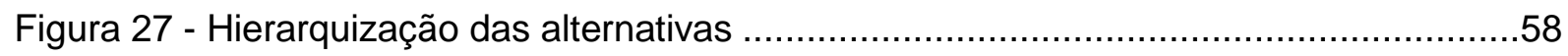


Figura 28 - Prioridade de critérios

Figura 29 - Resultado do Índice de Consistência realizado no estudo pela planilha Excel ...61

Figura 30 - Resultado Final Normalizado. .61

Figura 31 - Analise dos Valores Obtidos .62

Figura 32 - Comparação Resultados por município - valores absolutos 62

Figura 33 - Comparação Resultados por município - valores normalizados...... 63

Figura 34 - Gráfico das Alternativas para investimento. .65

Figura 35 - Aplicando TOPSIS na Alternativa .65 


\section{LISTA DE ABREVIATURAS}

ADMC - Análise de decisão com múltiplos critérios

AHP - The Analytical Hierarchy Process

AMD - Auxílio Multicritério à Decisão

ANP - Analytic network process

CA - Índice de consistência aleatória

CEIVAP - Comitê de Integração da Bacia do Paraíba do Sul

COPPE - Instituto Alberto Luiz Coimbra de Pós-Graduação e Pesquisa de Engenharia

CR - Razão de Consistência

DEA - Data Envelopment Analysis

ELECTRE - Elimination et Choice Translating Reality

IC - Índice de consistência

MADM - Multiple Attribute Decision Making

MCDA - Multiple Criteria Decision Aid

MCDM - Multiple Criteria Decision Making

MMAD - Método multicritério de apoio a decisão

MODM - Multiple Objective Decision Making

MTDM - Métodos de Tomada de Decisão Multicritério

NIS - Solução Ideal Negativa

PIS - Solução Ideal Positiva

PPG - Projeto preparatório para gerenciamento

PROMETHEE - Preference Ranking Organization Method for Enrichment Evaluations

SAW - Simple Additive Weighting

SPW - Simple Product Weighting

SRH/MMA - Secretaria de Recursos Hídricos do Ministério do Meio Ambiente

TOPSIS - Technique for Order Preference by Similarity to the Ideal Solution 


\section{Sumário}

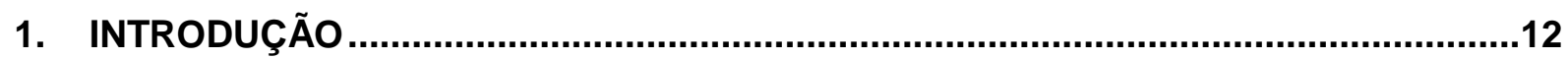

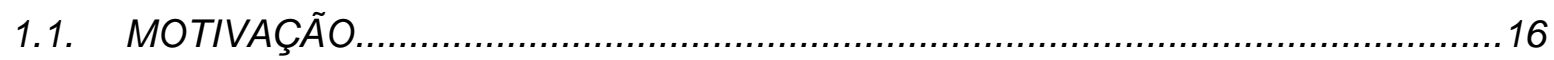

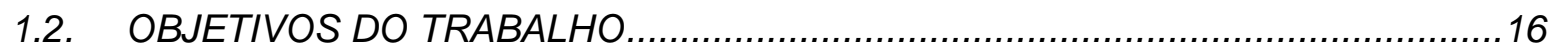

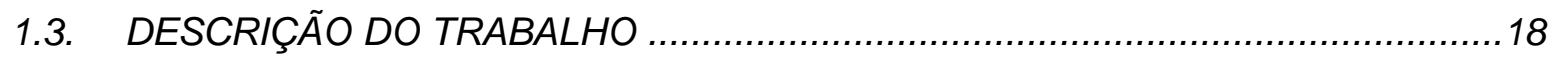

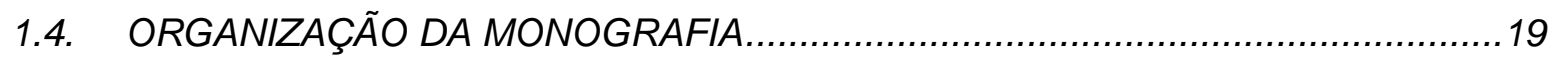

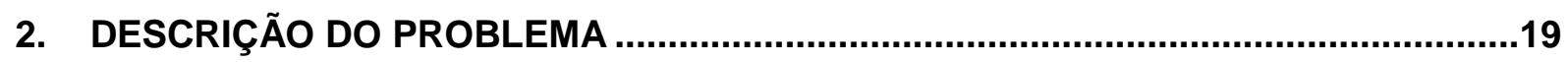

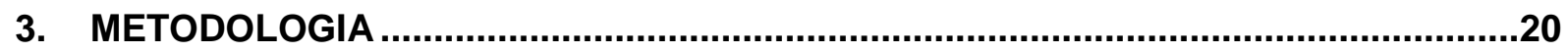

3.1. Métodos de Tomada de Decisão Multicritério - MTDM (Multicriteria Decision Making

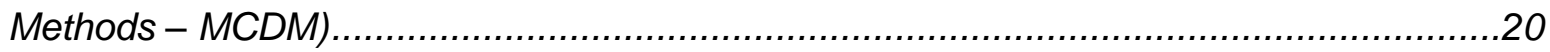

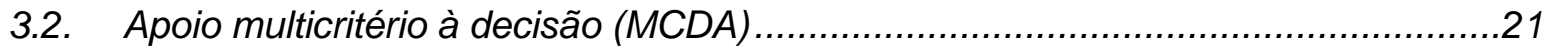

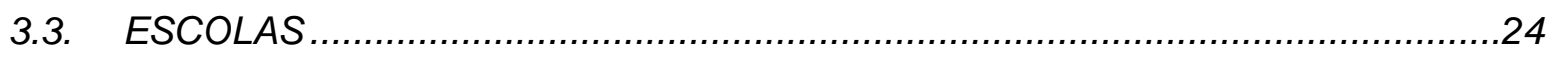

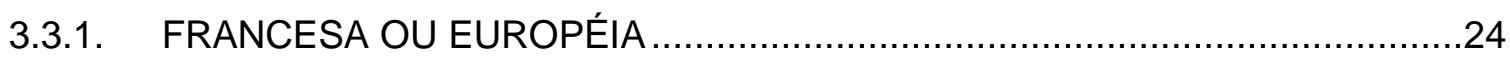

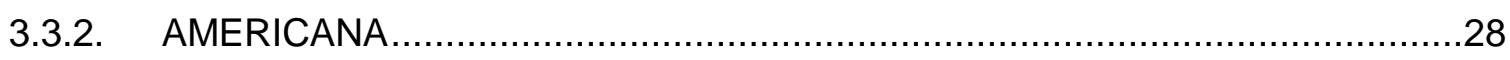

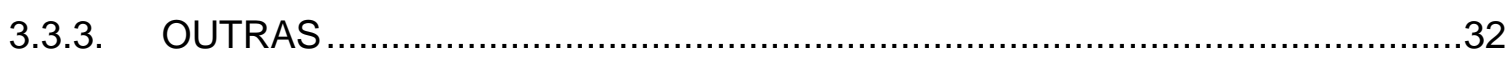

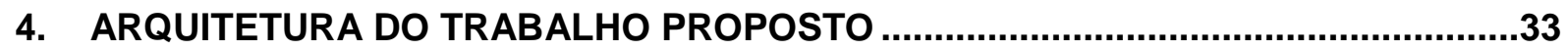

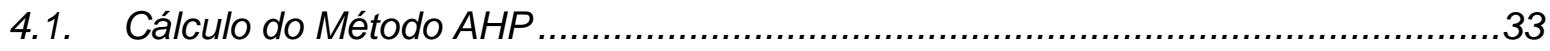

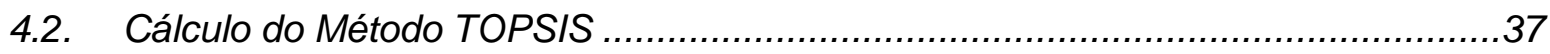

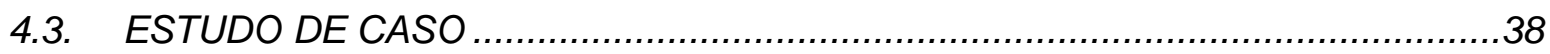

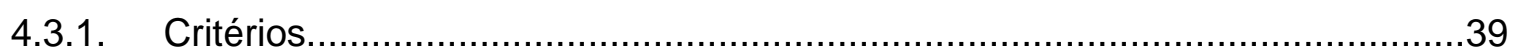

4.3.2. Cálculo - Metodologia AHP para os critérios ..............................................44

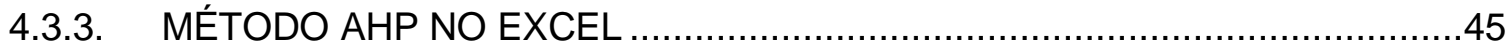

4.3.4. Cálculo - Metodologia TOPSIS para os critérios..........................................48

4.3.5. Cálculo - Metodologia TOPSIS para as Avaliações .........................................53

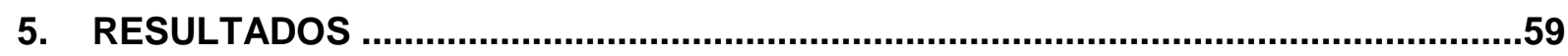

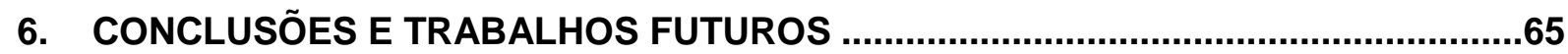




\section{INTRODUÇÃO}

A tomada de decisões está presente em todas as atividades humanas e constitui-se na mais importante função desempenhada por um executivo. A gestão de uma organização empresarial ou entidade governamental, de uma política pública, de um empreendimento específico ou mesmo de um simples projeto deve ser compreendida como uma sucessão de decisões que, uma vez postas em prática, abrem novas possibilidades e aproximam ou afastam a organização/ empreendimento/ projeto de suas metas conforme se mostrem adequadas ou não.

Uma decisão é, dessa forma, um ponto de direção no enfrentamento de um problema simples ou complexo, um comprometimento com a ação a ser desencadeada com vistas à sua solução imediata, de curto ou longo prazo.

O ser humano decide várias vezes ao longo de um dia. Desde o simples exercício de preferência sobre o que vai comer, às atividades que priorizará no seu dia e como vai preparar-se para atravessá-lo. Outras decisões requerem maiores reflexões, consomem mais tempo e demandam coleta de dados e negociações que permitam compreender melhor 0 contexto em que deverão ser tomadas, avaliar seus possíveis impactos e o esforço requerido para implementá-las e sustenta-las.

Xiang et al. (1992) identifica a tomada de decisões como sendo uma atividade humana complexa, possuindo três características proeminentes: múltiplos critérios, múltiplos participantes e imprecisão (fuzziness), independentemente de sua área de atuação

Gomes et al. (2002) apud Helmann e Marçal (2007) definem decisão como "o processo de colher informações, atribuir importância a elas, posteriormente buscar possíveis alternativas de solução e, depois, fazer a escolha entre alternativas". Ainda segundo o autor, tomada de decisões complexas é uma das mais difíceis tarefas enfrentadas individualmente ou por grupos, pois invariavelmente, tais decisões devem atender múltiplos objetivos e seus impactos não podem ser claramente identificados.

Segundo Freitas et al. (2005), a racionalidade reside na escolha dos meios (estratégia) mais adequados para o alcance de determinados fins (objetivos), no sentido de obter os melhores resultados. Dessa forma, as decisões de ordem estratégica e de planejamento a longo-prazo normalmente envolvem racionalidade limitada, múltiplos critérios, vários tomadores de decisão e incertezas.

Chiavenato (1999) identifica seis elementos para a tomada de decisão:

1. Decisor - pessoa, grupo, comitê, companhia que faz uma escolha ou opção entre várias alternativas; 
2. Objetivo - objetivos que o tomador de decisão pretende alcançar com suas ações;

3. Preferências - critérios que o tomador de decisão usa para fazer sua escolha;

4. Estratégia - metodologia para a tomada de decisão, para atingir seus objetivos;

5. Situação - aspectos ambientais, recursos e restrições;

6. Resultado - consequência do processo de decisão.

Enfim através da metodologia AMD - Auxílio Multicritério à Decisão é podemos tomar as seguintes decisões: atribuição de pesos (grau de prioridades), alocação de recursos (prioridades), ordenação ou ranking, escolha e classificação ordenada ou combinação de mais de uma delas.

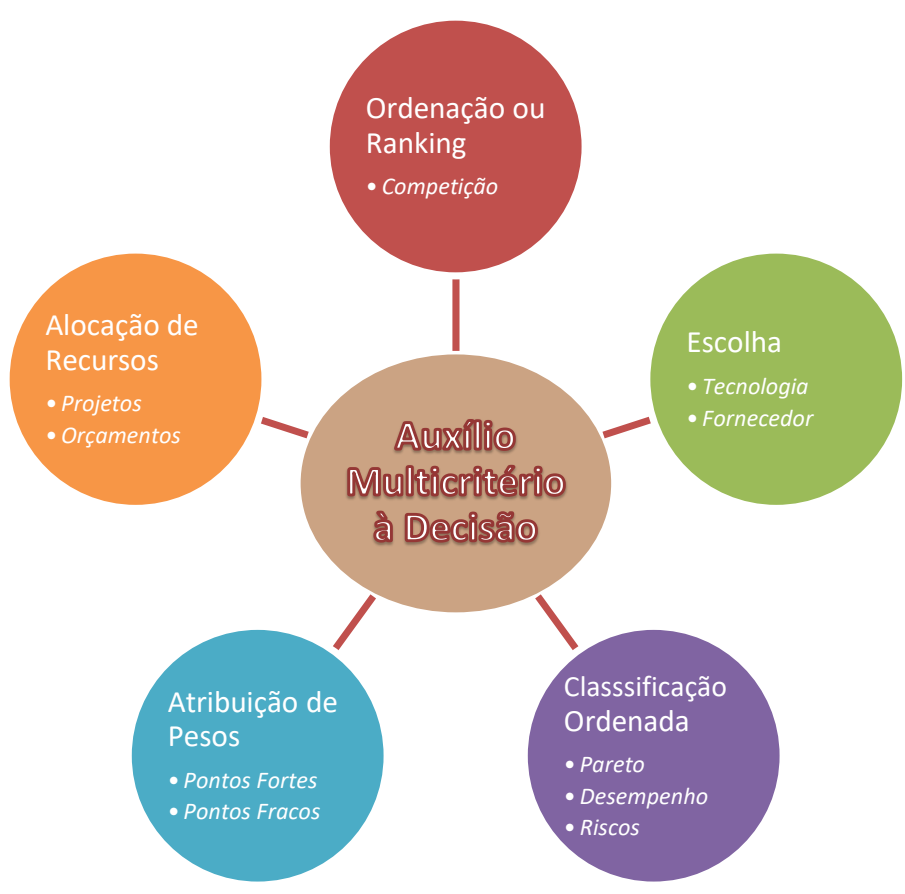

Figura 1 - Tipos de decisões - AMDs

Fonte: Adaptado pela autora de COSTA, H. http://slideplayer.com.br/slide/1233027/

No contexto voltado para a área de planejamento em recursos hídricos, Campos (2011) identifica seis tipos de metodologias:

1. Funções Multiatributo - agregam as preferências do decisor em uma função de valor e considera os pesos para cada atributo;

2. Sobreclassificação ou Superação - fazem a comparação entre ações potenciais por meio de relações binárias, determinando a superação de uma alternativa em relação a outra. Família ELECTRE e PROMETHEE;

3. Distância ideal - identificam valores ideais e não ideais para os critérios de decisão. TOPSIS e Programação de Compromisso. 
4. Comparação entre Pares - envolve a comparação entre alternativas e critérios par a par. AHP, ANP e MACBETH.

5. Lógica Fuzzy (Difusa ou Boleana) - modelos que trabalham com situações de incerteza, consideram valores lógicos intermediários entre 0 (falso) e 1 (verdadeiro).

6. Métodos baseados em série de Taylor - novos métodos de AMD baseados nos existentes ou algoritmos novos.

De acordo com o estudo de Mardani et al. (2015) em que realizaram uma revisão de bibliografia de um total de 393 artigos publicados no período de 2000 a 2014, em mais de 120 revistas especializadas extraídas do site Web of Science, agrupando em 15 campos de conhecimentos (Energia, meio ambiente e sustentabilidade, gestão da cadeia de suprimentos, gestão de materiais, qualidade, SIG, construção e gerenciamento de projetos, segurança e gerenciamento de riscos, sistemas de fabricação, gerenciamento de tecnologia, pesquisa operacional e soft computing, gestão estratégica, gestão do conhecimento, gestão da produção, gestão do turismo e outros). Houve um crescente aumento ao longo dos anos de publicações de artigos relacionados ao tema MCDM, iniciou-se com 3 artigos em 2000 indo para 10 em 2001. O ano de 2013 foi o ano que mais houve publicações totalizando em 75 artigos; o método mais abordado foi o AHP ficando em primeiro lugar e em quinto encontrase o método TOPSIS (Tabela 1 ).

Tabela 1 - Técnicas de Decisão Analisadas

\begin{tabular}{|l|r|r|}
\hline \# Técnicas de Decisão & N & \multicolumn{1}{|c|}{$\%$} \\
\hline 1 AHP & 128 & $32,6 \%$ \\
\hline 2 ELECTRE & 34 & $8,7 \%$ \\
\hline 3 DEMATEL & 7 & $1,8 \%$ \\
\hline 4 PROMETHEE & 26 & $6,6 \%$ \\
\hline 5 TOPSIS & 45 & $11,5 \%$ \\
\hline 6 ANP & 29 & $7,4 \%$ \\
\hline 7 Agregação de métodos de decisão & 46 & $11,7 \%$ \\
\hline 8 MCDM híbrido & 64 & $16,3 \%$ \\
\hline 9 VIKOR & 14 & $3,6 \%$ \\
\hline Total & $\mathbf{3 9 3}$ & $\mathbf{1 0 0 , 0 \%}$ \\
\hline
\end{tabular}

Fonte: Adaptado de Mardani et al. (2015).

As áreas de Energia, Meio Ambiente e Sustentabilidade foram classificadas como as áreas que veem merecendo maior atenção na aplicação de técnicas e abordagens MCDM (Tabela 2). Esta mesma publicação permitiu confirmar que o MCDM é o método de decisão mais utilizado nos diversos campos, como energia, ambiental, administração, economia, produção entre outros. As técnicas e abordagens melhoram a qualidade das decisões, criando o desenvolvimento mais eficiente, racional e explícito. 
Tabela 2 - Distribuição das publicações por áreas de estudo (MCDM)

\begin{tabular}{|l|r|r|}
\hline Áreas & N & \multicolumn{1}{c}{$\%$} \\
\hline Pesquisa operacional e computação soft & 109 & $30,0 \%$ \\
\hline Energia, meio ambiente e sustentabilidade & 53 & $14,6 \%$ \\
\hline Sistemas de fabricação & 32 & $8,8 \%$ \\
\hline Gestão da tecnologia da informação & 25 & $6,9 \%$ \\
\hline Gestão da cadeia de abastecimento & 23 & $6,3 \%$ \\
\hline Materiais & 21 & $5,8 \%$ \\
\hline Construção e gestão de projetos & 18 & $5,0 \%$ \\
\hline Gerenciamento de produção & 18 & $5,0 \%$ \\
\hline SIG & 14 & $3,9 \%$ \\
\hline Segurança e gestão de riscos & 14 & $3,9 \%$ \\
\hline Gerenciamento de qualidade & 12 & $3,3 \%$ \\
\hline Gerência de turismo & 11 & $3,0 \%$ \\
\hline Gestão Estratégica & 8 & $2,2 \%$ \\
\hline Gestão do conhecimento & 5 & $1,4 \%$ \\
\hline Outros campos & 30 & $8,3 \%$ \\
\hline Total & $\mathbf{3 6 3}$ & $\mathbf{1 0 0 \%}$ \\
\hline
\end{tabular}

Fonte: Mardani et al. (2015).

Com relação ao tema TOPSIS, Behzadian (2012) listou 266 artigos publicados em mais de 103 jornais acadêmicos, desde 2000 (Tabela 3).

Tabela 3 - Distribuição das publicações por áreas de estudo (TOPSIS)

\begin{tabular}{|l|r|c|}
\hline \# Áreas & N & \% \\
\hline 1 Gestão da Cadeia de Suprimentos e Logística & 74 & $27,5 \%$ \\
\hline 2 Design, Engenharia e Sistemas deFabricação & 62 & $23,0 \%$ \\
\hline 3 Gestão de Negócios e Marketing & 33 & $12,3 \%$ \\
\hline 4 Saúde, Segurança e Meio Ambiente & 28 & $10,4 \%$ \\
\hline 5 Gestão de Recursos Humanos & 24 & $8,9 \%$ \\
\hline 6 Gestão de Energia & 14 & $5,2 \%$ \\
\hline 7 Engenharia Química & 7 & $2,6 \%$ \\
\hline 8 Gestão de Recursos Hídricos & 7 & $2,6 \%$ \\
\hline 9 Outros tópicos & 20 & $7,4 \%$ \\
\hline Total & $\mathbf{2 6 9}$ & $\mathbf{1 0 0 \%}$ \\
\hline
\end{tabular}

Fonte: Behzadian et al. (2012).

Foi observado que 68,57\% (209) das publicações foram geradas por autores do Oriente Médio e Ásia (Taiwan, China, Irã, Turquia e Índia), enquanto que os EUA se encontra em sexto lugar com apenas 4,60\% (14 publicações) de um total de 305 (Tabela 4). 
Tabela 4 - Distribuição da Nacionalidade dos Autores

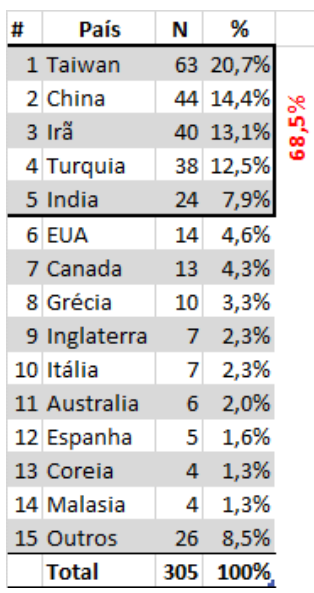

Fonte: Adaptado pela autora de Behzadian et al. (2012).

\subsection{MOTIVAÇÃO}

A grande dificuldade de tomada de decisão em ambientes em que os projetos estão cada vez mais complexos, com grande volume de informação, critérios e alternativas, vem a ser a busca por metodologias que priorizem e classifiquem por importância esses dados. A técnica mais utilizada, desde os anos 70, é o AHP. Porém, apresenta como desvantagem a limitação, em trabalhar com grandes quantidades de critérios/ alternativas, além de incorporar tendenciosidade dos decisores na tomada de decisão.

A necessidade de se utilizar uma técnica que não possua essa limitação, com relação a quantidade de critérios a se trabalhar e necessidade de ponderação externa ao sistema, levou a buscar então a utilizar o método TOPSIS. O trabalho proposto será realizar a comparação destas duas metodologias em um estudo de caso.

\subsection{OBJETIVOS DO TRABALHO}

O exposto até aqui mostra claramente a existência de políticas/planos/programas/ empreendimentos/projetos que reúnem um grau de complexidade tal que impõe a necessidade de empregar-se métodos multicritério capazes de orientar decisões de vários tipos, especialmente as que objetivam priorizar ações, escolhas ou mesmo um conjunto de alternativas de implementação viáveis tecnicamente, que abrigam um amplo conjunto de variáveis com influência direta nos resultados globais, muitas destas podendo ou devendo integrar o processo decisório na condição de critérios de seleção da alternativa a adotar ou priorizar, com diferentes performances ou consequências.

Considerados os elementos expostos nos parágrafos anteriores deste capítulo introdutório, é possível situar esta monografia no campo da Teoria da Decisão e delinear os 
limites e interesses específicos, recortando-os para conformarem-se com a proposta de monografia apresentada anteriormente.

O primeiro eixo delimitador é o foco aplicado na caracterização dos diferentes métodos de decisão multicritério, com objetivo de escolher dois dentre aqueles julgados mais atraentes para aplicações dirigidas à seleção e priorização de projetos. O projeto se estrutura também ao longo de um segundo eixo, que reúne projetos dotados de complexidade e com interações diretas com a conservação de recursos naturais, a qualidade de vida humana e o desenvolvimento regional. E ganha seus contornos finais com a seleção de dois desses métodos para aplicação a um caso concreto, com a finalidade de comparar os resultados que oferecem, assim como a adequação, acurácia e robustez de cada um.

A introdução deixou implícitas uma série de questões que essa monografia se propõe responder:

1. Há necessidade de se empregar métodos especiais que considerem o atendimento simultâneo de múltiplos objetivos, além dos vinculados à análise econômicofinanceira, tradicionais na avaliação de projetos/ empreendimentos?

2. Que métodos estão hoje disponíveis para avaliar projetos mais complexos e como podem eles ser adequadamente avaliados?

3. Como identificar métodos de decisão multicritério que possam ser aplicados com propriedade na tomada de decisão como propósito de estabelecer uma priorização/ seleção/ classificação de projetos ou empreendimentos que contemplem simultaneamente o uso de recursos naturais, melhoria da qualidade de vida, 0 desenvolvimento regional e proteção ambiental?

4. Uma vez escolhidos dois métodos de decisão multicritério com diferentes características, e aplicados a um caso concreto, como se comparam os resultados obtidos com essa aplicação? Que adequações e que limitações apresentam?

5. Qual, dentre os métodos escolhidos para essa análise comparativa, admite melhor a participação social mediante incorporação de tomadores de decisão que representem segmentos da sociedade no processo decisório?

6. Diante da possibilidade de introdução de tendenciosidade (bias) pelos decisores na etapa de ponderação dos critérios selecionados, qual dos métodos comparados apresenta menor suscetibilidade de ter os resultados afetados por essa conduta, adotada intencionalmente ou não?

7. Em uma avaliação ex-post conduzida na comparação dos resultados obtidos com os dois métodos escolhidos em um caso concreto de análise multicritério, qual dos dois se mostrou mais adequado para o tipo de problema considerado perante o "estudo de caso" escolhido? Qual deles se mostra suficientemente robusto para priorizar projetos que integram um portfólio amplo de projetos de intervenções com potencial de 
impactar ambientalmente bacias hidrográficas (positiva ou negativamente) cobrindo situações complexas?

Definem-se, assim, os objetivos da presente monografia: comparar dois métodos de decisão multicriterial entre si, após uma avaliação dos métodos disponíveis, aplicando-os a um caso real, avaliando a precisão e a robustez de cada um, assim como sua susceptibilidade a escolhas tendenciosas dos decisores. O caso escolhido foi a escolha e priorização de projetos de estações de tratamento de esgotos em sedes municipais da bacia do rio Paraíba do Sul, no âmbito do Projeto de Qualidade de Água da Bacia do Paraíba do Sul - Projeto Inicial, realizado em 1999, no qual foi aplicado o método AHP, a partir de um programa desenvolvido pela COPPE - UFRJ e que contou com um grupo de decisores do Comitê de Integração da Bacia do Paraíba do Sul - CEIVAP.

Adicionalmente, tendo em vista os altos custos envolvidos na aquisição de sistemas de suporte à decisão e outros softwares de decisão multicriterial, bem como a necessidade cortar custos e reduzir os prazos associados ao emprego desses métodos, procurou-se utilizar o software Excel, de amplo emprego nas empresas, desenvolvendo fórmulas/ algoritmo para cada método selecionado em uma planilha Excel, que não apenas organize os dados de entrada mas registre as ponderações de cada decisor participante do processo, realize os cálculos, registre os resultados em tabelas e, ainda, construa gráficos que auxiliem na análise dos resultados obtidos

\subsection{DESCRIÇÃO DO TRABALHO}

Tendo em conta os objetivos estabelecidos, o trabalho foi elaborado em cinco etapas:

1. Uma pesquisa bibliográfica e revisão da literatura técnica, interessando o tema Teoria da Decisão, na biblioteca da PUC e em sites da INTERNET cobrindo livros, artigos científicos, teses de mestrado ou doutorado. O foco foi concentrado na evolução e comparação das metodologias de decisão, buscando principalmente compreender os fundamentos teóricos, as diferentes correntes metodológicas, os vários métodos propostos e suas aplicações. Uma análise mais minuciosa sobre os métodos de análise multicriterial, com ênfase nos métodos AHP e TOPSIS, particularmente quanto aos procedimentos de cálculo de cada um, em um segundo exame da bibliografia reunida.

2. Um estudo detalhado sobre o "caso" escolhido: a priorização de projetos de estações de tratamento de esgotos que integram um portfólio de projetos do Plano de Qualidade de Água da Bacia do Rio Paraíba do Sul, a partir dos relatórios produzidos pelos responsáveis por essa decisão. O caso se encontra relatado no endereço: http://www.hidro.ufrj.br/ppg/ documentos RE-26, RE-30 e RE-50, e a aplicação do 
método se deu em 1999, por professores da COPPE/UFRJ, com decisores selecionados pelo CEIVAP (Comitê para Integração da bacia Hidrográfica do Rio Paraíba do Sul).

3. O desenvolvimento das fórmulas/ algoritmos de cálculo para cada método selecionado, com a assistência de uma planilha Excel.

4. A análise comparativa dos resultados obtidos aplicando cada método, visando identificar como atenderam às exigências definidas.

5. O estabelecimento de um conjunto de conclusões em acorde com os objetivos determinados, juntamente com recomendações para a continuidade das pesquisas sobre o emprego de métodos de decisão multicriterial em problemas e situações cuja complexidade não permita a simples aplicação de métodos mais simples baseados exclusivamente na vertente econômico-financeira.

\subsection{ORGANIZAÇÃO DA MONOGRAFIA}

O trabalho desenvolvido, está contido em 5 capítulos que se seguem a esta Introdução, cujos conteúdos principais são resumidamente descritos nos parágrafos seguintes.

O capítulo 2 apresenta a Descrição do problema.

O capítulo 3 trata da Metodologia, oferece-se ao leitor uma síntese da revisão empreendida da bibliografia existente sobre tomada de decisão de projetos, histórico e a lista que define os métodos de avaliação multicritério existentes, principais e mais usados.

No capítulo 4 detalha a arquitetura do sistema proposta, isto é, realiza um aprofundamento das técnicas selecionadas para o estudo de caso e explica o passo a passo dos cálculos realizados.

O capítulo 5 concentra-se os seus resultados e suas abordagens.

Por fim, o capítulo 6 oferece as conclusões e recomendações para a continuidade das investigações ora empreendidas.

\section{DESCRIÇÃO DO PROBLEMA}

A seleção e/ ou hierarquização de projetos é assunto de grande relevância do ponto de vista de investimentos financeiros, devido à complexidade dos projetos hoje empreendidos. Eles exigem grandes equipes multidisciplinares, bem como enfrentam uma competitividade 
por recursos financeiros e físicos, além de disputas por mercados, fazendo com que seja necessária a utilização de métodos que permitam agilizar, conferir precisão e confiança às tomadas de decisão e, dessa forma, otimizar projetos, maximizando seus resultados e retirando a subjetividade de julgamentos baseados exclusivamente em procedimentos incompatíveis com a natureza do problema. Para isso, é importante verificar, através de um caso real, a aplicabilidade da lógica TOPSIS e comparar com o método de Hierarquização AHP (método SAATY) se os resultados finais são semelhantes e confiáveis, possibilitando a utilização do TOPSIS como uma ferramenta no dia a dia na escolha de projetos.

\section{METODOLOGIA}

Foi feita pesquisa bibliográfica buscando artigos na internet e principais bases de dados científicos como: Science Direct, Google Scholar, Scielo, Web of Science, bases de monografia de universidades, artigos científicos nacionais e internacionais, utilizando como palavras-chaves: TOPSIS, Apoio Multicritério à Decisão (AMD), Método multicritério de apoio a decisão (MMAD); AHP; Os termos de busca utilizados em inglês foram: Multiple Criteria Decision Making (MCDM), Multiple Criteria Decision Aid (MCDA).

\subsection{Métodos de Tomada de Decisão Multicritério - MTDM (Multicriteria Decision Making Methods - MCDM)}

O Método de Tomada de Decisão Multicritério (MCDM) é uma ferramenta relativamente nova, com cerca de 40 anos. Ela se propagou juntamente com 0 desenvolvimento dos computadores, tornando possível a análise de problemas complexos de MCDM, sendo cada vez mais necessário o seu uso, devido ao grande volume de informação gerada diariamente.

Ho (2008) define MCDM como um termo genérico para definir todos os métodos existentes que auxiliam as pessoas a tomar decisões, de acordo com suas preferências, nos casos em que existam mais de um critério conflitante. Para Mardani et al. (2015) nas décadas mais recentes houve um aumento significativo nas principais áreas do MCDM: modelos formais (algoritmos, procedimentos e seleção de paradigmas); teorias de avaliação (suposições sobre valores ou preferências e representações estruturadas de valores ou preferências); metodologias de avaliação (elicitação, estimativa e escalonamento das preferências dos indivíduos, utilidades e probabilidades subjetivas em situações MCDM).

As primeiras técnicas envolvendo análise de decisões complexas surgiram com a Pesquisa Operacional, na década de 50, durante a $2^{\text {a }}$ Guerra Mundial, para resolução de 
problemas logísticos-militares nas forças armadas, quando o agente da decisão fazia uso de múltiplos critérios para auxiliá-lo no processo decisório. Segundo Chiavenato (1999) consistiu na "aplicação de métodos, técnicas e instrumentos científicos a problemas que envolvam as operações de um sistema, de modo a proporcionar, aos que controlam o sistema, soluções ótimas para o problema".

$\mathrm{Na}$ década de 60 surgiram métodos probabilísticos, voltados para a tomada de decisão, que foram aplicados em diversos trabalhos técnicos, desenvolvidos até a década passada (GOMES E FREITAS JR., 2009 apud WERNKE E BORNIA, 2001).

Na década de 70, pesquisadores perceberam que certas decisões, na prática, não podiam ser tomadas baseadas apenas em um critério de decisão. A partir dessa observação surgiram as metodologias de Apoio multicriterial à decisão (métodos AMD), que passaram a incorporar critérios subjetivos do tomador de decisão. Para viabilizar a inclusão destes critérios na análise, estabeleceu-se uma métrica comum aos diversos critérios utilizados. A psicologia quantitativa foi utilizada para converter a expressão das preferências destes critérios em uma escala. Dessa forma, as soluções alternativas para a decisão puderam ter o critério "conforto", por exemplo, sendo avaliado e comparado em uma escala de 0 a 10 (NUNES JR, 2006)

Nas décadas de 70 e 80, houve o surgimento de várias técnicas novas de avaliação por múltiplos critérios que ajudaram os administradores a decidirem de forma eficaz em relação a custos, e também, riscos e desempenho quando da análise de alternativas de investimento. Entre as abordagens que surgiram, em resposta a estas questões, talvez as mais importantes tenham sido as Metodologias Multicritério de Apoio à Decisão metodologias MCDA. (WERNKE E BORNIA, 2001).

Desde o seu surgimento, o estudo de problemas de decisão inseridos em um ambiente complexo tem sido objeto de preocupação de pesquisadores sobre o assunto. Nos itens destaca-se alguns métodos aplicados aos problemas de decisão com múltiplos critérios, dentro da área de Pesquisa Operacional, de onde surgiu o campo de estudo Apoio Multicritério à Decisão.

\subsection{Apoio multicritério à decisão (MCDA)}

O Método de Apoio ou Auxílio à decisão baseado em multicritérios ou múltiplos atributos ou múltiplo objetivos, também denominado Análise de decisão com múltiplos critérios (MCDA), pode ser aplicado em várias áreas, com o objetivo de selecionar, ordenar, classificar ou descrever, dentre as alternativas visualizadas em um processo decisório na presença de múltiplos critérios. Em inglês é conhecido como: Multiple Attribute Decision Making (MADM), 
Multiple Criteria Decision Making (MCDM), Multiple Objective Decision Making (MODM), Multiple Criteria Decision Aiding (MCDA). Porém alguns autores não citam todos estes como sinônimos, mas sim campos dentro MCDM, isto é, MADM seria um campo pertencente a MCDM (GOMES et al., 2002). Enfim, as terminologias se confundem; ao longo deste trabalho adotar-se-á o termo Método de Tomada à Decisão Multicritério (MCDM) como designativo genético de todos as situações particulares que tratem de métodos de decisão que consideram critérios múltiplos.

Oliveira (2003) apud Campos (2011) cita como vantagens para a metodologia de decisão multicritério:

a) Fácil uso por não especialistas, softwares mais amigáveis possíveis para o usuário, dispondo de recursos gráfico-visuais;

b) Metodológico e transparente;

c) Livre de ambiguidade para interpretações dos dados de entrada;

d) Engloba tanto critérios quantitativos como qualitativos;

e) Julgamentos de valor

f) $O$ decisor deve dispor de algoritmos que permitam a utilização de critérios independentes uns dos outros

g) Incorpora questões do comportamento humano nos processos de decisão.

A tomada de decisão multicritério refere-se à busca da melhor opinião de todas as alternativas viáveis na presença de critérios de decisão múltiplos, geralmente conflitantes. (BALL E KORUKOĞLU, 2009)

O objetivo desse modelo não é apresentar uma solução final única para o problema, mas sim apoiar o processo decisório, recomendando ações ou cursos de ações a quem vai decidir. É apenas um conjunto de métodos e técnicas para auxiliar ou apoiar pessoas e organizações a tomarem decisões, sob a influência de uma multiplicidade de critérios (GOMES et al., 2002). Se a qualidade da informação disponível, ao longo do processo de resolução de um problema complexo é de inquestionável importância, também o é a forma de tratamento analítico daquela mesma informação. Dessa forma deve-se agregar valor a qualidade da informação, havendo, por conseguinte, uma perfeita simbiose entre a qualidade da informação e a qualidade da decisão, segundo Gomes \& Freitas Jr. (2000) apud Wernke e Bornia (2001). De acordo com Arroyo (2002) apud Campos (2011), na solução de problemas multiobjectivo, podem ser identificados dois aspectos importantes: busca de soluções (processo de otimização) e tomada de decisões que envolvam a seleção de critérios adequados para a tomada de uma solução eficiente. E necessário que o decisor faça concessões (trade-off) em torno dos objetivos conflitantes. 
O apoio multicritério a decisão não busca uma solução ótima predeterminada para o problema, como ocorre na pesquisa operacional tradicional, mas uma solução de compromisso, em que as prevaleça o consenso entre as partes envolvidas. (Gomes et al., 2002).

Os principais problemas da abordagem de avaliação multicritério são: estruturação do problema a resolver (decisão a tomar), confiabilidade da informação, tempo de coleta das informações, custo da aquisição e destas informações, além dos critérios a serem adotados e o desenho das alternativas (soluções possíveis) para que se possa realizar a seleção da melhor opção, a partir de um conjunto disponível.

Segundo Campos (2011) as Escolas Americana e Francesa foram as pioneiras na utilização de Método de Tomada à Decisão Multicritério (MCDM) nas décadas de 70 e 80 , substituindo os modelos de pesquisa operacional (FREITAS et al., 2005).

Para Diehl (1999) apud Freitas et al. (2005), esse tipo de abordagem não apresenta uma solução ideal para os problemas, porém a mais coerente com a escala de valores e o método, entre todas as possíveis. Dentre as muitas classificações empregadas para designar os métodos do MCDM, as que subdivide os métodos são:

a) Escola Francesa ou Europeia - Métodos de subordinação ou outranking, uma modelagem mais flexível do problema, pois não admite necessariamente a comparabilidade entre todas as alternativas. Uma alternativa pode ser preferida a outra de modo estrito ou fraco, pode ser indiferente, mas também pode ser incomparável, o que não é admitido na Escola Americana. (GOMES et al., 2004).

- ELECTRE (Elimination et Choice Translating Reality)

- PROMETHEE (Preference Ranking Organization Method for Enrichment Evaluations)

b) Escola Americana - Métodos de agregação a um critério único de síntese, isto é, critérios/atributos recebem pesos (valor atribuído) diante de outros com mais ou menos importância, permitindo assim definir uma função que busca agregar valores de cada alternativa classificada em cada critério. Apresenta-se o efeito trade-off ou "taxa de substituição" de um atributo em relação a outro, agregando todas as informações acerca do problema que se pretende resolver por meio de uma função utilidade que tem que ser otimizada.

- $\quad$ AHP (The Analytical Hierarchy Process)

- $\quad$ ANP (Analytic network process)

- TOPSIS (Technique for Order Preference by Similarity to the Ideal Solution) 
c) Outras metodologias que não se enquadram nestas duas escolas como por exemplo:

- SAW (Simple Additive Weighting)

- SPW (Simple Product Weighting)

- DEA (Data Envelopment Analysis)

A figura 2 apresenta os principais métodos utilizados.

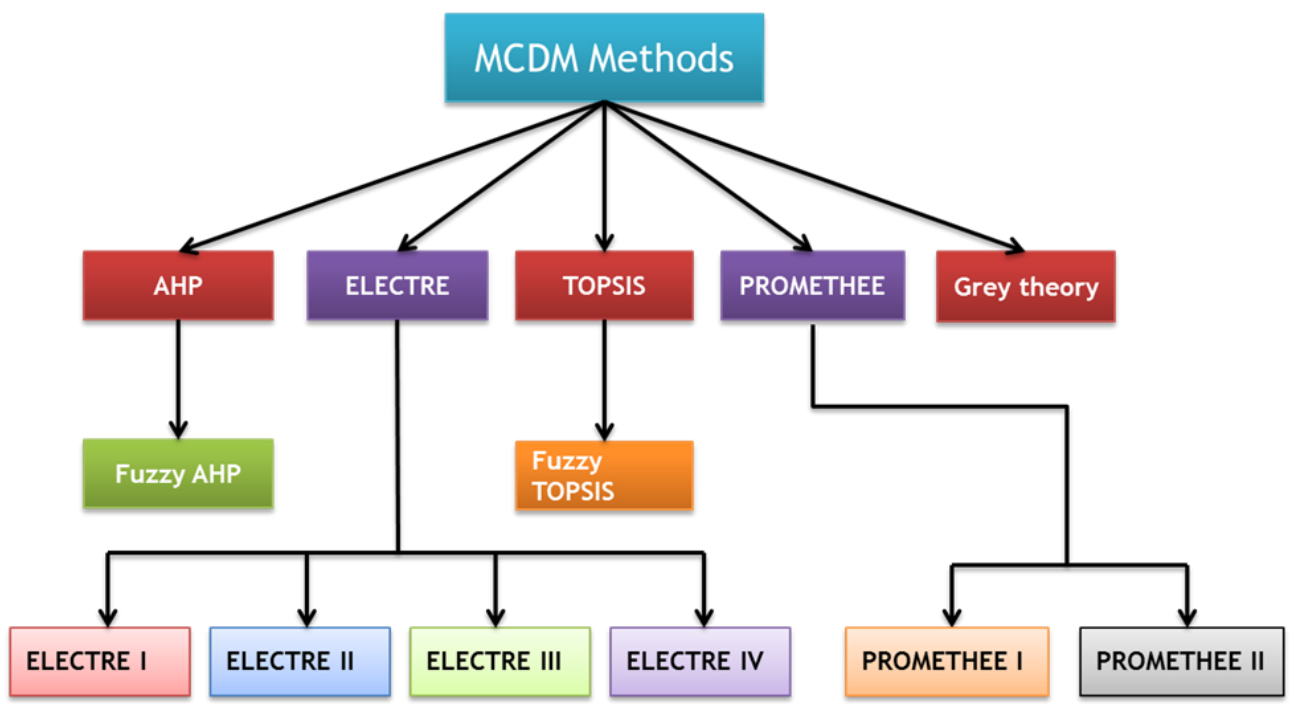

Figura 2 Métodos de Decisão Multicritério

Fonte: Aruldoss, Martin; Lakshmi, T. Miranda; Venkatesan; V. Prasanna (2013)

\subsection{ESCOLAS}

\subsubsection{FRANCESA OU EUROPÉIA}

a) ELECTRE (Elimination et Choice Translating Reality)

Este método matemático desenvolvido por Bernard Roy, em 1965, tem origem na escola francesa de decisão e possui característica de comparação par a par entre as alternativas, buscando uma relação de sobreclassificação ou subordinação ou superação entre elas, assumindo também a possibilidade de incomparabilidade na matriz de preferência do decisor. Sua transitividade nem sempre é observada e pode trazer resultados parciais na recomendação. A avaliação intercritério pode ser representada pelos pesos dos critérios, que assumem a noção de grau de importância, construindo-se relações não compensatórias entre as alternativas (RODRIGUEZ et al., 2013). 
É um algoritmo de decisão para problemas com múltiplos critérios, que reduz o tamanho do conjunto de alternativas possíveis, classificando-as conforme o critério de dominância de uma sobre a outra (MEDEIROS JR., 2009).

A família ELECTRE inclui vários métodos e é aplicada em duas fases. A primeira fase consiste em uma construção de prevalência, constituindo uma comparação par a par entre as alternativas. Em seguida, na segunda fase, a sobreclassificação é explorada aplicando o algoritmo em que o problema da função construída é resolvido (OLIVEIRA ET AL., 2013 apud ARAUJO E AMARA, 2015). Cada uma das versões ELECTRE difere operacionalmente e também com respeito aos tipos de problemas que podem ser usados (ARAUJO E AMARAL, 2015):

- Os métodos ELECTRE I (método de Estruturação), IV e IS são aplicáveis para uma problemática de escolha, onde o objetivo é selecionar um menor conjunto de melhores alternativas.

- Os métodos ELECTRE II (método de decisão), III (leva em conta as incertezas associadas aos atributos por meio de valores difusos ou fuzzy) e IV destina-se à tarefa de construir uma ordenação das alternativas do melhor para o pior. Conhecido como problemática de ranking.

- O ELECTRE II é baseado em critérios verdadeiros, enquanto que os outros dois métodos usam pseudo-critérios.

- Os métodos ELECTRE III e IV diferem em um número de pontos, mas a principal diferença é que o último não utiliza critérios de pesos.

O quadro abaixo lista os métodos ELECTRE mais indicados de acordo com os problemas de decisão a serem solucionados.

Tabela 5 - Família ELECTRE e seus problemas de decisão

\begin{tabular}{|c|c|}
\hline $\begin{array}{c}\text { Problema de } \\
\text { Decisão }\end{array}$ & Método \\
\hline \multirow{3}{*}{ Escolha } & ELECTRE I \\
\hline & ELECTRE IV \\
\hline & ELECTRE IS \\
\hline \multirow{3}{*}{ Ordenação } & ELECTRE II \\
\hline & ELECTRE III \\
\hline & ELECTRE IV \\
\hline \multirow{2}{*}{ Classificação } & ELECTRE-Tri-B \\
\hline & ELECTRE-Tri-C \\
\hline \multirow{4}{*}{ Descrição } & Elicita ção dos pesos em ELECTRE \\
\hline & Elicitação para ELECTRE-Tri: \\
\hline & - Método IRIS \\
\hline & - Outros métodos de elicitação \\
\hline
\end{tabular}

Fonte: ISHIZAKA e NEMERY (2013). 
Esta técnica também usa a comparação par a par através de índices de concordância e discordância. O índice de concordância indica que a alternativa A é melhor que a alternativa $B$ em termos de soma de pesos. O índice de discordância representa a diferença absoluta do par alternativo dividido pela diferença máxima em todos os pares. $O$ índice de concordância global $\mathrm{C}_{\mathrm{ik}}$, mostra que o valor que suporta a concordância entre todos os critérios sob a hipótese de que $A_{i}$ ultrapassa $A_{k}$ pode ser definido da seguinte forma (THOR, DING, KAMARUDDIN, 2013):

$\Rightarrow$ Onde $W_{j}$ é o peso relativo ao j-ésimo critério. A sobreclassificação pode ser realizada para determinar a relação de dominância entre alternativas, definindo um valor limiar para os índices.

b) PROMETHEE (Preference Ranking Organization Method for Enrichment Evaluations)

É um método da escola francesa de tomada de decisão desenvolvida pelos professores J.P. Brans, B. Mareschal e P. Vincke, em 1984, e aperfeiçoado desde então. A sua utilização é rápida, de fácil verificação, transparência nos resultados e a flexibilização do processo de comparação são fatores fundamentais na sua escolha. É uma ferramenta que tanto pode ser aplicada em grupos como individualmente (PEREIRA, 2004). Este método pode ser aplicado para:

- Selecionar uma alternativa dentre as listadas onde há múltiplos critérios;

- Priorização para determinar o mérito relativo dos membros de um conjunto de alternativas, ao contrário de selecionar um único ou meramente classificá-los;

- Alocação de recursos entre um conjunto de alternativas;

- Classificar as alternativas do maior para o menor; e

- Resolução de conflitos entre partes, com objetivos aparentemente incompatíveis.

O método PROMETHÉE se diferencia dos outros da Escola Francesa nos tipos de critérios utilizados. Podem-se empregar seis tipos de funções para descrever os critérios avaliados na implementação do método (Figura 3). Cada tipo de critério é caracterizado por uma função que busca representar a preferência do decisor. A Função de Preferência $P_{j}\left(a_{i}\right.$, $a_{k}$ ) que descreve cada critério assume valores entre 0 e 1 (ALMEIDA \& COSTA, 2002 apud GOMES et al., 2003). 


\begin{tabular}{|c|c|c|}
\hline 1 - Critério usual não há parâmetro a ser definido & $\begin{array}{l}g_{\mathrm{f}}(a)-g_{\mathrm{f}}(b)>0 \\
g_{\mathrm{f}}(a)-g_{\mathrm{f}}(b) \leq 0\end{array}$ & $\begin{array}{l}F(a, b)=1 \\
F(a, b)=0\end{array}$ \\
\hline $\begin{array}{l}2 \text { - Quase-critério define-se o parâmetro q (limite de } \\
\text { indiferença) }\end{array}$ & $\begin{array}{l}g_{f}(a)-g_{f}(b)>q \\
g_{f}(a)-g_{f}(b) \leq q\end{array}$ & $\begin{array}{l}F(a, b)=1 \\
F(a, b)=0\end{array}$ \\
\hline $\begin{array}{l}3 \text { - Limite de preferência define-se o parâmetro } p \text { (limite } \\
\text { de preferência) }\end{array}$ & $\begin{array}{l}g_{f}(a)-g_{f}(b)>p \\
g_{f}(a)-g_{f}(b) \leq p \\
g_{f}(a)-g_{f}(b) \leq 0\end{array}$ & $\begin{array}{l}F(a, b)=1 \\
F(a, b)=\frac{\frac{g_{j}(a)-g_{j}(b)}{p}}{F(a, b)=0}\end{array}$ \\
\hline $\begin{array}{l}\text { 4-Pseudocritério definem-se os parâmetros q (limite de } \\
\text { indiferença) e p (limite de preferência) }\end{array}$ & $\begin{array}{l}\left|g_{\mathrm{f}}(a)-g_{\mathrm{f}}(b)\right|>p \\
q<\left|g_{\mathrm{f}}(a)-g_{\mathrm{f}}(b)\right| \leq p \\
\left|g_{\mathrm{f}}(a)-g_{\mathrm{f}}(b)\right| \leq q\end{array}$ & $\begin{array}{l}F(a, b)=1 \\
F(a, b)=1 / 2 \\
F(a, b)=0\end{array}$ \\
\hline $\begin{array}{l}5 \text {-Área de indiferença definem-se os parâmetros q } \\
\text { (limite de indiferença) e p (limite de preferência) }\end{array}$ & $\begin{array}{l}\left|g_{f}(a)-g_{f}(b)\right|>p \\
q<\left|g_{f}(a)-g_{f}(b)\right| \leq p \\
\left|g_{f}(a)-g_{f}(b)\right| \leq q\end{array}$ & $\begin{array}{l}F(a, b)=1 \\
F(a, b)=\left(\left|g_{\mathrm{f}}(a)-g_{\mathrm{f}}(b)\right|-q /(p-q)\right. \\
F(a, b)=0\end{array}$ \\
\hline $\begin{array}{l}\text { 6-Critério Gaussiano } \\
\text { O desvio-padrào deve ser fixado }\end{array}$ & $\begin{array}{l}g_{f}(a)-g_{f}(b)>0 \\
g_{f}(a)-g_{f}(b) \leq 0\end{array}$ & $\begin{array}{l}\text { A preferência aumenta segundo uma } \\
\text { distribuição normal } \\
F(a, b)=0\end{array}$ \\
\hline
\end{tabular}

Figura 3 - Tipos de função de preferencias para critérios

Fonte: Araújo e Almeida (2009) apud Vieira e Amaral (2015)

Diversas metodologias da "Família" (Adaptações):

- PROMETHÉE I - classificação parcial - escolha e ordenação;

- PROMETHÉE II - completa classificação - escolha e ordenação, se mostra mais eficaz que o anterior pois consegue priorizar as alternativas através de uma ordenação completa;

- PROMETHÉE III - classificação baseada em intervalos - Ampliação da noção de indiferença e tratamento probabilísticos dos fluxos;

- PROMETHÉE IV - conjunto de alternativas é contínuo;

- PROMETHÉE V - ordenação e restrições - Otimização;

- PROMETHEE VI - não é possível estabelecer valor fixo para os pesos (representação do cérebro humano);

- PROMETHÉE GAIA - extensão de procedimento visual e interativo e

- F - PROMETHÉE - incorporadas incertezas utilizando conceitos fuzzy as operações tradicionais. 


\subsubsection{AMERICANA}

a) AHP (Analytic Hierarchy Process)

O método AHP ou Processo Analítico Hierárquico foi desenvolvido por Tomas L. Saaty, no início da década de 70 e é o método de multicritério mais amplamente utilizado e conhecido no apoio à tomada de decisão, na resolução de conflitos negociados e em problemas com múltiplos critérios. Ele identifica a melhor opção dentro das alternativas possíveis e ajuda na determinação de prioridades, considerando aspectos quantitativos e qualitativos. Através da redução de decisões complexas a decisões comparativas par a par. O AHP se divide em estruturação, julgamentos e síntese dos resultados. (PERDIGÃO, FULGÊNCIO E SOUSA, 2012)

O seu pressuposto básico é que um problema complexo pode ser eficientemente resolvido quando é decomposto em diversas partes interligadas por uma estrutura hierárquica, determinando-se pesos específicos para cada um dos critérios - comparados par a par - para que ocorra o cotejo entre alternativas (MEDEIROS JR, 2009).

"O AHP é uma metodologia matemática destinada a ponderar quantitativamente variáveis mediante a interação do pesquisador com o modelo matemático e fazer isso em forma de considerações qualitativas" (RAFFO, 2012). Ainda, segundo o mesmo autor, os pesos são obtidos por comparação das variáveis que participam do problema tratando elas em pares e segundo sua importância para o problema em questão. A aplicação do AHP envolve a síntese matemática de vários julgamentos sobre o problema de decisão. Muitas vezes estes julgamentos são efetuados a partir de consultas realizadas a especialistas nas áreas de conhecimento referentes às diversas variáveis tratadas no problema.

Perdigão, Fulgêncio e Sousa (2012) compara o método a uma árvore, à medida que se afasta da raiz (objetivo), os fatores são mais específicos, e os mais extremos (as folhas) representam os fatores ou critérios de avaliação. Assim, quanto mais genéricos forem os atributos, mais altos eles deverão estar na hierarquia. As alternativas ficam na base da árvore, abaixo do último nível de atributos (Figura 4). Esse arranjo permite fazer com que seja possível para o tomador de decisão focalizar cada parte e todo o complexo problema, com isso obter prioridades através de uma simples comparação par a par baseada nos dados obtidos pelo usuário. 


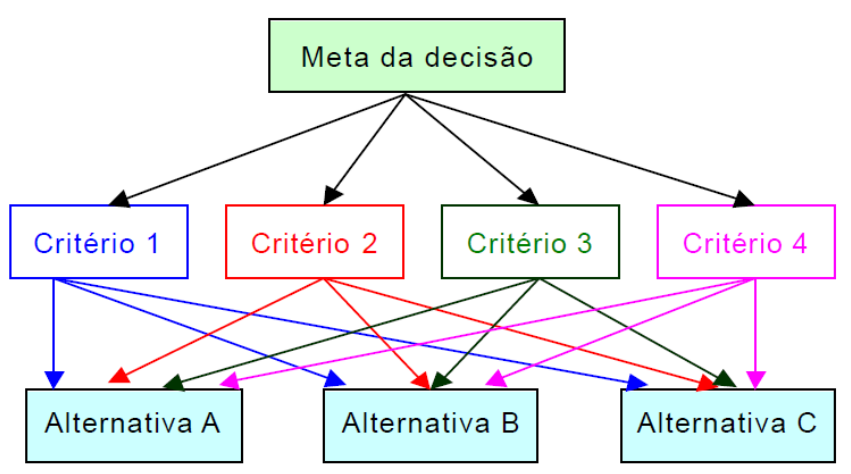

Figura 4 - Estrutura hierárquica genérica de problemas de decisão Fonte: Vilas-Boas (2006)

O método AHP é vastamente utilizado para análises de custo benefício, planejamento estratégico, escolhas tecnológicas, priorização de investimentos, priorização de desenvolvimentos turísticos, avaliação de novos serviços de telecomunicação entre outras possibilidades (BUNRUAMKAEW, 2012).

A vantagem deste método é que permite que o usuário atribua pesos relativos para múltiplos critérios, ou múltiplas alternativas para um dado critério, de forma intuitiva, ao mesmo tempo em que realiza uma comparação par a par entre os mesmos. Isso permite que, mesmo quando duas variáveis são incomparáveis, com os conhecimentos e a experiência das pessoas, pode-se reconhecer qual dos critérios é mais importante (SAATY, 1991 apud PERDIGÃO, FULGÊNCIO E SOUSA, 2012).

A desvantagem para este método é que a ordenação final, expressa por um número, não permita captar a sutileza de pequenas variações ocasionadas por mudança de hipótese de um cenário, o mesmo ocorre na Matriz de Ponderações e no PROMETHEE.

Por ser uma das metodologias escolhidas para a aplicação prática no estudo de caso deste trabalho, será detalhado na etapa de cálculo no item Cálculo - I. Método AHP deste capítulo.

b) ANP (Analytic Network Process)

ANP ou Processo de Rede Analítica é uma generalização do AHP, pois permite feedback entre as conexões. Este possibilita ao decisor considerar a possível existência de dependências entre os fatores de decisão e analisar o efeito e retroalimentação decorrentes dessas dependências. Isso é obtido por julgamentos e uso de medições por escalas proporcionais. Enquanto o AHP é a teoria que depende dos valores e dos julgamentos dos indivíduos e grupos, baseado em um dado cenário, o ANP é a generalização do AHP (SAATY, 
2001), pois permite a construção de diversos cenários, para problemas complexos de decisão. A principal diferença entre o AHP e o ANP é que este tem uma abordagem que substitui as hierarquias por redes sendo que, em ambas as abordagens de tomada de decisão, os julgamentos são executados conjuntamente e de uma forma organizada para produzir prioridades. No ANP, a interação e a retroalimentação (feedback) dão-se em agrupamentos (clusters) de elementos com dependência interna e entre esses agrupamentos com dependência externa, capturando melhor os "efeitos complexos das reciprocidades nas sociedades humanas, especialmente quando ocorrem riscos e incertezas" (SAATY, 2001). O ANP, por possibilitar a retroalimentação do julgamento e por sua característica de possibilitar agrupamentos, foi escolhido como instrumento de pesquisa dos Estudos de Caso, uma vez ser o ANP um método multicritérios relativamente simples e com uma abordagem intuitiva que pode ser aceita facilmente por administradores e outros (MEDEIROS JR, 2009).

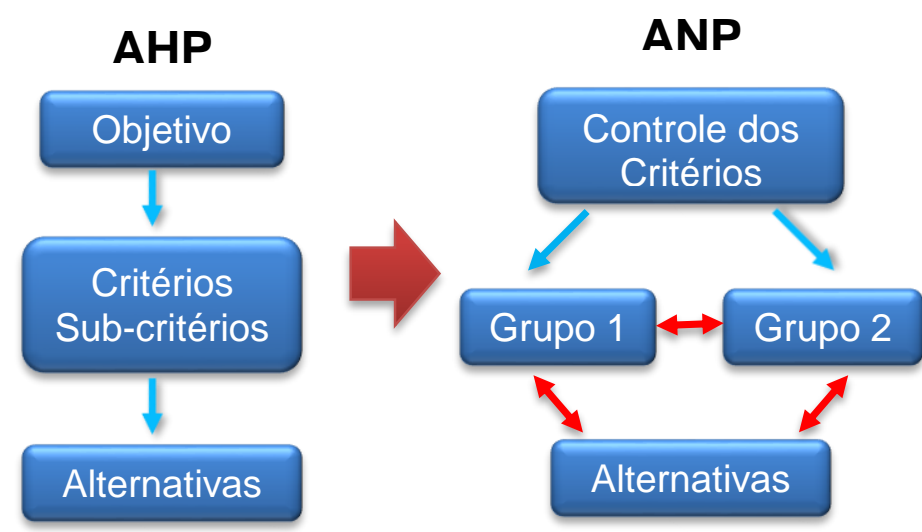

Figura 5 - Estrutura hierárquica genérica de problemas de decisão ANP Fonte: Adaptado de Vilas-Boas (2006)

\section{c) TOPSIS}

A palavra TOPSIS vem do inglês "Technique for Order Preference by Similarity to Ideal Solution" que significa em português "Técnica de ordem de preferência por Similaridade para a Solução Ideal", apresenta simplicidade e facilidade de aplicação, abordando um problema pela comparação de duas situações hipotéticas: ideal (melhor nível para todos os atributos considerados) e não desejada (o que tem os piores valores de atributos).

TOPSIS baseia-se na busca de uma solução que mais se aproxime da ideal e, ao mesmo tempo, se afaste mais da solução não desejada ( $G R H, 2004$ apud RESENDE 2012), isto é, tem por objetivo avaliar o desempenho através da similaridade com a solução ideal, onde a alternativa escolhida deve ter a menor distância entre a Solução Ideal Positiva (PIS) e a maior distância a partir da Solução Negativa Ideal (NIS). PIS representa a opção que 
maximiza os critérios de "benefício" e minimiza os critérios de "custo", enquanto que as funções NIS é o caminho oposto. A medida da distância de separação de cada critério com relação ao ideal positivo $S_{i}^{+}$, e ao ideal negativo $S_{\bar{i}}$, para cada alternativa, deve ser calculada usando a distância Euclidiana П-dimensional. A precisão na medida da distância de uma alternativa à PIS e à NIS é o ponto-chave do TOPSIS (MUSSOI, 2012).

Logo, TOPSIS é um método de agregação compensatória que compara um conjunto de alternativas, identificando pesos para cada critério, normalizando pontuações para cada critério e calcula a distância geométrica entre cada alternativa e a alternativa ideal, que é a melhor pontuação em cada critério. Esta técnica foi originalmente desenvolvida por Hwang e Yoon em 1981, e aperfeiçoada por Yoon em 1987 e Hwang, Lai e Liu, em 1993. (PONTES, 2012). Ela considera três tipos de atributo/ critérios: benefício qualitativo, benefício quantitativo e de custo.

Por ser uma das metodologias escolhidas para a aplicação prática no estudo de caso deste trabalho, será detalhado na etapa de cálculo no item Cálculo - Método TOPSIS deste capítulo.

A figura abaixo mostra a comparação entre as técnicas baseadas na sua estrutura de avaliação.

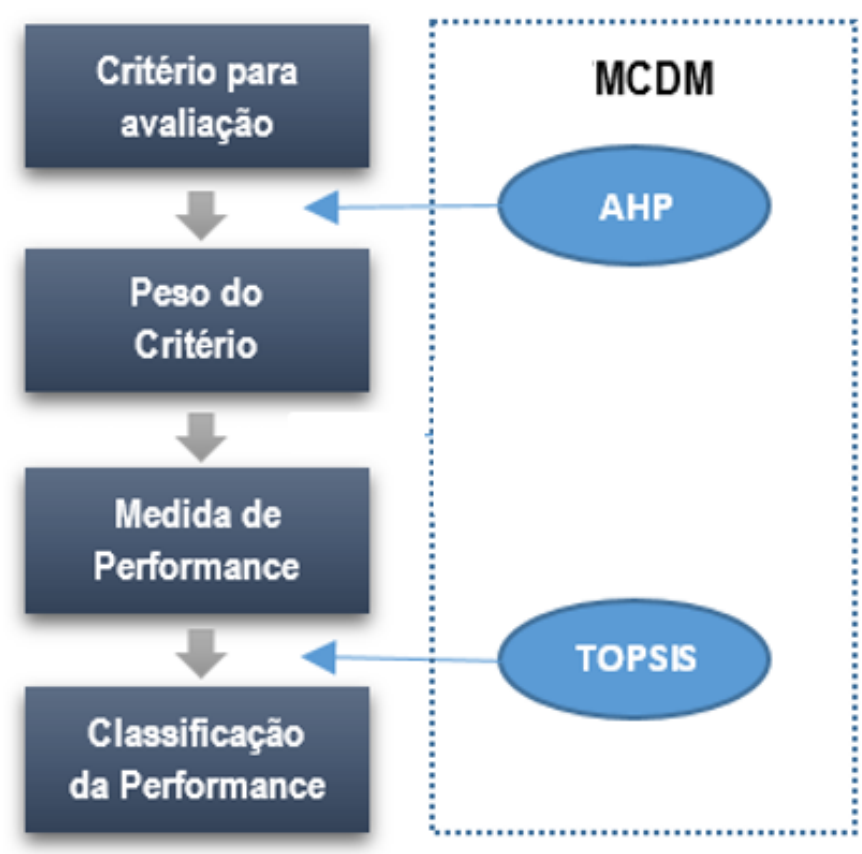

Figura 6 - Estrutura de Avaliação da Avaliação de Performance

Fonte: Adaptado pela autora de AHMADI, G. A. A.; TAGHIPOURIAN, M. J.; TAGHIPOURIAN, Y. (2009) 


\subsubsection{OUTRAS}

a) SAW (Simple Additive Weighting)

O método SAW ou Ponderação Simples Aditiva, desenvolvida por MacCrimon em 1968, é o método de apoio multicritério à decisão mais conhecido e amplamente utilizado devido a sua simplicidade (THOR, DING, KAMARUDDIN, 2013). Sua técnica consiste nas seguintes etapas:

- Normalizar a matriz de decisão inicial (os valores de utilidade das alternativas para torná-los comparáveis) podendo estas ser de maximização ou minimização;

- Aplicar pesos a esses valores de utilidade;

- Somar os valores de utilidade de cada alternativa de acordo com a equação:

O resultado do método é que para cada alternativa haverá uma pontuação de desempenho, cujos maiores valores indicarão a preferência da alternativa.

b) SPW (Simple Product Weighting)

O método SPW ou Ponderação Simples de Produto não requer a normalização dos valores dos critérios e sim a multiplicação entre si, dos valores das avaliações para cada alternativa, elevados ao peso dos seus respectivos critérios. Isto acarreta o mesmo efeito, em termos de unificação da escala dos valores da avaliação das alternativas, que o processo de normalização do método SAW. Também considerado simples como anterior, mudando apenas a expressão de cálculo para a obtenção da pontuação das alternativas, que efetua o produto entre si, de todos os indicadores de cada alternativa, anteriormente elevados ao peso de seu respectivo critério (RESENDE, 2012).

\section{c) DEA (Data Envelopment Analysis)}

A origem da técnica DEA ou Análise Envoltória de Dados surgiu a partir do trabalho desenvolvido por Charnes, Cooper, Rhodes em 1978, mas com base no trabalho de M.J.Farrel de 1957, referência nas publicações sobre a metodologia DEA, cujo objetivo foi de comparar a eficiência das escolas públicas americanas, sem a necessidade de se arbitrar pesos para cada variável, e sem converter as variáveis em valores econômicos comparáveis. É uma técnica de programação matemática que permite avaliar o grau de eficiência produtiva entre várias empresas, denominadas unidades tomadoras de decisão (Decision Making Units DMU's), considerando os recursos de que se dispõe (entradas - inputs) com os resultados alcançados (saídas - outputs). O princípio básico é medir e comparar o desempenho das unidades tomadoras de decisão, que realizam tarefas similares, considerando a relação entre insumos (inputs) e produtos (output) (GUERREIRO, 2006). 


\section{ARQUITETURA DO TRABALHO PROPOSTO}

Os métodos escolhidos para o estudo foram o AHP, originalmente implantado no projeto, através do software Expert Choice e o TOPSIS, que vem sendo aplicado, nos últimos anos, para problemas de tomada de decisão em diversas áreas no Brasil (Krohling e Souza, 2011). O objetivo é comparar os resultados dos dois métodos na priorização e seleção de duas sedes municipais por estado, para que estas recebam investimento de esgotamento sanitário.

\subsection{Cálculo do Método AHP}

De acordo com Nunes Jr (2006) existem as seguintes premissas:

a) Comparação recíproca - o tomador de decisão deve ser capaz de fazer comparações e declarar a força de suas preferências. A intensidade destas preferências deve satisfazer a condição recíproca: Se $A$ é $X$ vezes mais preferido que $B$, então $B$ é $1 / X$ vezes da preferência de A.

b) Homogeneidade - as preferências são representadas por meio de uma escala definida.

c) Independência - quando se expressa preferências, critérios para avaliação da melhor solução são assumidos, independente das alternativas existentes para solução do problema.

d) Expectativa/Perspectiva - para os propósitos de tomar uma decisão, a estrutura hierárquica é considerada como sendo completa.

São realizadas as seguintes etapas para a construção do modelo:

- Especificação do foco principal ou objetivo geral que se espera atingir com a classificação;

- Identificação do conjunto de alternativas viáveis para a priorização;

- Identificação do conjunto de critérios relevantes e construção da hierarquia;

- Seleção dos julgadores e definição dos métodos para a obtenção dos julgamentos paritários: é nesta etapa de julgamentos paritários que se avalia a importância de cada critério e o desempenho de cada alternativa, à luz dos critérios;

- Síntese dos dados obtidos dos julgamentos, calculando-se a prioridade de cada alternativa em relação ao foco principal; e

- Análise de consistência do julgamento, identificando-se o quanto o sistema de classificação é consistente na classificação das alternativas viáveis. 
O método AHP segue os seguintes passos:

\begin{tabular}{|c|c|}
\hline FLUXOGRAMA: & DESCRITIVO: \\
\hline $\begin{array}{c}\text { PASSO } 1 \\
\text { Matriz - critérios par a par }\end{array}$ & 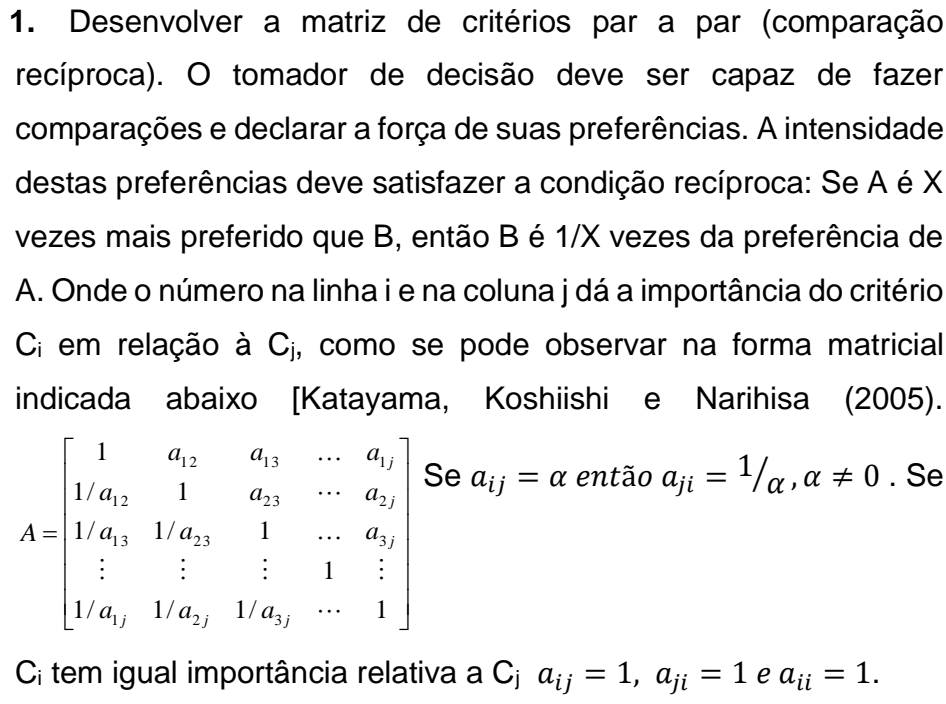 \\
\hline $\begin{array}{l}\text { PAsso } 2 \\
\text { Normaliza matriz }\end{array}$ & $\begin{array}{l}\text { 2. As comparações par a par são convertidas em valores } \\
\text { numéricos usando a Escala Fundamental de Saaty para } \\
\text { julgamentos comparativos, onde a quantificação dos julgamentos } \\
\text { é feita utilizando-se uma escala de valores (Tabela } 6 \text { e } 7 \text { ). Desta } \\
\text { forma, é medido o grau de importância do elemento de um } \\
\text { determinado nível sobre elementos de um nível inferior. }\end{array}$ \\
\hline $\begin{array}{l}\text { PASso } 3 \\
\text { Atribuição de Pesos (Criteria Weight) - } \\
\text { média dos itens da linha normalizados. }\end{array}$ & $\begin{array}{l}\text { 3. Em seguida, as matrizes são submetidas a uma técnica } \\
\text { matemática denominada auto vetor, que calcula os pesos locais e } \\
\text { globais para cada critério/indicador nos diversos níveis } \\
\text { hierárquicos e em relação às alternativas em análise. O auto vetor } \\
\text { da matriz pode ser estimado pela expressão. } W_{i}=\sqrt[n]{\prod_{i=1}^{n} a_{i j}}\end{array}$ \\
\hline $\begin{array}{c}\text { PAsso } 4 \\
\text { Soma dos Pesos (Ws) - multiplicar matriz, } \\
\text { linha do critério } x \text { coluna do peso. }\end{array}$ & $\begin{array}{l}\text { 4. T é o auto vetor normalizado, } T=\mid W_{1} / \sum W_{i} W_{2} / \sum W_{i} \cdots W_{n} / \\
\sum W_{i} \mid \text { fornecendo a hierarquia ou ordem de prioridade das } \\
\text { características estudadas. }\end{array}$ \\
\hline $\begin{array}{c}\text { Passo } 5 \\
\text { Vetor de Consistência }- \text { multiplica Ws pelo } \\
1 / \text { peso. }\end{array}$ & $\begin{array}{l}\text { 5. } \lambda_{\max }=T \times w \text {, onde w é calculado pela soma das colunas da } \\
\text { matriz de comparações. }\end{array}$ \\
\hline $\begin{array}{c}\text { PASSO } 6 \\
\text { Índice de Consistência }\end{array}$ & $\begin{array}{l}\text { 6. Calcula-se o Índice de consistência (IC) para cada alternativa. } \\
C I=\frac{\lambda_{\max }-n}{n-1}\end{array}$ \\
\hline $\begin{array}{c}\text { PAsso } 7 \\
\text { Razão de Consistência } \\
\end{array}$ & $\begin{array}{l}\text { 7. Calcula-se o Quociente (ou Razão) de Consistência (CR), } \\
\text { devendo este ser } C R<0,10 \text {, caso seja superior deve ser } \\
\text { reanalisado os critérios. Índice de consistência (IC) para cada } \\
\text { alternativa. IC }=\frac{\lambda_{\max }-n}{n-1} \text { A Razão de Consistência } R C=I C / C A \\
\text { (índice de consistência aleatória - tabela } 8 \text { abaixo). }\end{array}$ \\
\hline
\end{tabular}


Tabela 6 - Escala Numérica de SAATY

\begin{tabular}{|c|c|c|}
\hline $\begin{array}{c}\text { ESCALA } \\
\text { NUMÉRICA }\end{array}$ & $\begin{array}{l}\text { ESCALA } \\
\text { VERBAL }\end{array}$ & EXPLICAÇÃO \\
\hline 1 & $\begin{array}{l}\text { Ambos elementos são de } \\
\text { igual importância. }\end{array}$ & $\begin{array}{l}\text { Ambos elementos contribuem com a } \\
\text { propriedade de igual forma. }\end{array}$ \\
\hline 3 & $\begin{array}{l}\text { Moderada importância de um } \\
\text { elemento sobre o outro. }\end{array}$ & $\begin{array}{l}\text { A experiência e a opinião favorecem um } \\
\text { elemento sobre o outro. }\end{array}$ \\
\hline 5 & $\begin{array}{l}\text { Forte importância de um } \\
\text { elemento sobre o outro. }\end{array}$ & Um elemento é fortemente favorecido. \\
\hline 7 & $\begin{array}{l}\text { Importância muito forte de um } \\
\text { elemento sobre o outro. }\end{array}$ & $\begin{array}{l}\text { Um elemento é muito fortemente favorecido } \\
\text { sobre o outro. }\end{array}$ \\
\hline 9 & $\begin{array}{l}\text { Extrema importância de um } \\
\text { elemento sobre o outro. }\end{array}$ & $\begin{array}{l}\text { Um elemento é favorecido atividade } \\
\text { em relação ao outro com o mais alto } \\
\text { grau de certeza. }\end{array}$ \\
\hline $2,4,6,8$ & Valores intermediários. & $\begin{array}{l}\text { Usados como valores de consenso entre } \\
\text { as opiniões. }\end{array}$ \\
\hline $\begin{array}{c}\text { Incremento } \\
\qquad, 1\end{array}$ & $\begin{array}{l}\text { Valores intermediários na } \\
\text { graduação mais fina de } 0.1 \text {. }\end{array}$ & $\begin{array}{c}\text { Usados para graduações mais finas das } \\
\text { opiniões. }\end{array}$ \\
\hline
\end{tabular}

Fonte: SAATY, 1999

Tabela 7 - Escala de comparação de critérios

\begin{tabular}{|c|c|c|c|c|c|c|c|c|}
\hline $\mathbf{1 / 9}$ & $\mathbf{1 / 7}$ & $\mathbf{1 / 5}$ & $\mathbf{1 / 3}$ & $\mathbf{1}$ & $\mathbf{3}$ & $\mathbf{5}$ & $\mathbf{7}$ & $\mathbf{9}$ \\
\hline Extremamente & Bastante & Muito & Pouco & Igual & Pouco & Muito & Bastante & Extremamente \\
\hline \multicolumn{3}{|c|}{ Menos importante... } & & \multicolumn{3}{c|}{ Mais importante... } \\
\hline
\end{tabular}

Fonte: SAATY, 1999

Tabela 8 - índice de consistência aleatória (CA) em função da ordem da matriz

\begin{tabular}{|c|c|c|c|c|c|c|c|c|c|c|c|c|c|c|c|}
\hline ORDEM & 1 & 2 & 3 & 4 & 5 & 6 & 7 & 8 & 9 & 10 & 11 & 12 & 13 & 14 & 15 \\
\hline CA & 0 & 0 & 0,58 & 0,9 & 1,12 & 1,24 & 1,32 & 1,41 & 1,45 & 1,49 & 1,51 & 1,48 & 1,56 & 1,57 & 1,59 \\
\hline
\end{tabular}

Fonte: SAATY, 1999 
As vantagens e desvantagens desta metodologia estão listadas no quadro abaixo compilado por Vilas-Boas (2016).

Tabela 9 - Vantagens e Desvantagens - AHP

\begin{tabular}{l} 
ASPECTOS POSITIVOS \\
\hline - Simplicidade; \\
- Clareza; \\
- Facilidade de uso; \\
- Permite a interação entre o analista e o decisor; \\
inconsistentes;
\end{tabular}

- A representação hierárquica de um sistema pode ser usada para descrever como as mudanças em prioridades nos níveis mais altos afetam a prioridade dos níveis mais baixos;

- Permite que todos os envolvidos no processo decisório entendam o problema da mesma forma;

- O desenvolvimento dos sistemas estruturados hierarquicamente é preferível àqueles montados de forma geral;

- Pequenas modificações em uma hierarquia bem estruturada têm efeitos flexíveis e pouco significativos;

- Capacidade em lidar com problemas que envolvam variáveis tanto quantitativas como qualitativas;

- A forma de agregação dessas variáveis exige que o tomador de decisão participe ativamente no processo de estruturação e avaliação do problema, o que contribui para tornar os resultados propostos pelo modelo mais exequíveis;

- Estruturando hierarquicamente um problema, os usuários são capazes de ordenar e comparar um uma lista menor de itens dentro de seus próprios contextos;

- Sintetiza os resultados dentro de uma lista ordenada que permite a comparação de prioridades e importância relativa de cada fator;

- É capaz de prover pesos numéricos para opções onde julgamentos subjetivos de alternativas quantitativas ou qualitativas constituem uma parte importante do processo de decisão.

\section{ASPECTOS NEGATIVOS}

- Subjetividade na formulação da matriz de preferência;

- Deve ser procedida uma análise acurada para identificar e caracterizar as propriedades dos níveis da hierarquia que afetam o desempenho do objetivo mais alto;

- É muito importante que haja consenso na priorização dos níveis mais altos da hierarquia;

- Os critérios representados devem ser independentes ou, pelo menos, suficientemente diferentes, em cada nível;

- Em qualquer processo de interação de grupo, não deve haver idealismo demais nem forte predisposição para liderança entre os envolvidos;

- Requer procedimento para estruturar o questionário de perguntas e preferências;

- O trabalho computacional é sensivelmente maior quando se eleva o número de alternativas;

- Pesos para os critérios são obtidos antes que as escalas de medida tenham sido ajustadas;

- A introdução de novas opções pode mudar a posição relativa de algumas das opções originais;

- O método não integra a chamada "condição fundamental de medida" ou não garante automaticamente sua satisfação;

- O número de comparações requeridas pode ser muito alto;

- As prioridades dependem do método usado para derivá-las;

- Alternativas incomparáveis não são permitidas;

- Por não existir nenhuma base teórica para a formação das hierarquias, os tomadores de decisão, quando se deparam com situações idênticas de decisão, podem derivar hierarquias diferentes, obtendo então diferentes soluções;

- Existem falhas nos métodos para agregar os pesos individuais dentro dos pesos compostos;

- Uma ausência de fundamento de teoria estatística. 


\subsection{Cálculo do Método TOPSIS}

O método TOPSIS classifica as alternativas utilizando um procedimento de sete passos:

\begin{tabular}{|c|c|}
\hline FLUXOGRAMA & DESCRITIVO \\
\hline $\begin{array}{c}\text { PAsso } 1 \\
\text { Normalizar os critérios }\end{array}$ & $\begin{array}{l}\text { 1. Normalizar a matriz de decisão inicial (tabela de valores para cada } \\
\text { critério), para que todos os valores estejam no intervalo de } 0 \text { a } 1 \text {, gerando } \\
\text { uma matriz; } P_{i j}=\frac{x_{i j}}{\operatorname{Max} X_{i}} \text { Sendo } \mathrm{J}=1 \text {...n e Max - o valor máximo apresentado } \\
\text { em cada critério. }\end{array}$ \\
\hline $\begin{array}{l}\text { PAsso } 2 \\
\text { Cálculo dos pesos }\end{array}$ & $\begin{array}{l}\text { 2. Cálculo dos pesos para cada critério, baseados na Entropia } \\
e_{j}=-\frac{1}{\ln (m)} \sum_{i=1}^{m} P_{i j} \ln \left(p_{i j}\right) \text { e Grau de Diversidade } d_{j}=1-e_{j} \text {. Normalizada, } \\
\text { aplicando os pesos dos critérios aos seus respectivos valores, para cada } \\
\text { alternativa. }\end{array}$ \\
\hline $\begin{array}{c}\text { PAsso } 3 \\
\text { Matriz normalizada pelo Peso }\end{array}$ & $\begin{array}{l}\text { 3. Cálculo dos valores normalizados pelo peso. Essa nova matriz é } \\
\text { construída baseada no produto de } \mathrm{P}_{\mathrm{ij}} \text { pelo } \mathrm{W}_{\mathrm{ij}} \text { de cada critério. } V_{i j}=W_{i j} x P_{i j} \text {. }\end{array}$ \\
\hline $\begin{array}{l}\text { PASSO } 4 \\
\frac{\text { Identificação Solução ideal }}{\text { positiva (PIS) e }} \\
\text { Solução Ideal negativa (NIS) }\end{array}$ & 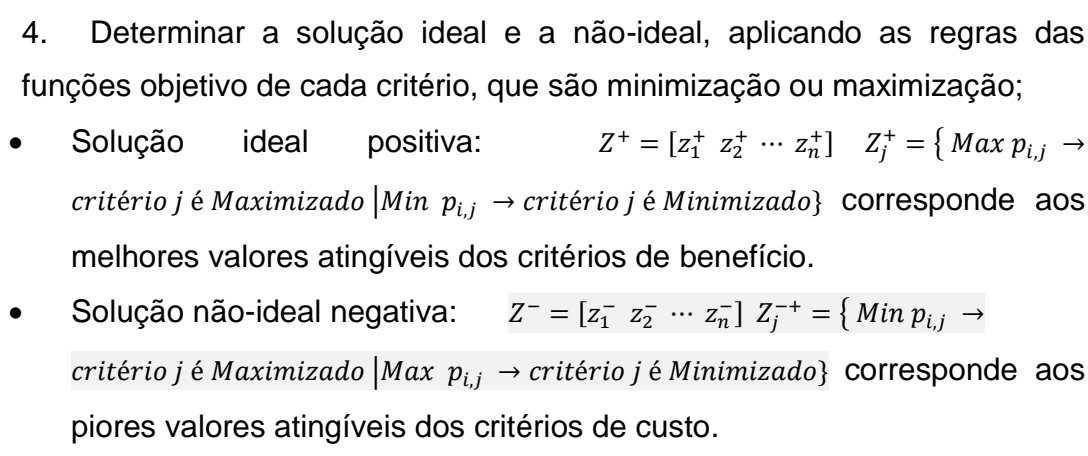 \\
\hline $\begin{array}{l}\text { PASSO } 5 \\
\text { Calcular a distância Euclidiana - } \\
\text { Solução Ideal Positiva e } \\
\text { Solução Ideal negativa }\end{array}$ & $\begin{array}{l}\text { 5. Calcular as medidas de separação, que é a distância euclidiana n- } \\
\text { dimensional, para as alternativas; } \\
\text { - Solução ideal: } \mathrm{d}+=\sqrt{\sum_{j=1}^{n} \mathrm{Wj}(\mathrm{Vij}-\mathrm{Vij}+)^{2}} \\
\text { - Solução não-ideal: } \quad \mathrm{d}-=\sqrt{\sum_{j=1}^{n} \mathrm{Wj}(\mathrm{Vij}-\mathrm{Vij}-)^{2}}\end{array}$ \\
\hline $\begin{array}{c}\text { PAsso 6 } \\
\frac{\text { Calcular a solução ideal - }}{\text { Similaridade relativa }}\end{array}$ & $\begin{array}{l}\text { 6. Calcular similaridade relativa da solução ideal e; } \\
\mathrm{S}_{\mathrm{i}}=\frac{d i-}{d i-+d i+} \text { Os valores Si denotam então a melhor alternativa (maior valor) e as } \\
\text { subsequentes pelos valores decrescentes, efetuando-se a ordenação } \\
\text { referente ao sexto e último passo do método TOPSIS. }\end{array}$ \\
\hline $\begin{array}{c}\text { PASso } 7 \\
\text { Ordenação dos resultados }\end{array}$ & $\begin{array}{l}\text { Ordenar as alternativas (SRDJEVIC, 2004). As melhores alternativas são } \\
\text { aquelas que têm os maiores valores e que devem ser escolhidas pois estão } \\
\text { mais próximas da solução ideal positiva. }\end{array}$ \\
\hline
\end{tabular}


Tabela 10 - Comparação AHP e TOPSIS como MCDM

\begin{tabular}{|c|c|c|c|c|}
\hline $\mathbf{N}^{\circ}$. & $\begin{array}{l}\text { Método de Decisão } \\
\text { Multicritério (MCDM) }\end{array}$ & Descrição & Vantagens & Desvantagens \\
\hline 1. & $\begin{array}{l}\text { AHP } \\
\text { Processo de } \\
\text { Hierarquia Analítica }\end{array}$ & $\begin{array}{l}\text { Também inclui } \\
\text { comparação par a par } \\
\text { de diferentes } \\
\text { alternativas para } \\
\text { diferentes critérios. }\end{array}$ & $\begin{array}{l}\text { 1. Flexível, intuitivo e checagem de } \\
\text { inconsistências } 2 \text {. Uma vez que o } \\
\text { problema é construído em uma } \\
\text { estrutura hierárquica, a importância } \\
\text { de cada elemento torna-se clara. } 3 \text {. } \\
\text { Sem influência na tomada de decisão. }\end{array}$ & $\begin{array}{l}\text { 1. Irregularidades na } \\
\text { classificação } \\
\text { 2. A agregação aditiva é } \\
\text { utilizada. Portanto, informações } \\
\text { importantes podem ser } \\
\text { perdidas. } \\
\text { 3. Mais número de } \\
\text { comparações par a par são } \\
\text { necessários }\end{array}$ \\
\hline 2 & $\begin{array}{l}\text { TOPSIS } \\
\text { Técnica de ordem de } \\
\text { preferência por } \\
\text { Similaridade para a } \\
\text { Solução Ideal }\end{array}$ & $\begin{array}{l}\text { Solução de } \\
\text { compromisso - escolher } \\
\text { a melhor alternativa e } \\
\text { mais próxima para a } \\
\text { solução ideal positiva } \\
\text { (solução ótima) e a mais } \\
\text { distante da solução ideal } \\
\text { negativa }\end{array}$ & $\begin{array}{l}\text { 1. Adequado para modelar valores de } \\
\text { critérios quantitativos precisamente } \\
\text { conhecidos. } \\
\text { 2. O processo de coleta de dados é } \\
\text { mais simples e requer menor } \\
\text { quantidade de julgamentos. } \\
\text { 3. Menor complexidade } \\
\text { computacional. }\end{array}$ & $\begin{array}{l}\text { 1. Inadequado para modelar } \\
\text { variáveis qualitativas. } \\
\text { 2. Dificuldade para definição } \\
\text { dos pesos. } \\
\text { 3. Pode ocorrer inversão no } \\
\text { ranking. }\end{array}$ \\
\hline
\end{tabular}

Fonte: Adaptado pela autora de Aruldoss, Martin; Lakshmi, T. Miranda; Venkatesan; V. Prasanna (2013) e Lima Jr e Carpinetti (2015)

Tabela 11 - Comparação das principais características entre AHP e TOPSIS

\begin{tabular}{|c|c|c|}
\hline & AHP & TOPSIS \\
\hline Conceito & $\begin{array}{l}\text { Modelo de pontuação - pontuação } \\
\text { obtida por alternativas concorrentes. }\end{array}$ & $\begin{array}{l}\text { Modelo Comprometimento - não existe solução ideal, } \\
\text { mas solução com valores ótimos, em todos os atributos } \\
\text { selecionados. }\end{array}$ \\
\hline Processo Central & $\begin{array}{l}\text { Princípio Hierárquico de } \\
\text { comparação de critérios par a par. }\end{array}$ & $\begin{array}{l}\text { Princípio da distância - calcula a menor distância da } \\
\text { alternativa para a Solução positiva ideal (PIS) e a maior } \\
\text { para a Solução negativa ideal (NIS). }\end{array}$ \\
\hline Consistência & $\begin{array}{l}\text { Sim - é calculado o índice de } \\
\text { consistência. }\end{array}$ & Não - Não existe índices comparativos como indicadores. \\
\hline Estrutura do Problema & $\begin{array}{l}\text { Poucos critérios e alternativas - } \\
\text { torna-se complicado a medida que se } \\
\text { aumenta a quantidade de critérios e } \\
\text { alternativas. }\end{array}$ & $\begin{array}{l}\text { Muitos critérios e alternativas - é facilitado por serem } \\
\text { cálculos matemáticos simples. }\end{array}$ \\
\hline Resultados finais & Global, ordenação líquida & Global, ordenação líquida \\
\hline
\end{tabular}

Fonte: Adaptado pela autora de THOR, DING, KAMARUDDIN (2013)

\subsection{ESTUDO DE CASO}

O Projeto preparatório para gerenciamento dos recursos hídricos do Paraíba do Sul foi desenvolvido pelo Laboratório de Hidrologia da COPPE/UFRJ e coordenado pela Secretaria de Recursos Hídricos do Ministério do Meio Ambiente (SRH/MMA), intermediada pela Agencia Brasileira de Cooperação (ABC) do Ministério de Relações Exteriores e o Banco Internacional para Reconstrução e Desenvolvimento (Banco Mundial) em articulação com os Estados (RJ/MG/SP) e o Comitê para Integração da Bacia Hidrográfica do Rio Paraíba do Sul (CEIVAP) (Figura 7). 


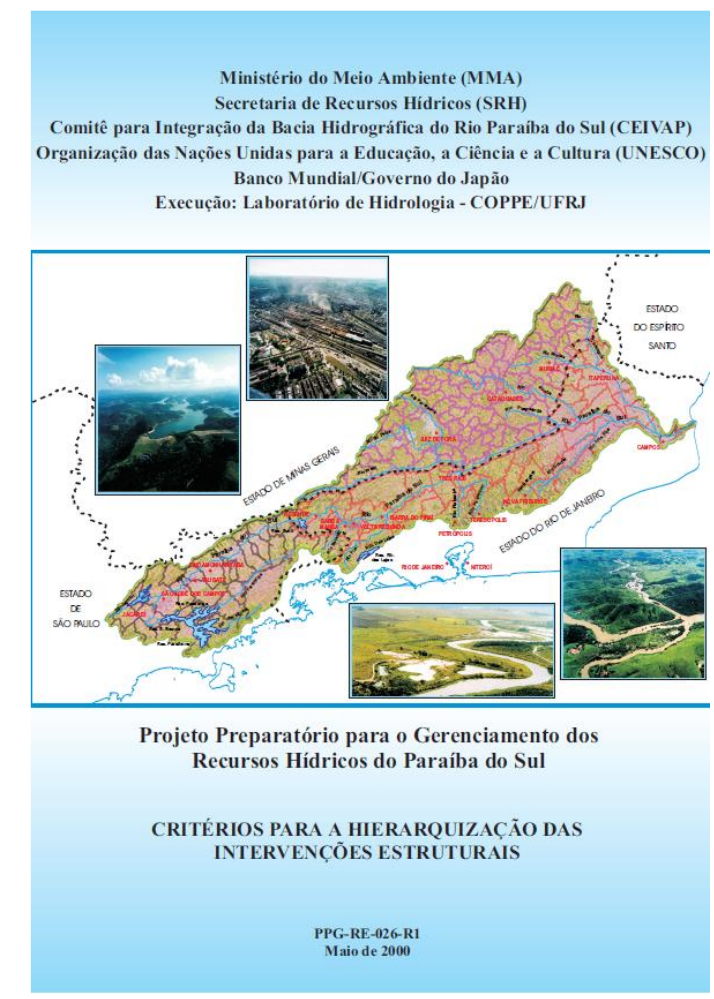

Figura 7 - Capa do projeto utilizado como estudo de caso

Fonte: LABORATÓRIO DE HIDROLOGIA - COPPE/UFRJ (2001) PPG-RE-026-R1

Após várias reuniões com todos os envolvidos foi elaborado o plano de trabalho, cujos objetivos são o fortalecimento da gestão na bacia do Rio Paraíba do Sul e preparação do programa de investimentos. Para este último, foram estabelecidos critérios de elegibilidade e uma metodologia para hierarquiza-los. O montante total do investimento ficará em torno de US $\$ 40$ milhões, sendo cerca de $35 \%$ destinados ao componente institucional do projeto (implantação do sistema de gerenciamento dos recursos hídricos). Os critérios de elegibilidade serão aplicados somente às obras de infraestrutura (US\$26 milhões).

\subsubsection{Critérios}

Foram relacionados no total seis critérios, listados abaixo:

1) Financeiro - relativo ao investimento (pontuação de 1 a 9)

a) Contrapartidas financeiras relativas ao empreendimento (pontuação de 1 a 5) -

\begin{tabular}{|l|}
\hline Classificação: \\
1 -Recursos firmes em forma de caixa disponível para contrapartida \\
2 -Recursos próprios não suficientes para contrapartida (50\%) complementados por Fundos Estaduais, ou \\
Recursos "potenciais" com facilidade de conversão em caixa no curto prazo \\
3 -Recursos com previsão orçamentária ou de Programas e Fundos Estaduais \\
4 -Recursos de obtenção duvidosa \\
5 -Sem contrapartida
\end{tabular}


b) Capacidade de recuperação dos custos do investimento (pontuação de 1 a 4) Considera-se os custos de investimento, administração e operação. Payback máximo de 30 anos (sua vida útil).

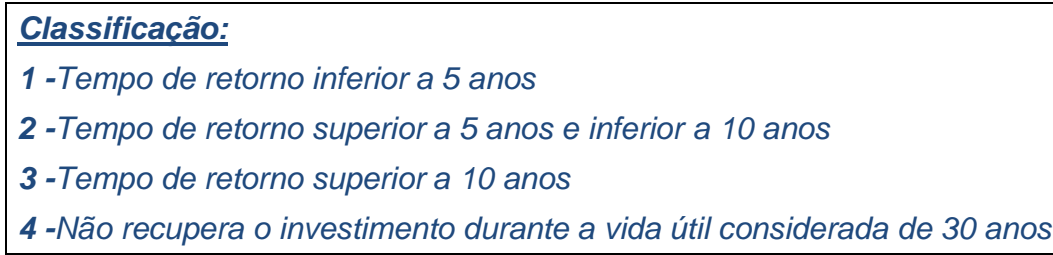

2) Financeiro - relativo à empresa executora (pontuação de 1 a 6)

a) Situação Econômica e Financeira do Empreendedor (pontuação de 1 a 4) Indicadores Financeiros (Liquidez, Endividamento e Cobertura de Juros) e econômicos (Margem Operacional, Margem Líquida, Retorno do Ativo e Retorno sobre PL)

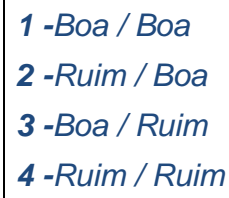

b) Compatibilidade do Tamanho da Executora X Projeto (pontuação de 1 a 2) - avaliar se a estrutura do capital da empresa é capaz de suportar o nível de investimento (Ativo Total do Empreendedor / Investimento Total do Projeto)

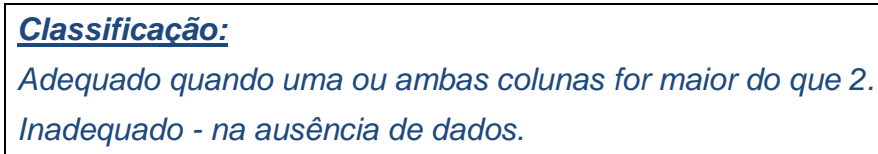

3) Ambiental - melhoria da qualidade da água (pontuação de 1 a 3) - melhoria da água na bacia em pontos específicos de controle ou pré-determinados e abatimento da carga poluidora lançada com a implantação do projeto (de DBO e coliformes fecais)

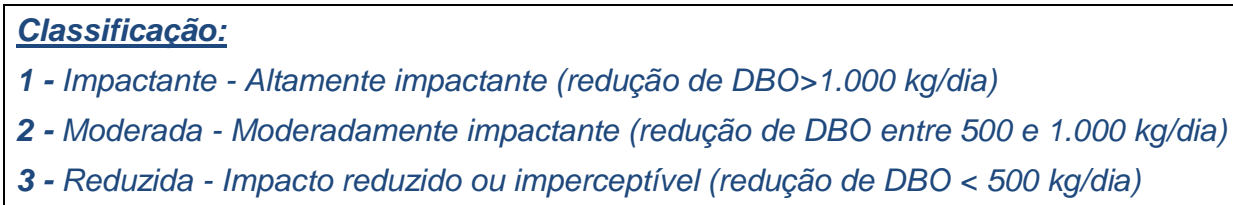

4) Econômico: Impacto do Empreendimento (pontuação de 1 a 3) - considera os benefícios econômicos esperados, além dos financeiros.

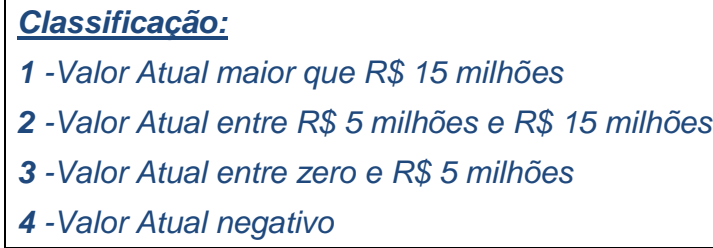


5) Social: Impacto do Empreendimento (pontuação de 1 a 3) - \% da população de baixa renda beneficiada direta ou indiretamente na área de influência do projeto.

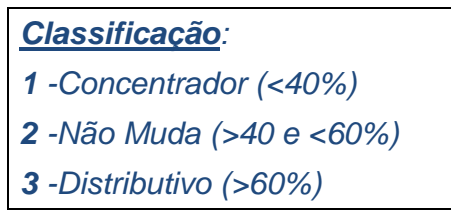

6) Demonstrativo do Empreendimento (pontuação de 1 a 4) - capacidade do projeto de atuar como catalizador para precipitar o processo de recuperação ambiental da bacia.

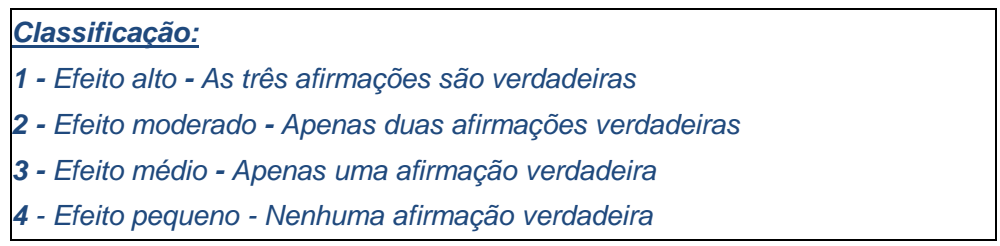

Foram listados ao todo 22 municípios, sendo que 7 são dos Estado do Rio de Janeiro, 7 de Minas Gerais e 8 de São Paulo.

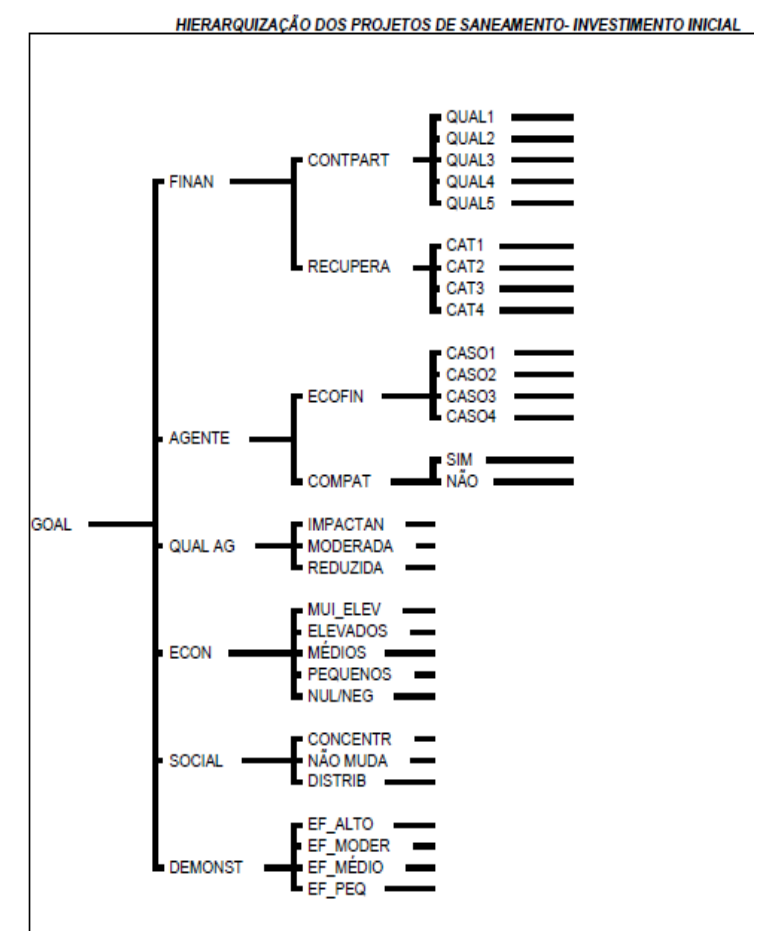

Figura 8 - Resumo dos Critérios

Fonte: LABORATÓRIO DE HIDROLOGIA - COPPE/UFRJ (2001) PPG-RE-026-R1 
Tabela 12 - Relação dos Critérios do Projeto

\begin{tabular}{|c|c|c|c|c|c|c|c|c|c|}
\hline \multicolumn{10}{|c|}{ TODOS OS CRITÉRIOS } \\
\hline & \multirow[t]{2}{*}{ Projeto } & \multicolumn{2}{|c|}{ Financeiro (Projeto) } & \multicolumn{2}{|c|}{ Financeiro (Agente) } & \multirow{2}{*}{$\begin{array}{c}\text { Qualidade } \\
\text { Água }\end{array}$} & \multirow[b]{2}{*}{ Econômico } & \multirow[b]{2}{*}{ Social } & \multirow[b]{2}{*}{ Demonstrativo } \\
\hline & & Contrapartida & Recuperação & Econ./financ. & Compatib. & & & & \\
\hline & \multicolumn{9}{|l|}{ Rio de Janeiro } \\
\hline 1 & Volta Redonda & 1 & 3 & 4 & 1 & 1 & 2 & 1 & 1 \\
\hline 2 & Resende & 4 & 3 & 4 & 2 & 1 & 1 & 1 & 1 \\
\hline 3 & Barra Mansa & 5 & 4 & 4 & 2 & 1 & 2 & 2 & 2 \\
\hline 4 & Três Rios & 5 & 3 & 4 & 2 & 1 & 2 & 2 & 4 \\
\hline 5 & Valença & 5 & 4 & 4 & 2 & 2 & 3 & 2 & 4 \\
\hline 6 & Agulhas Negras (Resende) & 4 & 4 & 4 & 2 & 2 & 3 & 1 & 1 \\
\hline \multirow[t]{2}{*}{7} & Itatiaia & 5 & 4 & 4 & 2 & 3 & 3 & 1 & 3 \\
\hline & Minas Gerais & & & & & & & & \\
\hline 8 & Juiz de Fora & 2 & 3 & 4 & 2 & 1 & 1 & 1 & 3 \\
\hline 9 & Ubá & 5 & 4 & 4 & 2 & 2 & 2 & 3 & 4 \\
\hline 10 & Leopoldina & 5 & 4 & 4 & 2 & 3 & 2 & 3 & 4 \\
\hline 11 & Muriaé & 2 & 3 & 2 & 2 & 2 & 3 & 3 & 3 \\
\hline 12 & Cataguases & 5 & 4 & 4 & 2 & 2 & 3 & 3 & 4 \\
\hline 13 & Santos Dumont & 5 & 4 & 4 & 2 & 2 & 2 & 3 & 4 \\
\hline \multirow[t]{2}{*}{14} & Visconde de Rio Branco & 5 & 4 & 4 & 2 & 3 & 3 & 3 & 4 \\
\hline & São Paulo & & & & & & & & \\
\hline 15 & Jacareí & 2 & 3 & 4 & 2 & 1 & 2 & 3 & 1 \\
\hline 16 & São José dos Campos & 1 & 3 & 4 & 2 & 1 & 1 & 1 & 1 \\
\hline 17 & Cachoeira Paulista & 1 & 3 & 4 & 2 & 3 & 2 & 2 & 2 \\
\hline 18 & Queluz & 1 & 3 & 4 & 2 & 3 & 3 & 3 & 3 \\
\hline 19 & Paraibuna & 3 & 3 & 4 & 2 & 3 & 4 & 2 & 2 \\
\hline 20 & Pindamonhangaba & 1 & 3 & 4 & 2 & 3 & 3 & 2 & 2 \\
\hline 21 & São Luiz do Paraitinga & 1 & 3 & 4 & 2 & 3 & 4 & 3 & 3 \\
\hline 22 & Santa Isabel & 5 & 4 & 2 & 2 & 3 & 3 & 2 & 2 \\
\hline
\end{tabular}

Valores quanto menores melhor

Para facilitar os cálculos juntamos os critérios $1 a$ e $1 b$ e $2 a$ e2b

Fonte: LABORATÓRIO DE HIDROLOGIA - COPPE/UFRJ (2001) PPG-RE-026-R1 
Tabela 13 - Relação dos Critérios Agrupados

\begin{tabular}{|c|c|c|c|c|c|c|c|c|}
\hline \multicolumn{9}{|c|}{ TODOS OS CRITÉRIOS } \\
\hline & Projeto & UF & $\begin{array}{l}\text { Financeiro } \\
\text { (Projeto) }\end{array}$ & $\begin{array}{c}\text { Financeiro } \\
\text { (Agente) }\end{array}$ & $\begin{array}{c}\text { Qualidade } \\
\text { Água }\end{array}$ & Econômico & Social & Demonstrativo \\
\hline 1 & Volta Redonda & RJ & 4 & 5 & 1 & 2 & 1 & 1 \\
\hline 2 & Resende & RJ & 7 & 6 & 1 & 1 & 1 & 1 \\
\hline 3 & Barra Mansa & RJ & 9 & 6 & 1 & 2 & 2 & 2 \\
\hline 4 & Três Rios & RJ & 8 & 6 & 1 & 2 & 2 & 4 \\
\hline 5 & Valença & RJ & 9 & 6 & 2 & 3 & 2 & 4 \\
\hline 6 & Agulhas Negras (Resende) & RJ & 8 & 5 & 2 & 3 & 1 & 1 \\
\hline 7 & Itatiaia & RJ & 9 & 6 & 3 & 3 & 1 & 3 \\
\hline 8 & Juiz de Fora & MG & 5 & 6 & 1 & 1 & 1 & 3 \\
\hline 9 & Ubá & MG & 9 & 6 & 2 & 2 & 3 & 4 \\
\hline 10 & Leopoldina & MG & 9 & 6 & 3 & 2 & 3 & 4 \\
\hline 11 & Muriaé & MG & 5 & 4 & 2 & 3 & 3 & 3 \\
\hline 12 & Cataguases & MG & 9 & 6 & 2 & 3 & 3 & 4 \\
\hline 13 & Santos Dumont & MG & 9 & 6 & 2 & 2 & 3 & 4 \\
\hline 14 & Visconde de Rio Branco & MG & 9 & 6 & 3 & 3 & 3 & 4 \\
\hline 15 & Jacareí & SP & 5 & 6 & 1 & 2 & 3 & 1 \\
\hline 16 & São José dos Campos & SP & 4 & 5 & 1 & 1 & 1 & 1 \\
\hline 17 & Cachoeira Paulista & $\mathrm{SP}$ & 4 & 5 & 3 & 2 & 2 & 2 \\
\hline 18 & Queluz & $\mathrm{SP}$ & 4 & 5 & 3 & 3 & 3 & 3 \\
\hline 19 & Paraibuna & $\mathrm{SP}$ & 6 & 6 & 3 & 4 & 2 & 2 \\
\hline 20 & Pindamonhangaba & $\mathrm{SP}$ & 4 & 5 & 3 & 3 & 2 & 2 \\
\hline 21 & São Luiz do Paraitinga & $\mathrm{SP}$ & 4 & 5 & 3 & 4 & 3 & 3 \\
\hline 22 & Santa Isabel & $\mathrm{SP}$ & 9 & 4 & 3 & 3 & 2 & 2 \\
\hline & pontuação máx: & & 9 & 6 & 3 & 4 & 3 & 4 \\
\hline
\end{tabular}

Fonte: Autoria própria 


\subsubsection{Cálculo - Metodologia AHP para os critérios}

Foi encaminhado um questionário solicitando a opinião sobre a importância relativa de cada critério utilizado na modelagem, sendo realizado uma comparação par a par do critério, posicionado a esquerda ele é (+) mais ou menos (-) importante que o da direita e qual a intensidade da importância relativa em cada uma das seguintes quinze (15) comparações.

\section{AVALIAÇÃO DOS ESPECIALISTAS E CRIAÇÃO DO PESO}

\begin{tabular}{|c|c|c|c|c|c|c|c|c|c|c|c|c|c|c|c|c|c|}
\hline ăo & & 8 & 1 & 6 & 5 & 4 & & 2 & 1 & 2 & 3 & 4 & 5 & 6 & 7 & 8 & 9 \\
\hline Critérios e subc & 1 & 2 & 3 & 4 & 5 & 6 & 7 & 8 & 9 & 10 & 11 & 12 & 13 & 14 & 15 & 16 & \\
\hline Arrigo & -3 & -3 & 7 & 3 & -3 & 1 & 7 & 3 & -2 & 7 & 5 & 1 & -3 & \begin{tabular}{|c|}
-7 \\
\end{tabular} & \begin{tabular}{|c|}
-7 \\
\end{tabular} & 3 & \\
\hline Cláudi & & -5 & 5 & 4 & 2 & \begin{tabular}{|c|}
-7 \\
\end{tabular} & 3 & 2 & -2 & 8 & 8 & 6 & -2 & \begin{tabular}{|c|}
-4 \\
\end{tabular} & -3 & & \\
\hline Emy d & 1 & -5 & 2 & 1 & -2 & -4 & -3 & 1 & 2 & 5 & 5 & 5 & -2 & 1 & & & \\
\hline Epifa & 2 & -4 & -4 & 6 & 8 & -2 & 2 & 4 & 4 & 3 & 5 & 3 & 6 & 5 & 1 & 1 & \\
\hline & -4 & -8 & -4 & -5 & 1 & -8 & 1 & -5 & 1 & & 8 & 8 & -8 & 4 & 6 & 4 & \\
\hline Julio & 1 & -4 & 2 & -4 & -8 & -4 & 2 & -4 & -8 & & 4 & \begin{tabular}{|l|}
-3 \\
\end{tabular} & -5 & -9 & -4 & -7 & \\
\hline Luis A & 2 & -7 & & \begin{tabular}{|c|}
-7 \\
\end{tabular} & 7 & \begin{tabular}{|c|}
-7 \\
\end{tabular} & 4 & -5 & 5 & & 3 & 7 & -5 & 3 & 3 & 5 & \\
\hline Maria A & 1 & -2 & 4 & 4 & -4 & 1 & 1 & -2 & -4 & & 1 & 1 & -2 & -4 & 1 & 4 & \\
\hline Maria d & 1 & & & 7 & 5 & 3 & 5 & 5 & 5 & & 5 & 5 & 3 & 3 & 3 & 3 & \\
\hline Maric & -5 & -9 & 1 & -9 & \begin{tabular}{l|}
-6 \\
\end{tabular} & -3 & 5 & -8 & -4 & 7 & -3 & \begin{tabular}{|l|}
-2 \\
\end{tabular} & -8 & -4 & 4 & -7 & \\
\hline Silvino S & 3 & -5 & 3 & -3 & 4 & -5 & -2 & -5 & 3 & 5 & 5 & 5 & -5 & 3 & 5 & -4 & \\
\hline \multicolumn{18}{|l|}{ Grupo } \\
\hline Média & 0,2 & $-4,5$ & 2,2 & $-0,3$ & 0,4 & $-3,2$ & 2,3 & $-1,3$ & 0 & 5,5 & 4,2 & \begin{tabular}{|l|}
3,3 \\
\end{tabular} & \begin{tabular}{|l|}
$-2,8$ \\
\end{tabular} & $-0,8$ & 1,1 & 0,4 & 0, \\
\hline Desvio & 2,8 & 3 & 3,5 & 5,5 & 5,4 & 3,6 & 3 & 4,4 & \begin{tabular}{|l|}
4,3 \\
\end{tabular} & 2,4 & 3,1 & \begin{tabular}{|c|}
3,6 \\
\end{tabular} & \begin{tabular}{|l|}
4,3 \\
\end{tabular} & 4,9 & \begin{tabular}{|l|}
4,1 \\
\end{tabular} & \begin{tabular}{|l|}
4,4 \\
\end{tabular} & \\
\hline Nota Ajustada & 1 & \begin{tabular}{|l|}
-5 \\
\end{tabular} & 2 & 1 & 1 & -3 & & -1 & 1 & & 4 & \begin{tabular}{|l|}
3 \\
\end{tabular} & -3 & \begin{tabular}{|c|} 
\\
\end{tabular} & & 1 & \\
\hline
\end{tabular}

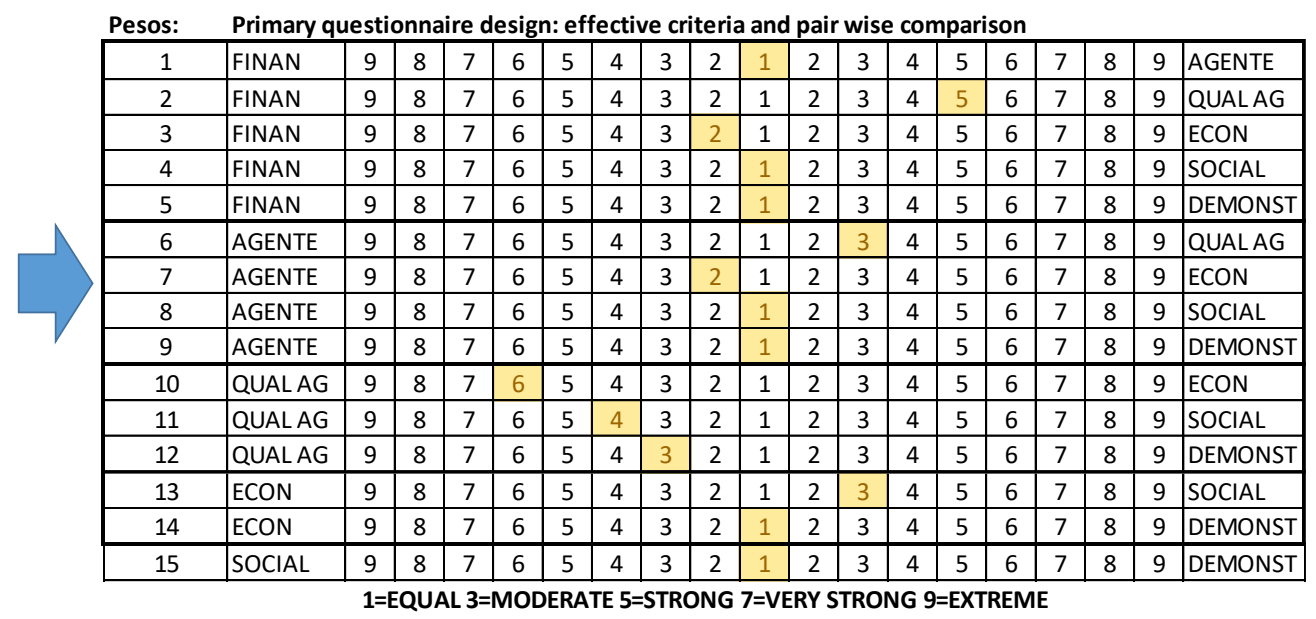

\section{Definition}

Goal HIERARQUIZAÇÃO DOS PROJETOS DE SANEAMENTO INVESTIMENTO INICIAL

FINAN CRITÉRIO FINANCEIRO/EMPREENDIMENTO

AGENTE CAPACIDADE FINANCEIRA DO AGENTE EMPREENDEDOR

QUAL AG IMPACTOS AMBIENTAIS

ECON IMPACTOS ECONÔMICOS DO EMPREENDIMENTO

SOCIAL IMPACTO SOCIAL

DEMONST EFEITO DEMONSTRATIVO

Figura 9 - Avaliação e peso dos critérios

Fonte: LABORATÓRIO DE HIDROLOGIA - COPPE/UFRJ (2001) PPG-RE-026-R1 


\subsubsection{MÉTODO AHP NO EXCEL}

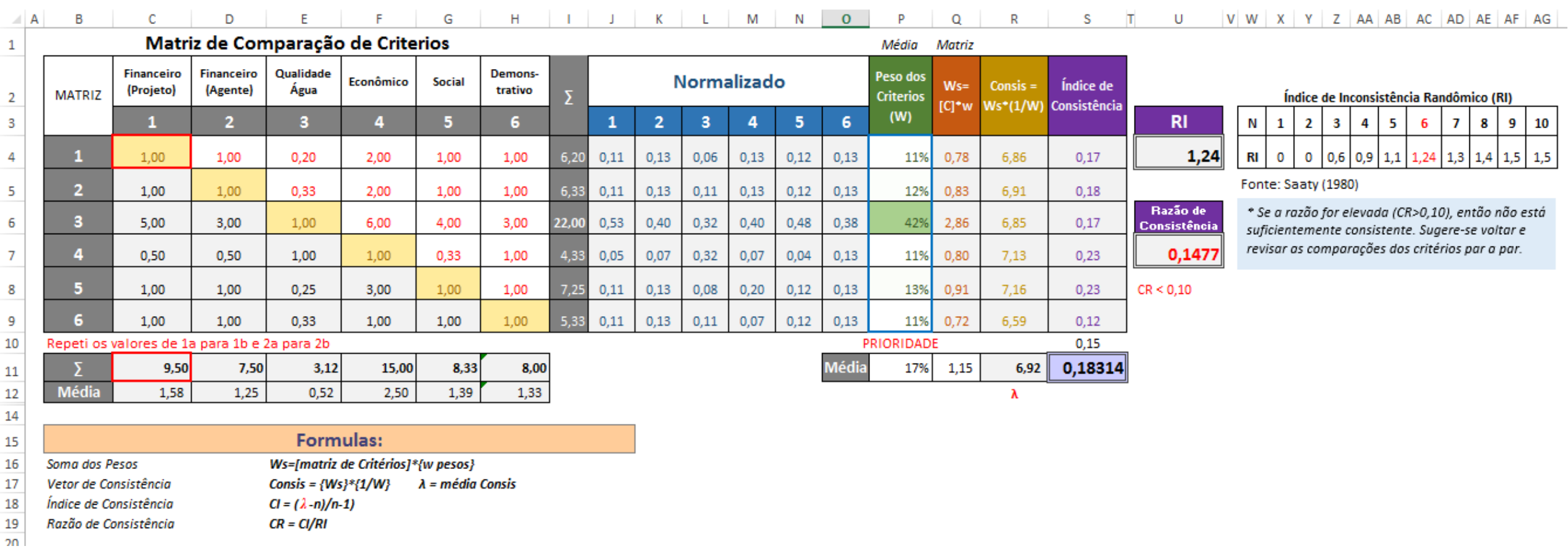

Figura 10 - Método AHP para critérios

Fonte: Autoria própria

- Passo 1: Matriz par a par, dos critérios, mediante a criação dos pesos na figura 10.

- Passo 2: Normalizar - soma-se a coluna e divide o valor da linha pela soma total da coluna. $=C 4 / \$ C \$ 11 \therefore 1,00 / 9,50=0,11$.

- Passo 3: Peso - realiza-se a média dos itens da linha normalizados. $=$ MÉDIA(J4: 04$) \therefore(0,11+0,13+0,06+0,13+0,12+0,13) / 6=0,11$

- Passo 4: Soma dos Pesos (Ws) - multiplicação de matrizes, cada linha do critério pela coluna do peso. $\{$ Ws $\}=[C] *\{W\} \therefore M A T R I Z . M U L T=0,78$

- Passo 5: Vetor de Consistência - multiplicação de Ws pelo inverso do peso. $\{$ Consis Vect $\}=\{$ Ws $\} *\left\{\frac{1}{W}\right\} \therefore Q 4 *\left(\frac{1}{P 4}\right)=0,78 *\left(\frac{1}{0,11}\right)=6,86$ 
- Passo 6: Índice de Consistência - Vetor de consistência menos o número de critérios divididos pelo número de critério menos 1. IC $=(\lambda-n) / n-1) \therefore(R 4-\$ B \$ 14) /(\$ B \$ 14-1)=$ $(6,86-6) /(6-1)=0,17$

- Passo 7: Razão de Consistência - Segundo SAATY o ideal é que este valor seja inferior a 0,10 , caso contrário é necessário rever as comparações. (CA ver tabela 8 ). $\mathrm{RC}=\mathrm{IC} / \mathrm{CA}$ : $(S 11 / U 4)=(0,1831 / 1,24)=0,1477$

Desta forma aplicou-se na tabela dos critérios por Estado da seguinte forma:

- Passo1: Normalizar - de acordo com os critérios e sua pontuação máxima, foi dividido linha a linha. $=D 4 / \$ D \$ 26 \therefore 4 / 9=0,44$.

Figura 11 - Exemplo do cálculo normalização AHP

\begin{tabular}{|c|c|c|c|c|c|c|c|c|c|c|c|}
\hline$\Delta$ & A & B & C & D & $\mathrm{E}$ & $\mathrm{F}$ & G & $\mathrm{H}$ & 1 & J & K \\
\hline \multicolumn{12}{|c|}{1} \\
\hline 2 & & \multicolumn{10}{|l|}{ TODOS OS CRITÉRIOS } \\
\hline 3 & & Projeto & UF & Financeiro (Projeto) & Financeiro (Agente) & $\begin{array}{c}\text { Qualidade } \\
\text { Água }\end{array}$ & Econômico & Social & Demonstrativo & PONTOS & \# \\
\hline 4 & 1[ & Volta Redonda & RJ & 4 & 5 & 1 & 2 & 1 & 1 & 0,76 & 1 \\
\hline 5 & 2 & Resende & RJ & 7 & 6 & 1 & 1 & 1 & 1 & 0,76 & 2 \\
\hline 6 & 3 & Barra Mansa & RJ & 9 & 6 & 1 & 2 & 2 & 2 & 0,61 & 3 \\
\hline 23 & 20 & Pindamonhangaba & SP & 4 & 5 & 3 & 3 & 2 & 2 & 0,35 & 5 \\
\hline 24 & 21 & São Luiz do Paraitinga & $\mathrm{SP}$ & 4 & 5 & 3 & 4 & 3 & 3 & 0,33 & 6 \\
\hline 25 & 22 & Santa Isabel & $\mathrm{SP}$ & 9 & 4 & 3 & 3 & 2 & 2 & 0,25 & 8 \\
\hline 26 & & pontuação máx: & & 9 & 6 & 3 & 4 & 3 & 4 & & \\
\hline 27 & & & & & & & & & & & \\
\hline
\end{tabular}

Fonte: Autoria própria

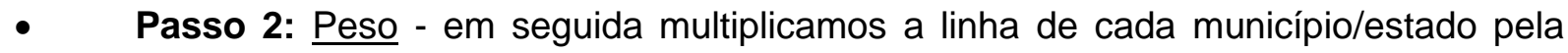
coluna de peso dos critérios estabelecido na figura 12.

$$
\Rightarrow \quad=1-(\text { MATRIZ.MULT }(L 3: Q 3 ; A H P ! \$ P \$ 4: \$ P \$ 9))=0,58
$$

Figura 12 - Cálculo do peso por município

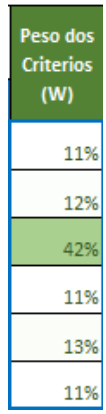


- Passo 3: A partir dos dados obtidos, é possível hierarquizar os estados.

Tabela 14 - Relação do Critérios Classificados por AHP - Normalizados

TODOS OS CRITÉRIOS

NORMALIZADOS

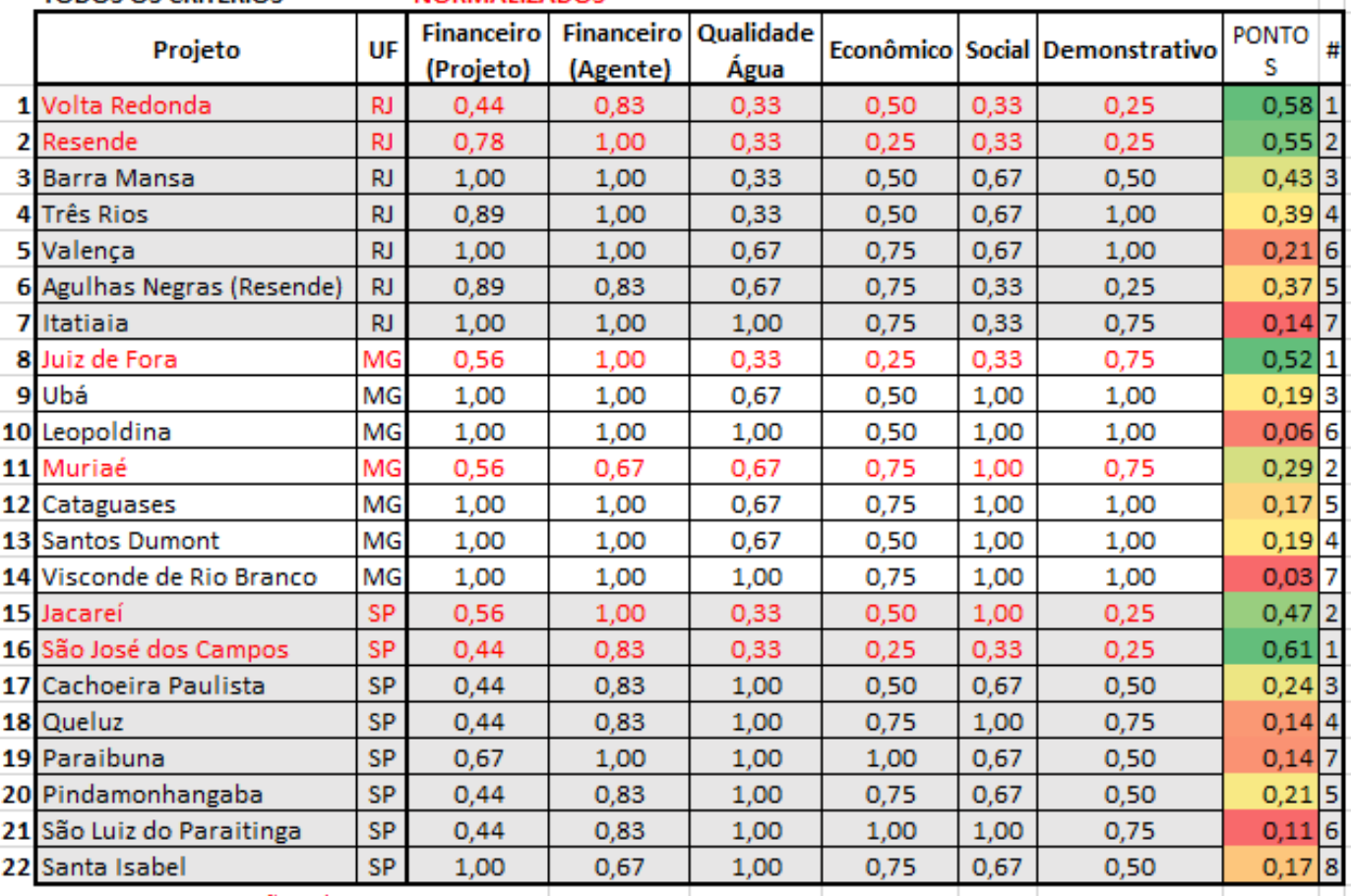

Fonte: Autoria própria 


\subsubsection{Cálculo - Metodologia TOPSIS para os critérios}

\begin{tabular}{|c|c|c|c|c|c|c|c|c|}
\hline 4 & A & $\mathrm{B}$ & $\mathrm{C}$ & $\mathrm{D}$ & $E$ & $\mathrm{~F}$ & G & $\mathrm{H}$ \\
\hline 1 & \multirow{2}{*}{\multicolumn{8}{|c|}{ TODOS OS CRITÉRIOS }} \\
\hline 2 & & & & & & & & \\
\hline 3 & Cidade & Estado & \begin{tabular}{|c|} 
Financeiro \\
(Projeto) \\
\end{tabular} & \begin{tabular}{|c|} 
Financeiro \\
(Agente)
\end{tabular} & $\begin{array}{c}\text { Qualidade } \\
\text { Água }\end{array}$ & Econômico & Social & Demonstrativo \\
\hline 4 & Volta Redonda & RJ & 4 & 5 & 1 & 2 & 1 & 1 \\
\hline 5 & Resende & RJ & 7 & 6 & 1 & 1 & 1 & 1 \\
\hline 6 & Barra Mansa & RJ & 9 & 6 & 1 & 2 & 2 & 2 \\
\hline 7 & Três Rios & RJ & 8 & 6 & 1 & 2 & 2 & 4 \\
\hline 8 & Valença & RJ & 9 & 6 & 2 & 3 & 2 & 4 \\
\hline 9 & Agulhas Negras (Resen & RJ & 8 & 5 & 2 & 3 & 1 & 1 \\
\hline 10 & Itatiaia & RJ & 9 & 6 & 3 & 3 & 1 & 3 \\
\hline 11 & Juiz de Fora & MG & 5 & 6 & 1 & 1 & 1 & 3 \\
\hline 12 & Ubá & MG & 9 & 6 & 2 & 2 & 3 & 4 \\
\hline 13 & Leopoldina & MG & 9 & 6 & 3 & 2 & 3 & 4 \\
\hline 14 & Muriaé & MG & 5 & 4 & 2 & 3 & 3 & 3 \\
\hline 15 & Cataguases & MG & 9 & 6 & 2 & 3 & 3 & 4 \\
\hline 16 & Santos Dumont & MG & 9 & 6 & 2 & 2 & 3 & 4 \\
\hline 17 & Visconde de Rio Branco & MG & 9 & 6 & 3 & 3 & 3 & 4 \\
\hline 18 & Jacareí & $\mathrm{SP}$ & 5 & 6 & 1 & 2 & 3 & 1 \\
\hline 19 & São José dos Campos & SP & 4 & 5 & 1 & 1 & 1 & 1 \\
\hline 20 & Cachoeira Paulista & SP & 4 & 5 & 3 & 2 & 2 & 2 \\
\hline 21 & Queluz & SP & 4 & 5 & 3 & 3 & 3 & 3 \\
\hline 22 & Paraibuna & SP & 6 & 6 & 3 & 4 & 2 & 2 \\
\hline 23 & Pindamonhangaba & SP & 4 & 5 & 3 & 3 & 2 & 2 \\
\hline 24 & São Luiz do Paraitinga & SP & 4 & 5 & 3 & 4 & 3 & 3 \\
\hline 25 & Santa Isabel & SP & 9 & 4 & 3 & 3 & 2 & 2 \\
\hline 26 & Pontuação Máx: & & 9 & 6 & 3 & 4 & 3 & 4 \\
\hline
\end{tabular}

Figura 13 - Todos os Critérios

Fonte: Autoria própria

- Passo 1: Normalizar - aplicou-se o mesmo critério do AHP dividindo o valor da linha pela soma total da coluna.

$$
\mathrm{P}_{\mathrm{ij}}=\frac{X \mathrm{ij}}{\operatorname{Max} X i}
$$

$\Rightarrow$ Ex: linha 1/ coluna 1: (\$C\$4) 4 / (\$C\$26) 9 (Pontuação máxima) = 0,44 (Volta Redonda Financeiro (projeto)), realizar para todos os outros critérios. 


\begin{tabular}{|c|c|c|c|c|c|c|c|c|}
\hline 4 & A & B & C & D & $\mathrm{E}$ & $\mathrm{F}$ & G & $\mathrm{H}$ \\
\hline 29 & Passo 1: & & & & & & & \\
\hline 30 & NORMALIZADO & & & & & & & \\
\hline 31 & Cidade & Estado & $\begin{array}{c}\text { Financeiro } \\
\text { (Projeto) }\end{array}$ & $\begin{array}{c}\text { Financeiro } \\
\text { (Agente) }\end{array}$ & $\begin{array}{c}\text { Qualidade } \\
\text { Água }\end{array}$ & Econômico & Social & Demonstrativo \\
\hline 32 & Volta Redonda & $\mathrm{RJ}$ & 0,44 & 0,83 & 0,33 & 0,50 & 0,33 & 0,25 \\
\hline 33 & Resende & RJ & 0,78 & 1,00 & 0,33 & 0,25 & 0,33 & 0,25 \\
\hline 34 & Barra Mansa & RJ & 1,00 & 1,00 & 0,33 & 0,50 & 0,67 & 0,50 \\
\hline 35 & Três Rios & RJ & 0,89 & 1,00 & 0,33 & 0,50 & 0,67 & 1,00 \\
\hline 36 & Valença & RJ & 1,00 & 1,00 & 0,67 & 0,75 & 0,67 & 1,00 \\
\hline 37 & Agulhas Negras (Reser & RJ & 0,89 & 0,83 & 0,67 & 0,75 & 0,33 & 0,25 \\
\hline 38 & Itatiaia & $\mathrm{RJ}$ & 1,00 & 1,00 & 1,00 & 0,75 & 0,33 & 0,75 \\
\hline 39 & Juiz de Fora & MG & 0,56 & 1,00 & 0,33 & 0,25 & 0,33 & 0,75 \\
\hline 40 & Ubá & MG & 1,00 & 1,00 & 0,67 & 0,50 & 1,00 & 1,00 \\
\hline 41 & Leopoldina & MG & 1,00 & 1,00 & 1,00 & 0,50 & 1,00 & 1,00 \\
\hline 42 & Muriaé & MG & 0,56 & 0,67 & 0,67 & 0,75 & 1,00 & 0,75 \\
\hline 43 & Cataguases & MG & 1,00 & 1,00 & 0,67 & 0,75 & 1,00 & 1,00 \\
\hline 44 & Santos Dumont & MG & 1,00 & 1,00 & 0,67 & 0,50 & 1,00 & 1,00 \\
\hline 45 & Visconde de Rio Branc & MG & 1,00 & 1,00 & 1,00 & 0,75 & 1,00 & 1,00 \\
\hline 46 & Jacareí & $\mathrm{SP}$ & 0,56 & 1,00 & 0,33 & 0,50 & 1,00 & 0,25 \\
\hline 47 & São José dos Campos & SP & 0,44 & 0,83 & 0,33 & 0,25 & 0,33 & 0,25 \\
\hline 48 & Cachoeira Paulista & $\mathrm{SP}$ & 0,44 & 0,83 & 1,00 & 0,50 & 0,67 & 0,50 \\
\hline 49 & Queluz & SP & 0,44 & 0,83 & 1,00 & 0,75 & 1,00 & 0,75 \\
\hline 50 & Paraibuna & SP & 0,67 & 1,00 & 1,00 & 1,00 & 0,67 & 0,50 \\
\hline 51 & Pindamonhangaba & SP & 0,44 & 0,83 & 1,00 & 0,75 & 0,67 & 0,50 \\
\hline 52 & São Luiz do Paraitinga & SP & 0,44 & 0,83 & 1,00 & 1,00 & 1,00 & 0,75 \\
\hline 53 & Santa Isabel & SP & 1,00 & 0,67 & 1,00 & 0,75 & 0,67 & 0,50 \\
\hline 54 & pontuação máx: & & 9 & 6 & 3 & 4 & 3 & 4 \\
\hline
\end{tabular}

Figura 14 - Critérios Normalizados

Fonte: Autoria própria

- Passo 2: Calcular pesos:

D Entropia: $\boldsymbol{e}_{\boldsymbol{j}}=\frac{1}{\ln (\mathrm{m})} \sum_{\boldsymbol{j}}^{\boldsymbol{m}} \mathrm{Pij} \cdot \ln (\mathrm{Pij})=>$ Exemplos:

$$
\begin{aligned}
\Rightarrow & -1 / \ln (7) *(C 32 * \ln (C 32)+C 33 * \ln (C 33)+C 34 * \ln (C 34)+C 35 * \ln (C 35)+C 36 * \\
& \ln (C 36)+C 37 * \ln (C 37)+C 38 * \ln (C 38)) \quad R E F E R E N T E A O R I O D E \text { JANEIRO } \\
\Rightarrow & -1 / \ln (7) *(0,44 * \ln (0,44)+0,78 * \ln (0,78)+1 * \ln (1)+0,89 * \ln (0,89)+1 * \ln (1)+ \\
& 0,89 * \ln (0,89)+1 * \ln (1)=\underline{0,39}
\end{aligned}
$$

Grau de diversidade: $d_{j}=1-e_{j} 1-0,39=\underline{0,61}$

Peso: $W_{j} \frac{\boldsymbol{d j}}{\sum_{j=\mathbf{1}}^{\boldsymbol{n}} \boldsymbol{d}_{\boldsymbol{j}}} \quad 0,39 / 4,62=\underline{0,09}$ 
Passo 2:

A

B

C

E

F

G

H

8 CÁLCULO DOS PESOS PARA CADA CRITÉRIO

\begin{tabular}{|c|c|c|c|c|c|c|c|c|c|}
\hline 59 & Cidade & Estado & $\begin{array}{c}\text { Financeiro } \\
\text { (Projeto) }\end{array}$ & $\begin{array}{c}\text { Financeiro } \\
\text { (Agente) }\end{array}$ & \begin{tabular}{|c} 
Qualidade \\
Água
\end{tabular} & Econômico & Social & Demonstrativo & $\Sigma$ \\
\hline 60 & \multirow{3}{*}{ Entropia } & RJ & 0,39 & 0,16 & 1,03 & 1,05 & 1,17 & 0,82 & 4,62 \\
\hline 61 & & MG & 0,38 & 0,08 & 1,03 & 1,05 & 1,17 & 0,76 & 4,46 \\
\hline 62 & & $\mathrm{SP}$ & 0,28 & 0,08 & 0,98 & 1,05 & 0,98 & 0,58 & 3,94 \\
\hline \multicolumn{9}{|l|}{63} & \\
\hline 64 & \multirow{3}{*}{ Grau de Diversidade } & RJ & 0,61 & 0,84 & $(0,03)$ & $(0,05)$ & $(0,17)$ & 0,18 & \\
\hline 65 & & MG & 0,62 & 0,92 & $(0,03)$ & $(0,05)$ & $(0,17)$ & 0,24 & \\
\hline 66 & & SP & 0,72 & 0,92 & 0,02 & $(0,05)$ & 0,02 & 0,42 & \\
\hline \multicolumn{9}{|l|}{67} & \\
\hline 68 & \multirow{3}{*}{ Peso } & RJ & 0,09 & 0,03 & 0,22 & 0,23 & 0,25 & 0,18 & \\
\hline 69 & & MG & 0,08 & 0,02 & 0,23 & 0,23 & 0,26 & 0,17 & \\
\hline 70 & & SP & 0,07 & 0,02 & 0,25 & 0,27 & 0,25 & 0,15 & \\
\hline
\end{tabular}

Figura 15 - Entropia, Diversidade e Peso

Fonte: Autoria própria

- Passo 3: Divide o valor normalizado pelo de cada estado

$\Rightarrow C 32 / C \$ 68 \$=>0,44 / 0,09=5,22$ (Volta Redonda Financeiro (projeto))

72 Passo 3:

A

B

C D D

$E$

F

G

$\mathrm{H}$

73 CÁLCULO DOS VALORES NORMALIZADOS PELO PESO

\begin{tabular}{|l|l|r|r|r|r|r|r|r|}
\hline 74 & \multicolumn{1}{|c|}{ Cidade } & Estado & $\begin{array}{c}\text { Financeiro } \\
\text { (Projeto) }\end{array}$ & $\begin{array}{r}\text { Financeiro } \\
\text { (Agente) }\end{array}$ & $\begin{array}{c}\text { Qualidade } \\
\text { Água }\end{array}$ & Econômico & Social & Demonstrativo \\
\hline 75 & Volta Redonda & RJ & 5,22 & 24,64 & 1,49 & 2,21 & 1,32 & 1,40 \\
\hline 76 & Resende & RJ & 9,13 & 29,57 & 1,49 & 1,10 & 1,32 & 1,40 \\
\hline 77 & Barra Mansa & RJ & 11,74 & 29,57 & 1,49 & 2,21 & 2,63 & 2,80 \\
\hline 78 & Três Rios & RJ & 10,44 & 29,57 & 1,49 & 2,21 & 2,63 & 5,61 \\
\hline 79 & Valença & RJ & 11,74 & 29,57 & 2,99 & 3,31 & 2,63 & 5,61 \\
\hline 80 & Agulhas Negras (Reser & RJ & 10,44 & 24,64 & 2,99 & 3,31 & 1,32 & 1,40 \\
\hline 81 & Itatiaia & RJ & 11,74 & 29,57 & 4,48 & 3,31 & 1,32 & 4,21 \\
\hline 82 & Juiz de Fora & MG & 6,58 & 57,06 & 1,44 & 1,07 & 1,27 & 4,42 \\
\hline 83 & Ubá & MG & 11,85 & 57,06 & 2,88 & 2,13 & 3,81 & 5,89 \\
\hline 84 & Leopoldina & MG & 11,85 & 57,06 & 4,32 & 2,13 & 3,81 & 5,89 \\
\hline 85 & Muriaé & MG & 6,58 & 38,04 & 2,88 & 3,20 & 3,81 & 4,42 \\
\hline 86 & Cataguases & MG & 11,85 & 57,06 & 2,88 & 3,20 & 3,81 & 5,89 \\
\hline 87 & Santos Dumont & MG & 11,85 & 57,06 & 2,88 & 2,13 & 3,81 & 5,89 \\
\hline 88 & Visconde de Rio Branc & MG & 11,85 & 57,06 & 4,32 & 3,20 & 3,81 & 5,89 \\
\hline 89 & Jacareíl & SP & 7,95 & 50,45 & 1,34 & 1,88 & 4,01 & 1,70 \\
\hline 90 & São José dos Campos & SP & 6,36 & 42,04 & 1,34 & 0,94 & 1,34 & 1,70 \\
\hline 91 & Cachoeira Paulista & SP & 6,36 & 42,04 & 4,01 & 1,88 & 2,68 & 3,41 \\
\hline 92 & Queluz & SP & 6,36 & 42,04 & 4,01 & 2,83 & 4,01 & 5,11 \\
\hline 93 & Paraibuna & SP & 9,53 & 50,45 & 4,01 & 3,77 & 2,68 & 3,41 \\
\hline 94 & Pindamonhangaba & SP & 6,36 & 42,04 & 4,01 & 2,83 & 2,68 & 3,41 \\
\hline 95 & São Luiz do Paraitinga & SP & 6,36 & 42,04 & 4,01 & 3,77 & 4,01 & 5,11 \\
\hline 96 & Santa Isabel & SP & 14,30 & 33,63 & 4,01 & 2,83 & 2,68 & 3,41 \\
\hline
\end{tabular}

I

Figura 16 - Divisão do Valor Normalizado pelo Peso

Fonte: Autoria própria 
- Passo 4: A próxima etapa é definir a distância euclidiana, isto é, Identificação das soluções ideais positivas $A^{+}$(benefício) e as soluções ideais negativas $A^{-}$(menor peso).

$>$ A Solução Ideal Positiva (PIS) serão as que estão com valor mínimo, então aplica-se a fórmula de mínimo para identificar os menores valores dos pesos encontrados por estado. Em seguida aplicamos a seguinte formula:

$$
d^{+}=\sqrt{\sum_{j=1}^{n} \mathrm{Wj}(\mathrm{Vij}-\mathrm{Vij}+)^{2}}
$$

$\Rightarrow \$ C \$ 68^{*}\left((C 75-\$ C \$ 104)^{\wedge} 2\right)=>0,09^{*}((5,22-5,22) 2)=0$ Volta Redonda Financeiro (projeto)

99 Passo 4:

100 IDENTIFICAÇÃO DAS SOLUÇões IDEAIS POSITIVAS A+(BENEFÍCIO) E

101 AS SOLUÇÕES IDEAIS NEGATIVAS A- (MENOR PESO) - DISTANCIA EUCLIDIANA

\begin{tabular}{|c|c|c|c|c|c|c|c|c|}
\hline 102 & & & $\begin{array}{c}\text { Financeiro } \\
\text { (Projeto) }\end{array}$ & $\begin{array}{c}\text { Financeiro } \\
\text { (Agente) }\end{array}$ & $\begin{array}{c}\text { Qualidade } \\
\text { Água }\end{array}$ & Econômico & Social & Demonstrativo \\
\hline 103 & & & mínimo & mínimo & mínimo & mínimo & mínimo & mínimo \\
\hline 104 & \multirow{3}{*}{ Positivas } & RJ & 5,22 & 24,64 & 1,49 & 1,10 & 1,32 & 1,40 \\
\hline 105 & & MG & 6,58 & 38,04 & 1,44 & 1,07 & 1,27 & 4,42 \\
\hline 106 & & SP & 6,36 & 33,63 & 1,34 & 0,94 & 1,34 & 1,70 \\
\hline
\end{tabular}

107

\begin{tabular}{|l|l|c|r|r|r|r|r|r|}
\hline \multicolumn{1}{|c|}{ Cidade } & Estado & $\begin{array}{c}\text { Financeiro } \\
\text { (Projeto) }\end{array}$ & $\begin{array}{c}\text { Financeiro } \\
\text { (Agente) }\end{array}$ & $\begin{array}{c}\text { Qualidade } \\
\text { Água }\end{array}$ & Econômico & Social & Demonstrativo \\
\hline 109 & Volta Redonda & RJ & - & - & - & 0,28 & - & - \\
\hline 110 & Resende & RJ & 1,30 & 0,82 & - & - & - & - \\
\hline 111 & Barra Mansa & RJ & 3,62 & 0,82 & - & 0,28 & 0,44 & 0,35 \\
\hline 112 & Três Rios & RJ & 2,32 & 0,82 & - & 0,28 & 0,44 & 3,16 \\
\hline 113 & Valença & RJ & 3,62 & 0,82 & 0,50 & 1,10 & 0,44 & 3,16 \\
\hline 114 & Agulhas Negras (Resen & RJ & 2,32 & - & 0,50 & 1,10 & - & - \\
\hline 115 & Itatiaia & RJ & 3,62 & 0,82 & 1,99 & 1,10 & - & 1,40 \\
\hline 116 & Juizde Fora & MG & - & 6,34 & - & - & - & - \\
\hline 117 & Ubá & MG & 2,34 & 6,34 & 0,48 & 0,27 & 1,69 & 0,37 \\
\hline 118 & Leopoldina & MG & 2,34 & 6,34 & 1,92 & 0,27 & 1,69 & 0,37 \\
\hline 119 & Muriaé & MG & - & - & 0,48 & 1,07 & 1,69 & - \\
\hline 120 & Cataguases & MG & 2,34 & 6,34 & 0,48 & 1,07 & 1,69 & 0,37 \\
\hline 121 & Santos Dumont & MG & 2,34 & 6,34 & 0,48 & 0,27 & 1,69 & 0,37 \\
\hline 122 & Visconde de Rio Brancc & MG & 2,34 & 6,34 & 1,92 & 1,07 & 1,69 & 0,37 \\
\hline 123 & Jacarei & SP & 0,18 & 5,61 & - & 0,24 & 1,78 & - \\
\hline 124 & São José dos Campos & SP & - & 1,40 & - & - & - & - \\
\hline 125 & Cachoeira Paulista & SP & - & 1,40 & 1,78 & 0,24 & 0,45 & 0,43 \\
\hline 126 & Queluz & SP & - & 1,40 & 1,78 & 0,94 & 1,78 & 1,70 \\
\hline 127 & Paraibuna & SP & 0,71 & 5,61 & 1,78 & 2,12 & 0,45 & 0,43 \\
\hline 128 & Pindamonhangaba & SP & - & 1,40 & 1,78 & 0,94 & 0,45 & 0,43 \\
\hline 129 & São Luiz do Paraitinga & SP & - & 1,40 & 1,78 & 2,12 & 1,78 & 1,70 \\
\hline 130 & Santa Isabel & SP & 4,41 & - & 1,78 & 0,94 & 0,45 & 0,43 \\
\hline & & & & & & & \\
\hline & & & & & & & \\
\hline
\end{tabular}

Figura 17 - Distância Euclidiana Positiva

Fonte: Autoria própria 
A Solução Ideal Negativa (NIS) serão as que estão com valor máximo, então aplicase a fórmula de máximo para identificar os maiores valores dos pesos encontrados por estado. Em seguida aplicamos a seguinte formula:

$$
d^{-}=\sqrt{\sum_{j=1}^{n} \mathrm{Wj}(\mathrm{Vij}-\mathrm{Vij}-)^{2}}
$$

$\Rightarrow \$ C \$ 68^{*}\left((C 75-\$ C \$ 132)^{\wedge} 2\right)=>0,09^{*}\left((5,62-11,74)^{\wedge} 2\right)=3,62$ Volta Redonda Financeiro (projeto)

\begin{tabular}{|c|c|c|c|c|c|c|c|c|}
\hline 4 & A & $\mathrm{B}$ & $\mathrm{C}$ & $\mathrm{D}$ & $E$ & $\mathrm{~F}$ & G & $\mathrm{H}$ \\
\hline 99 & Passo 4: & & & & & & & \\
\hline 100 & \multirow{2}{*}{\multicolumn{8}{|c|}{$\begin{array}{l}\text { IDENTIFICAÇÃO DAS SOLUÇÕES IDEAIS POSITIVAS A+(BENEFÍCIO) E } \\
\text { AS SOLUÇÕES IDEAIS NEGATIVAS A-(MENOR PESO) - DISTANCIA EUCLIDIANA }\end{array}$}} \\
\hline 101 & & & & & & & & \\
\hline 102 & & & \begin{tabular}{|c|} 
Financeiro \\
(Projeto)
\end{tabular} & \begin{tabular}{c|} 
Financeiro \\
(Agente)
\end{tabular} & $\begin{array}{c}\text { Qualidade } \\
\text { Água }\end{array}$ & Econômico & Social & Demonstrativo \\
\hline 131 & & & máxima & máxima & máxima & máxima & máxima & máxima \\
\hline 132 & \multirow{3}{*}{ Negativa } & RJ & 11,74 & 29,57 & 4,48 & 3,31 & 2,63 & 5,61 \\
\hline 133 & & MG & 11,85 & 57,06 & 4,32 & 3,20 & 3,81 & 5,89 \\
\hline 134 & & SP & 14,30 & 50,45 & 4,01 & 3,77 & 4,01 & 5,11 \\
\hline \multicolumn{9}{|l|}{135} \\
\hline 136 & Cidade & Estado & \begin{tabular}{|c|}
$\begin{array}{c}\text { Financeiro } \\
\text { (Projeto) }\end{array}$ \\
\end{tabular} & \begin{tabular}{|c|}
$\begin{array}{c}\text { Financeiro } \\
\text { (Agente) }\end{array}$ \\
\end{tabular} & $\begin{array}{c}\text { Qualidade } \\
\text { Água }\end{array}$ & Econômico & Social & Demonstrativo \\
\hline 137 . & Volta Redonda & RJ & 3,62 & \begin{tabular}{|l|}
0,82 \\
\end{tabular} & \begin{tabular}{|r|}
1,99 \\
\end{tabular} & 0,28 & 0,44 & 3,16 \\
\hline 138 & Resende & $R J$ & 0,58 & - & 1,99 & 1,10 & 0,44 & 3,16 \\
\hline 139 & Barra Mansa & RJ & - & - & 1,99 & 0,28 & - & 1,40 \\
\hline 140 & Três Rios & RJ & 0,14 & - & 1,99 & 0,28 & - & - \\
\hline 141 & Valença & RJ & - & - & 0,50 & - & - & - \\
\hline 142 & Agulhas Negras (Resen & RJ & 0,14 & 0,82 & 0,50 & - & 0,44 & 3,16 \\
\hline 143 & Itatiaia & RJ & - & - & - & - & 0,44 & 0,35 \\
\hline 144. & Juiz de Fora & MG & 2,34 & - & 1,92 & 1,07 & 1,69 & 0,37 \\
\hline 145 & Ubá & MG & - & - & 0,48 & 0,27 & - & - \\
\hline 146 & Leopoldina & MG & - & - & - & 0,27 & - & - \\
\hline 147[ & Muriaé & MG & 2,34 & 6,34 & 0,48 & - & - & 0,37 \\
\hline 148 & Cataguases & MG & - & - & 0,48 & - & - & - \\
\hline 149 & Santos Dumont & MG & - & - & 0,48 & 0,27 & - & - \\
\hline 150 & Visconde de Rio Brancd & MG & - & - & - & - & - & - \\
\hline 151 & \begin{tabular}{|l|} 
Jacareí \\
\end{tabular} & $\mathrm{SP}$ & 2,83 & - & 1,78 & 0,94 & - & 1,70 \\
\hline 152 & São José dos Campos & SP & 4,41 & 1,40 & 1,78 & 2,12 & 1,78 & 1,70 \\
\hline 153 & Cachoeira Paulista & SP & 4,41 & 1,40 & - & 0,94 & 0,45 & 0,43 \\
\hline 154 & Queluz & SP & 4,41 & 1,40 & - & 0,24 & - & - \\
\hline 155 & Paraibuna & SP & 1,59 & - & - & - & 0,45 & 0,43 \\
\hline 156 & Pindamonhangaba & $\mathrm{SP}$ & 4,41 & 1,40 & - & 0,24 & 0,45 & 0,43 \\
\hline 157 & São Luiz do Paraitinga & SP & 4,41 & 1,40 & - & - & - & - \\
\hline 158 & Santa Isabel & SP & - & 5,61 & - & 0,24 & 0,45 & 0,43 \\
\hline
\end{tabular}

Figura 18- Distância Euclidiana Negativa

Fonte: Autoria própria

- Passo 5: A similaridade relativa é calculada através da seguinte formula: utilizamos a distância Negativa e dividimos pela soma da Negativa com a Positiva.

$\Rightarrow C 137 /(C 137+C 109)=>3,62 /(3,62+0)=1$ Volta Redonda Financeiro (projeto) 
Passo 5:

SIMILARIDADE RELATIVA

\begin{tabular}{|c|c|c|c|c|c|c|c|c|}
\hline Cidade & Estado & \begin{tabular}{|c|} 
Financeiro \\
(Projeto)
\end{tabular} & $\begin{array}{c}\text { Financeiro } \\
\text { (Agente) }\end{array}$ & $\begin{array}{c}\text { Qualidade } \\
\text { Água }\end{array}$ & Econômico & Social & Demonstrativo & $\Sigma$ \\
\hline Volta Redonda & RJ & 1,00 & 1,00 & 1,00 & 0,50 & 1,00 & 1,00 & 5,50 \\
\hline Resende & RJ & 0,31 & - & 1,00 & 1,00 & 1,00 & 1,00 & 4,31 \\
\hline Barra Mansa & RJ & - & - & 1,00 & 0,50 & - & 0,80 & 2,30 \\
\hline Três Rios & RJ & 0,06 & - & 1,00 & 0,50 & - & - & 1,56 \\
\hline \begin{tabular}{|l|} 
Valença \\
\end{tabular} & $\mathrm{RJ}$ & - & - & 0,50 & - & - & - & 0,50 \\
\hline Agulhas Negras (Resen & $R J$ & 0,06 & 1,00 & 0,50 & - & 1,00 & 1,00 & 3,56 \\
\hline \begin{tabular}{|l|} 
Itatiaia \\
\end{tabular} & RJ & - & - & - & - & 1,00 & 0,20 & 1,20 \\
\hline Juiz de Fora & MG & 1,00 & - & 1,00 & 1,00 & 1,00 & 1,00 & 5,00 \\
\hline Ubá & MG & - & - & 0,50 & 0,50 & - & - & 1,00 \\
\hline Leopoldina & MG & - & - & - & 0,50 & - & - & 0,50 \\
\hline Muriaé & MG & 1,00 & 1,00 & 0,50 & - & - & 1,00 & 3,50 \\
\hline Cataguases & MG & - & - & 0,50 & - & - & - & 0,50 \\
\hline Santos Dumont & MG & - & - & 0,50 & 0,50 & - & - & 1,00 \\
\hline Visconde de Rio Branco & $M G$ & - & - & - & - & - & - & - \\
\hline 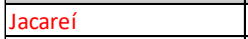 & SP & 0,94 & - & 1,00 & 0,80 & - & 1,00 & 3,74 \\
\hline São José dos Campos & SP & 1,00 & 0,50 & 1,00 & 1,00 & 1,00 & 1,00 & 5,50 \\
\hline Cachoeira Paulista & SP & 1,00 & 0,50 & - & 0,80 & 0,50 & 0,50 & 3,30 \\
\hline Queluz & SP & 1,00 & 0,50 & - & 0,20 & - & - & 1,70 \\
\hline Paraibuna & SP & 0,69 & - & - & - & 0,50 & 0,50 & 1,69 \\
\hline Pindamonhangaba & SP & 1,00 & 0,50 & - & 0,20 & 0,50 & 0,50 & 2,70 \\
\hline São Luiz do Paraitinga & SP & 1,00 & 0,50 & - & - & - & - & 1,50 \\
\hline Santa Isabel & SP & - & 1,00 & - & 0,20 & 0,50 & 0,50 & 2,20 \\
\hline
\end{tabular}

Figura 19- Similaridade

Fonte: Autoria própria

\subsubsection{Cálculo - Metodologia TOPSIS para as Avaliações}

Baseados no resultado da hierarquização foi possível para a COPPE montar 8 possíveis alternativas de investimentos, que foram submetidas à avaliação e decisão do CEIVAP para a aprovação de uma única alternativa. Foram considerados alguns critérios fundamentais para a montagem das alternativas de investimentos, tais como:

1. Os projetos seguem a hierarquização definida com base na análise multicriterial realizada.

2. O valor máximo aceitável pelo Banco para o investimento seria de US\$50 Milhões, valores superiores deveriam ser submetidos a uma nova negociação. (Teto para essa operação de financiamento um acréscimo de até $10 \%$ do valor de US\$ $\$ 40$ milhões).

3. Além das obras de esgotamento sanitário, contemplassem também investimentos em controle de erosão e drenagem, com exceção a Alternativa 4 que concentrou os investimentos em tratamento de esgotos sanitários, incluindo duas sedes municipais por estado. Ressalta-se, no entanto, que as obras previstas são sistemas que atendem parcialmente as áreas urbanas dos municípios selecionados.

4. Distribuição equitativa dos projetos de infraestrutura entre os estados, independentemente da sua classificação na hierarquização global da bacia.

5. Procurou-se obter um equilíbrio entre o investimento que cada estado receberá e o montante de contrapartida aportada (aceitável um desequilíbrio nessa relação de até 
10\%). Acima desse percentual significa que um estado está dando pouco e recebendo muito, o que não é desejável. Esse caso ocorre nas Alternativas $2 \mathrm{~A}$ e 5, em que essa variação é respectivamente de $14 \%$ e $13 \%$.

6. Procurou-se manter a contrapartida da União próxima a $20 \%$ do total do investimento. As maiores participações percentuais da União ocorrem nas

Alternativas 1, 2A, 5 e 5A, ficando na ordem de $22 \%$.

7. O custo da obra de desvio do rio dos Poços é o mesmo indicado na carta consulta. No entanto, como esse valor não foi estimado com base em projeto, não é possível, no momento, saber se esse valor será compatível com o custo real da alternativa de desvio que vier a ser definida.

8. A partir de uma análise minuciosa à luz dos aspectos considerados anteriormente as câmaras técnicas optaram por recomendar ao plenário do CEIVAP a escolha da Alternativa 2.

De acordo com o texto acima, as análises realizadas foram baseadas apenas nos conhecimentos dos experts, não foi mencionada a utilização de sistema para análise das alternativas.

Tendo em vista esta informação, busquei os mesmos dados e apliquei o mesmo critério do TOPSIS para as Alternativas.

A figura 20 (abaixo), lista resumidamente as alternativas e os investimentos pertinentes nos 3 subitens (áreas) Saneamento, Drenagem e Controle de Erosão de responsabilidade de cada Estado. As ações de Gestão serão de responsabilidade da União cujo investimento é igual por isso não serão utilizados nos cálculos.

INVESTIMENTO (Em milhões de dólares)

APLICANDO O MÉTODO TOPSIS

A

B C

\begin{tabular}{|c|c|c|c|c|c|c|c|c|c|c|c|}
\hline \multirow{2}{*}{ Alternativas } & \multirow{2}{*}{ Valor Total } & \multirow{2}{*}{$\begin{array}{c}\text { Ações de } \\
\text { Gestão }\end{array}$} & \multicolumn{3}{|c|}{ Saneamento } & \multicolumn{3}{|c|}{ Drenagem } & \multicolumn{3}{|c|}{ Controle de Erosão } \\
\hline & & & RJ & SP & MG & RJ & SP & MG & RJ & SP & MG \\
\hline Alternativa 1 & 49,94 & 13,78 & 9,36 & 10,61 & 9,85 & 1,97 & 0,64 & 1,86 & 0,67 & 0,60 & 0,61 \\
\hline Alternativa 2 & 43,86 & 13,78 & 9,36 & 8,99 & 9,85 & - & - & - & 0,67 & 0,60 & 0,61 \\
\hline Alternativa $2 \mathrm{~A}$ & 43,92 & 13,78 & 7,45 & 8,99 & 9,85 & 1,97 & - & - & 0,67 & 0,60 & 0,61 \\
\hline Alternativa 3 & 38,57 & 13,78 & 7,29 & 7,91 & 7,71 & - & - & - & 0,67 & 0,60 & 0,61 \\
\hline Alternativa $3 \mathrm{~A}$ & 38,73 & 13,78 & 7,45 & 7,91 & 7,71 & - & - & - & 0,67 & 0,60 & 0,61 \\
\hline Alternativa 4 & 41,98 & 13,78 & 9,36 & 8,99 & 9,85 & - & - & - & - & - & - \\
\hline Alternativa 5 & 39,87 & 13,78 & 7,29 & 7,91 & 7,71 & 1,97 & - & - & - & 0,60 & 0,61 \\
\hline Alternativa $5 \mathrm{~A}$ & 40,03 & 13,78 & 7,45 & 7,91 & 7,71 & 1,97 & - & - & - & 0,60 & 0,61 \\
\hline
\end{tabular}

Figura 20 - Resumo das Alternativas de Investimento

Fonte: Autoria própria 
Foram somados os investimentos dos 3 estados para cada um dos subitens (Figura 21)

- Passo 1: O valor normalizado foi baseado no maior valor e dividido pelo valor de cada linha por este maior valor estabelecido.

\begin{tabular}{|c|c|c|c|c|c|}
\hline 4 & A & B & C & D & $E$ \\
\hline 16 & Alternativas & Saneamento & Drenagem & $\begin{array}{c}\text { Controle } \\
\text { de Erosão }\end{array}$ & Total \\
\hline 17 & Alternativa 1 & 29,82 & 4,47 & 1,88 & 36,17 \\
\hline 18 & Alternativa 2 & 28,20 & - & 1,88 & 30,08 \\
\hline 19 & Alternativa $2 \mathrm{~A}$ & 26,29 & 1,97 & 1,88 & 30,14 \\
\hline 20 & Alternativa 3 & 22,91 & - & 1,88 & 24,79 \\
\hline 21 & Alternativa 3A & 23,07 & - & 1,88 & 24,95 \\
\hline 22 & Alternativa 4 & 28,20 & - & - & 28,20 \\
\hline 23 & Alternativa 5 & 22,91 & 1,97 & 1,21 & 26,09 \\
\hline 24 & Alternativa 5A & 23,07 & 1,97 & 1,21 & 26,25 \\
\hline 25 & Máximo & 29,82 & 4,47 & 1,88 & \\
\hline
\end{tabular}

Figura 21 - Alternativas por subitens

Fonte: Autoria própria

$\Rightarrow B 17 / B \$ 25=29,82 / 29,82=1$ (para Alternativa 1/ Saneamento)

\begin{tabular}{|c|c|c|c|c|}
\hline$\Delta$ & A & B & $\mathrm{C}$ & D \\
\hline 28 & \multicolumn{4}{|l|}{ NORMALIZADO } \\
\hline 29 & Alternativas & Saneamento & Drenagem & $\begin{array}{l}\text { Controle } \\
\text { de Erosão }\end{array}$ \\
\hline 30 & Alternativa 1 & 1,00 & 1,00 & 1,00 \\
\hline 31 & Alternativa 2 & 0,95 & - & 1,00 \\
\hline 32 & Alternativa $2 \mathrm{~A}$ & 0,88 & 0,44 & 1,00 \\
\hline 33 & Alternativa 3 & 0,77 & - & 1,00 \\
\hline 34 & Alternativa $3 \mathrm{~A}$ & 0,77 & - & 1,00 \\
\hline 35 & Alternativa 4 & 0,95 & - & - \\
\hline 36 & Alternativa 5 & 0,77 & 0,44 & 0,64 \\
\hline 37 & Alternativa 5A & 0,77 & 0,44 & 0,64 \\
\hline
\end{tabular}

Figura 22 - Alternativas Normalizadas

Fonte: Autoria própria

- Passo 2: é calculado os pesos, entropia e grau de diversidade.

Dntropia: $\boldsymbol{e}_{\boldsymbol{j}}=\frac{1}{\ln (\mathrm{m})} \sum_{j}^{\boldsymbol{m}} \mathrm{Pij} \cdot \ln (\mathrm{Pij})$

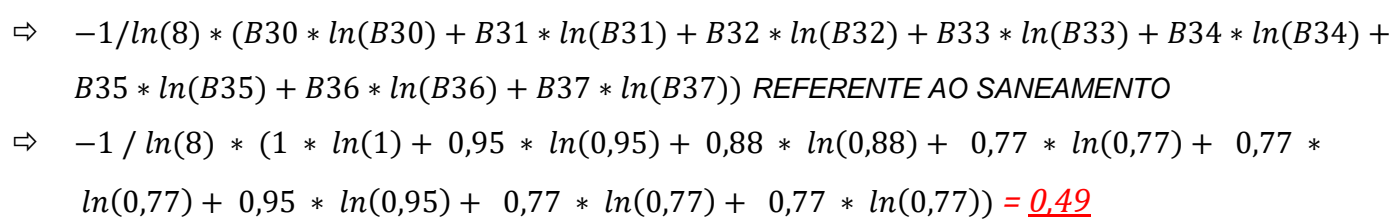

Grau de diversidade: $d_{j}=1-e_{j}$

$\Rightarrow 1-B 43=1-0,49=0,51$ 
Peso: $W_{j} \frac{d \mathbf{j}}{\sum_{j=1}^{n} d_{j}}$

$\Rightarrow B 43 / G 45=0,49 / 1,72=0,09$

40 Passo 2:

A $\quad B$

B $\quad$ C

C D

E

$\mathrm{F}$

41 CÁlCULO DOS PESOS PARA CADA CRITÉRIO

\begin{tabular}{|c|c|c|c|}
\hline Alternativas & Saneamento & Drenagem & $\begin{array}{c}\text { Controle } \\
\text { de Erosão }\end{array}$ \\
\hline Entropia & 0,49 & 0,52 & 0,27 \\
\hline
\end{tabular}
44 Grau de diversidade da informação dos mesmos a partir da seguinte fórmula: $\boldsymbol{d}_{j}=1-e_{j}$ Grau de
45 Diversidade
0,51
0,48
0,73
$\sum \quad 1,72$
46
47 Peso
0,30
0,28
0,42

Figura 23 - Cálculo dos Pesos para os subitens

Fonte: Autoria própria

- Passo 3: Multiplicado o valor normalizado pelo peso de cada subitem.

$\Rightarrow \$ B \$ 47 * B 30=0,30 * 1=0,30$

\begin{tabular}{|c|c|c|c|c|}
\hline$\angle$ & A & B & $\mathrm{C}$ & D \\
\hline 50 & \multicolumn{4}{|l|}{ Passo 3: } \\
\hline 51 & \multicolumn{4}{|c|}{ CÁLCULO DOS VALORES NORMALIZADOS PELO PESO } \\
\hline 52 & Alternativas & Saneamento & Drenagem & $\begin{array}{c}\text { Controle } \\
\text { de Erosão }\end{array}$ \\
\hline 53 & Alternativa 1 & 0,30 & 0,28 & 0,42 \\
\hline 54 & Alternativa 2 & 0,28 & - & 0,28 \\
\hline 55 & Alternativa $2 \mathrm{~A}$ & 0,26 & 0,12 & 0,28 \\
\hline 56 & Alternativa 3 & 0,23 & - & 0,28 \\
\hline 57 & Alternativa $3 \mathrm{~A}$ & 0,23 & - & 0,28 \\
\hline 58 & Alternativa 4 & 0,28 & - & - \\
\hline 59 & Alternativa 5 & 0,23 & 0,12 & 0,18 \\
\hline 60 & Alternativa 5A & 0,23 & 0,12 & 0,18 \\
\hline
\end{tabular}

Figura 24 - Calculo dos pesos

Fonte: Autoria própria 


\section{- Passo 4: Identificação das Soluções Ideais Positivas e Negativas.}

\begin{tabular}{|c|c|c|c|c|}
\hline & A & $B$ & C & D \\
\hline 62 & \multicolumn{4}{|l|}{ Passo 4: } \\
\hline 63 & \multirow{2}{*}{\multicolumn{4}{|c|}{ IDENTIFICAÇÃO DAS SOLUÇÕES IDEAIS POSITIVAS A+(BENEF }} \\
\hline 64 & \multicolumn{3}{|c|}{ AS SOLUÇÕES IDEAIS NEGATIVAS A- (MENOR PESO) - DISTAN } & \\
\hline$\frac{65}{66}$ & \multicolumn{4}{|c|}{$\mathrm{d}+=\sqrt{\sum_{j=1}^{n} \mathrm{Wj}(\mathrm{Vij}-\mathrm{Vij}+)^{2}} \quad \mathrm{~d}=\sqrt{\sum_{j=1}^{n} \mathrm{Wj}(\mathrm{Vij}-\mathrm{Vij}-)^{2}}$} \\
\hline 67 & & máximo & máximo & máximo \\
\hline 68 & Positivas & 0,30 & 0,28 & 0,42 \\
\hline 69 & Alternativas & Saneamento & Drenagem & $\begin{array}{l}\text { Controle } \\
\text { de Erosão }\end{array}$ \\
\hline 70 & Alternativa 1 & - & - & - \\
\hline 71 & Alternativa 2 & 0,00008 & 0,03060 & 0,00886 \\
\hline 72 & Alternativa $2 \mathrm{~A}$ & 0,00037 & 0,01566 & 0,00886 \\
\hline 73 & Alternativa 3 & 0,00141 & 0,03060 & 0,00886 \\
\hline 74 & Alternativa $3 \mathrm{~A}$ & 0,00134 & 0,03060 & 0,00886 \\
\hline 75 & Alternativa 4 & 0,00008 & 0,09782 & 0,07607 \\
\hline 76 & Alternativa 5 & 0,00141 & 0,03204 & 0,02524 \\
\hline 77 & Alternativa 5A & 0,00134 & 0,03204 & 0,02524 \\
\hline
\end{tabular}

Figura 25 - Cálculo do PIS

Fonte: Autoria própria

$\Rightarrow \quad$ POSITIVA: $B \$ 47 *\left((B 54-B \$ 68)^{\wedge} 2\right)=0,30 *\left((0,28-0,30)^{\wedge} 2\right)=0,00008$ ALTERNATIVA 2

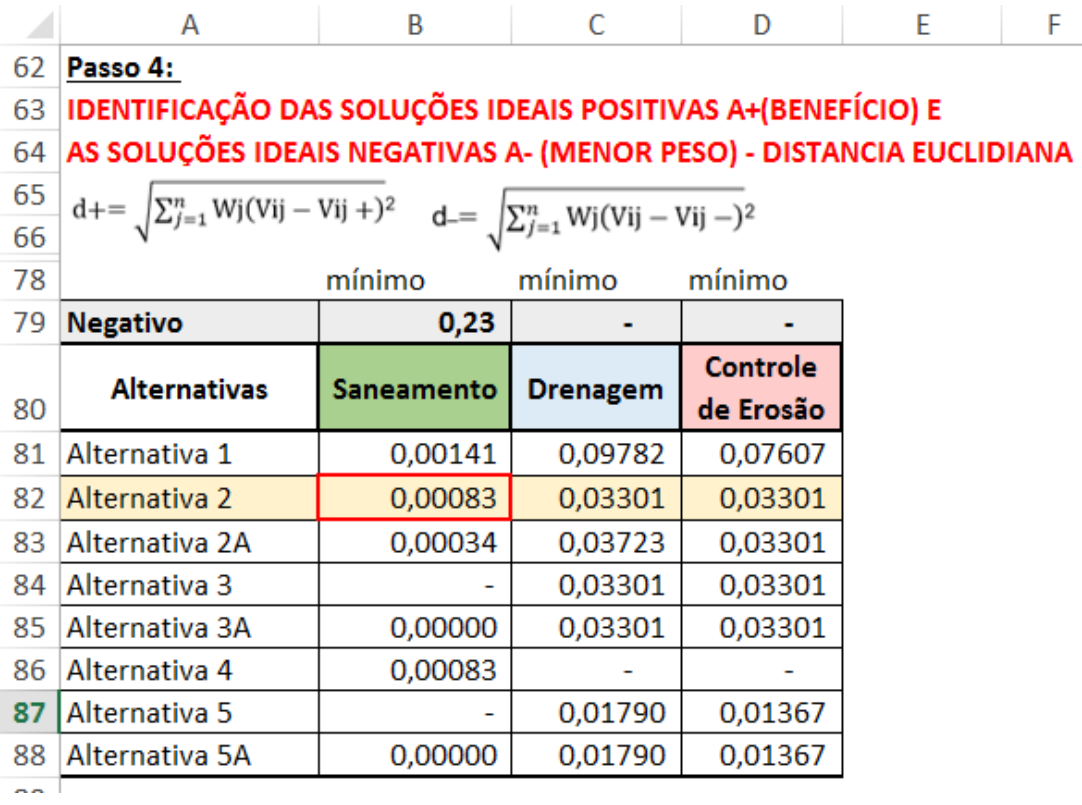

Figura 26 - Cálculo do NIS

Fonte: Autoria própria

$\Rightarrow \quad$ NEGATIVA: $B \$ 47 *\left((B 54-B \$ 79)^{2}\right)=0,30 *\left((0,28-0,23)^{\wedge} 2\right)=0,00083$ ALTERNATIVA 2 
- Passo 5: Calcular a Similaridade

$\Rightarrow \mathrm{B} 82 /(\mathrm{B} 82+\mathrm{B} 71)=0,00083 / 0,00083+0,00008=0,9143$

\begin{tabular}{|l|l|l|l|l|l|l|l|l|l|l|l|l|l|l|}
\hline A & B & C & D & E & F & G & H & I & J & K & L & M \\
\hline
\end{tabular}

90 Passo 5:

91 SIMILARIDADE RELATIVA

\begin{tabular}{|c|l|r|r|r|r|r|l|}
\hline 92 & \multicolumn{1}{|c|}{ Alternativas } & Saneamento & Drenagem & $\begin{array}{c}\text { Controle } \\
\text { de Erosão }\end{array}$ & \multicolumn{1}{c|}{ Total } & $\begin{array}{c}\text { Orde } \\
\text { m }\end{array}$ & OBS \\
\hline 93 & Alternativa 1 & 1,0000 & 1,0000 & 1,0000 & 3,0000 & 1 & aporte da união acima dos 20\% \\
\hline 94 & Alternativa 2 & 0,9143 & 0,5189 & 0,7884 & 2,2215 & 2 & \\
\hline 95 & Alternativa 2A & 0,4783 & 0,7039 & 0,7884 & 1,9706 & 3 & excedeu os 10\% de aporte / aporte da uniâo acima dos 20\% \\
\hline 96 & Alternativa 4 & - & 0,5189 & 0,7884 & 1,3073 & 4 & \\
\hline 97 & Alternativa 3 & 0,0006 & 0,5189 & 0,7884 & 1,3078 & 5 & \\
\hline 98 & Alternativa 5 & 0,9143 & - & - & 0,9143 & 6 & excedeu os 10\% de aporte / aporte da união acima dos 20\% \\
\hline 99 & Alternativa 5A & - & 0,3584 & 0,3514 & 0,7097 & 7 & aporte da união acima dos 20\% \\
\hline 100 & Alternativa 3A & 0,0006 & 0,3584 & 0,3514 & 0,7103 & 8 & \\
\hline
\end{tabular}

Figura 27 - Hierarquização das alternativas

Fonte: Autoria própria 


\section{RESULTADOS}

Dois métodos analíticos de Apoio Multicritério à Decisão foram empregados nesta pesquisa: AHP e TOPSIS. Para aplicar o método AHP foram utilizados os dados listados no PPG - Projeto Preparatório para o Gerenciamento dos Recursos Hídricos do Paraíba do Sul Critérios para a hierarquização das intervenções estruturais (LABORATÓRIO DE HIDROLOGIA - COPPE/UFRJ - 2000) onde a listagem de todos os critérios e o resultado do questionário "Instrumento para aplicação do método AHP", aplicado por professores da COPPE - UFRJ com a participação de especialistas convidados pelo CEIVAP.

5.1. Comparação dos resultados obtidos pela COPPE/URFJ com os calculados no Excel desenvolvido pela autora:

A comparação da priorização resultante da aplicação do método AHP no PPG, no âmbito do PQA Paraíba do Sul, com as prioridades obtidas com o emprego de fórmulas no Excel pela autora revelaram-se $100 \%$ idênticos, como se pode constatar na tabela 15.

Tabela 15 - Comparação Resultado do PPG x Estudo de Caso

\begin{tabular}{|c|c|c|c|c|c|c|}
\hline & TODOS OS CRITÉRIOS & & PPG & & $\begin{array}{r}\text { Estudo } \\
\text { de caso }\end{array}$ & \\
\hline & Projeto & UF & PONTOS & $\#$ & PONTOS & \# \\
\hline 1 & Volta Redonda & RJ & 0,76 & 1 & 0,58 & 1 \\
\hline 2 & Resende & RJ & 0,76 & 2 & 0,55 & 2 \\
\hline 3 & Barra Mansa & RJ & 0,61 & 3 & 0,43 & 3 \\
\hline 4 & Três Rios & RJ & 0,61 & 4 & 0,39 & 4 \\
\hline 5 & Valença & RJ & 0,33 & 6 & 0,21 & 6 \\
\hline 6 & Agulhas Negras (Resende) & RJ & 0,45 & 5 & 0,37 & 5 \\
\hline 7 & Itatiaia & RJ & 0,24 & 7 & 0,14 & 7 \\
\hline 8 & Juiz de Fora & MG & 0,73 & 1 & 0,52 & 1 \\
\hline 9 & Ubá & MG & 0,37 & 3 & 0,19 & 3 \\
\hline 10 & Leopoldina & MG & 0,25 & 6 & 0,06 & 6 \\
\hline 11 & Muriaé & MG & 0,44 & 2 & 0,29 & 2 \\
\hline 12 & Cataguases & MG & 0,36 & 5 & 0,17 & 5 \\
\hline 13 & Santos Dumont & MG & 0,37 & 4 & 0,19 & 4 \\
\hline 14 & Visconde de Rio Branco & MG & 0,24 & 7 & 0,03 & 7 \\
\hline 15 & Jacareí & $\mathrm{SP}$ & 0,39 & 2 & 0,47 & 2 \\
\hline 16 & São José dos Campos & SP & 0,90 & 1 & 0,61 & 1 \\
\hline 17 & Cachoeira Paulista & SP & 0,31 & 3 & 0,24 & 3 \\
\hline 18 & Queluz & SP & 0,35 & 4 & 0,14 & 4 \\
\hline 19 & Paraibuna & SP & 0,28 & 7 & 0,14 & 7 \\
\hline 20 & Pindamonhangaba & SP & 0,35 & 5 & 0,21 & 5 \\
\hline 21 & São Luiz do Paraitinga & SP & 0,33 & 6 & 0,11 & 6 \\
\hline 22 & Santa Isabel & SP & 0,25 & 8 & 0,17 & 8 \\
\hline
\end{tabular}

Fonte: Autoria própria 
5.2. Comparação entre os resultados da aplicação do método AHP1 e o método TOPSIS:

O gráfico abaixo (Figura 28) mostra a ampla prevalência do critério 3 - Qualidade da Água como o critério de maior importância para o projeto. Os demais critérios apresentaram pouca diferença entre si, demonstrando a boa compreensão dos decisores sobre as relações entre a importância de melhorar a qualidade das águas do rio Paraíba do Sul (efeito pretendido) e a necessidade de construir estações de tratamento de esgotos, intervenções necessárias. Os demais critérios exibiram pequenas diferenças entre si, operando na calibragem fina da priorização das intervenções.

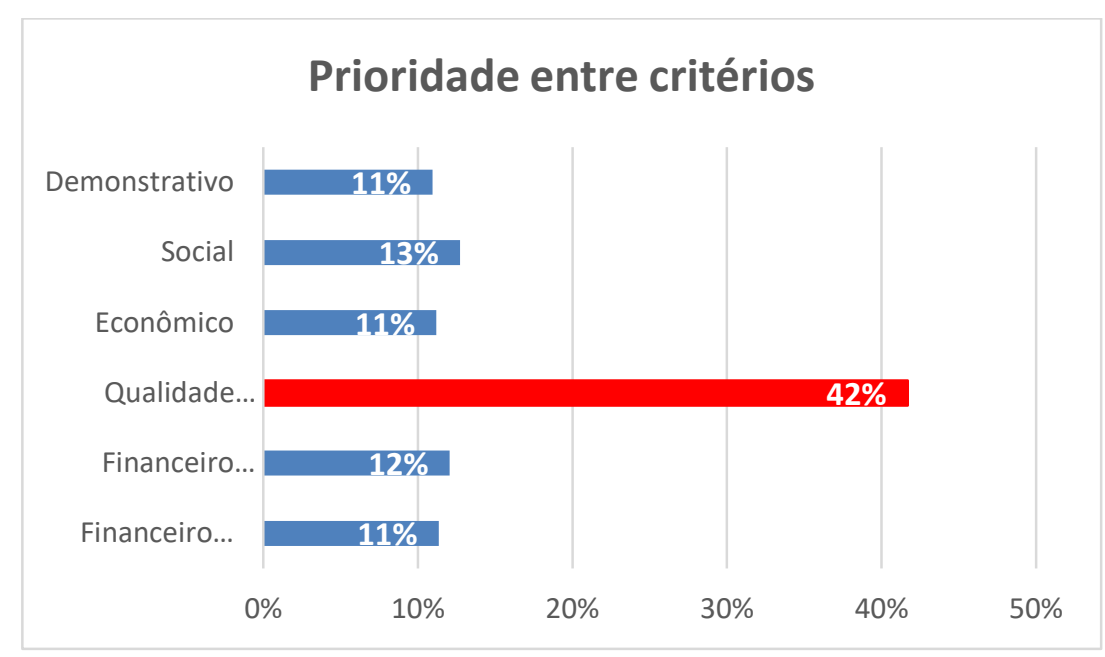

Figura 28 - Prioridade de critérios

Fonte: Autoria própria

A razão de consistência $(C R)$ foi 0,1477 , acima de 0,10 , valor não indicado por SAATY (1999), o que não impediu que se chegasse à seleção dos mesmos municípios em cada Estado nas duas metodologias. Não tendo acesso aos decisores, sem poder conduzir uma segunda rodada de ponderações, e tendo sido usada as mesmas manifestações dos decisores que a COPPE, manteve-se o valor encontrado para o CR na aplicação do Excel desenvolvido. A COPPE teve oportunidade, no dia seguinte de promover alguns ajustamentos nas ponderações o que não foi reproduzido pela autora pela falta de informações detalhadas.

\footnotetext{
${ }^{1}$ Com emprego do algoritmo da autora
} 


\section{Índice de Consistência}

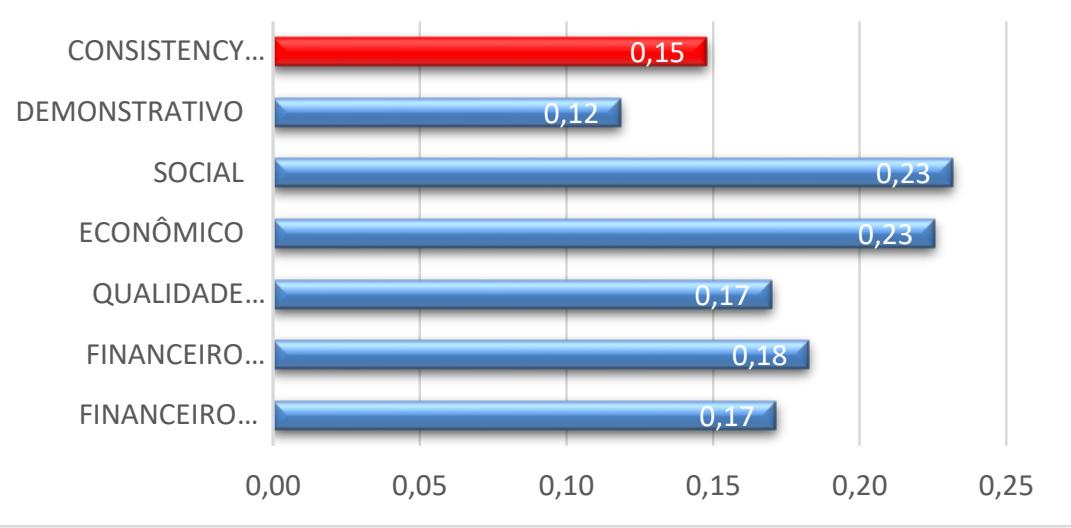

Figura 29 - Resultado do Índice de Consistência realizado no estudo pela planilha Excel Fonte: Autoria própria

Para verificar a robustez da solução, optou-se por comparar os valores obtidos para os resultados finais normalizados do AHP e TOPSIS (Figura 28). Os pesos foram calculados mantendo-se a mesma proporção entre eles (Figura 29).

$\Rightarrow$ No $\underline{A H P}$ o maior resultado final foi 0,61 , logo, todos os outros resultados (de cada município) foram divididos por este valor. Ex: Volta Redonda: 0,58/0,61 =0,95

$\Rightarrow$ No $\underline{\text { TOPSIS } ~ o ~ m a i o r ~ n u ́ m e r o ~ f o i ~ 5,50, ~ o ~ m e s m o ~ p r o c e d i m e n t o ~ f o i ~ e n t a ̃ o ~ r e a l i z a d o . ~ E x: ~ V o l t a ~ R e d o n d a: ~}$ $5,50 / 5,50=1$

\begin{tabular}{|c|c|c|c|c|}
\hline \multicolumn{3}{|r|}{ RESULTADOS } & \multicolumn{2}{|c|}{ NORMALIZADOS } \\
\hline & UF & Projeto & AHP & TOPSIS \\
\hline 1 & $\mathrm{RJ}$ & Volta Redonda & 0,95 & 1,00 \\
\hline 2 & RJ & Resende & 0,91 & 0,78 \\
\hline 3 & RJ & Barra Mansa & 0,70 & 0,42 \\
\hline 4 & RJ & Três Rios & 0,64 & 0,28 \\
\hline 5 & RJ & Valença & 0,34 & 0,09 \\
\hline 6 & RJ & Agulhas Negras (Resende) & 0,60 & 0,65 \\
\hline 7 & $\mathrm{RJ}$ & Itatiaia & 0,23 & 0,22 \\
\hline 8 & MG & Juiz de Fora & 0,86 & 0,91 \\
\hline 9 & MG & Ubá & 0,32 & 0,18 \\
\hline 10 & MG & Leopoldina & 0,09 & 0,09 \\
\hline 11 & MG & Muriaé & 0,47 & 0,64 \\
\hline 12 & MG & Cataguases & 0,27 & 0,09 \\
\hline 13 & MG & Santos Dumont & 0,32 & 0,18 \\
\hline 14 & MG & Visconde de Rio Branco & 0,05 & 0,00 \\
\hline 15 & SP & Jacareí & 0,76 & 0,68 \\
\hline 16 & SP & São José dos Campos & 1,00 & 1,00 \\
\hline 17 & SP & Cachoeira Paulista & 0,39 & 0,60 \\
\hline 18 & SP & Queluz & 0,23 & 0,31 \\
\hline 19 & SP & Paraibuna & 0,22 & 0,31 \\
\hline 20 & SP & Pindamonhangaba & 0,34 & 0,49 \\
\hline 21 & SP & São Luiz do Paraitinga & 0,18 & 0,27 \\
\hline 22 & SP & Santa Isabel & 0,27 & 0,40 \\
\hline
\end{tabular}

Figura 30 - Resultado Final Normalizado

Fonte - Autoria Própria 


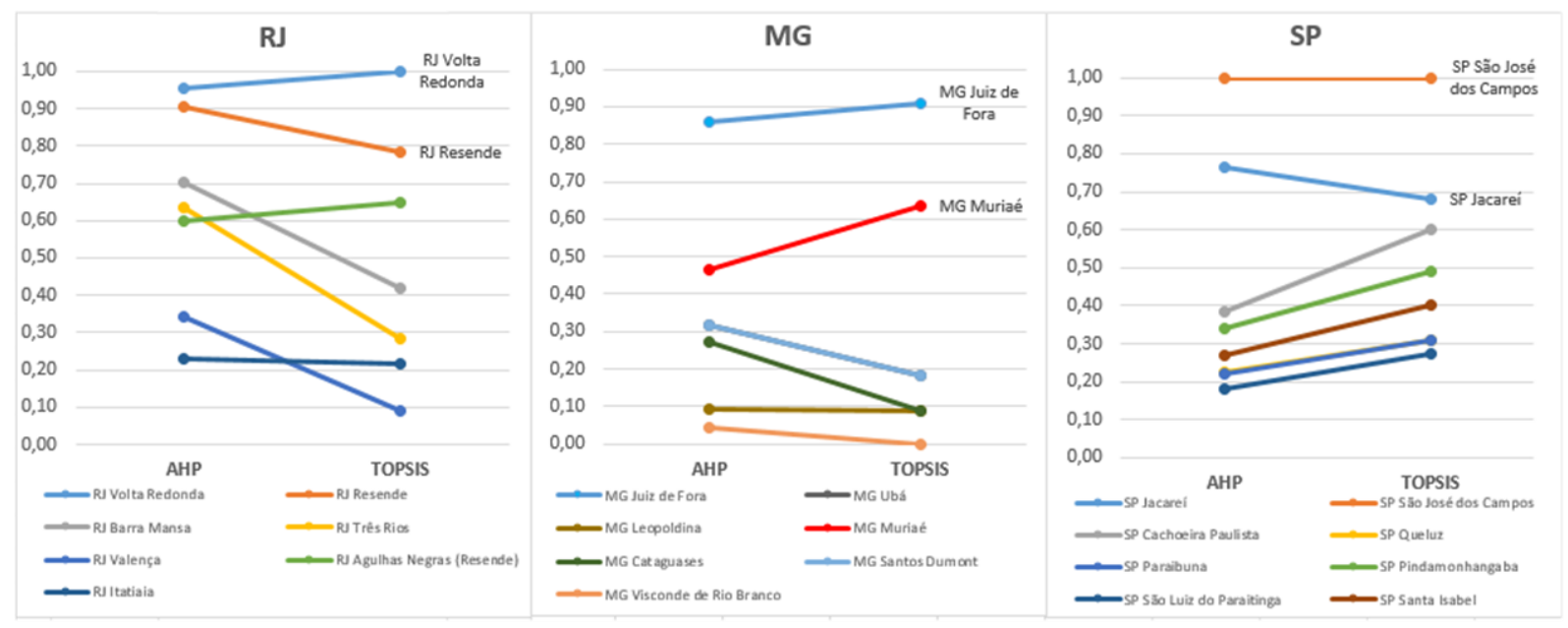

Figura 31 - Analise dos Valores Obtidos

Fonte - Autoria Própria

O comportamento dos valores obtidos para os municípios, organizados por estado, é apresentado no gráfico acima (Figura 31). As soluções do TOPSIS são semelhantes àquelas obtidas pelo AHP (Figura 32 e 33). As mesmas respostas quanto à escolha de sedes municipais por estado foram obtidas nos dois métodos empregados: RJ - Rezende e Volta Redonda; MG - Juiz de Fora e Muriaé e SP - São José dos Campos e Jacareí.

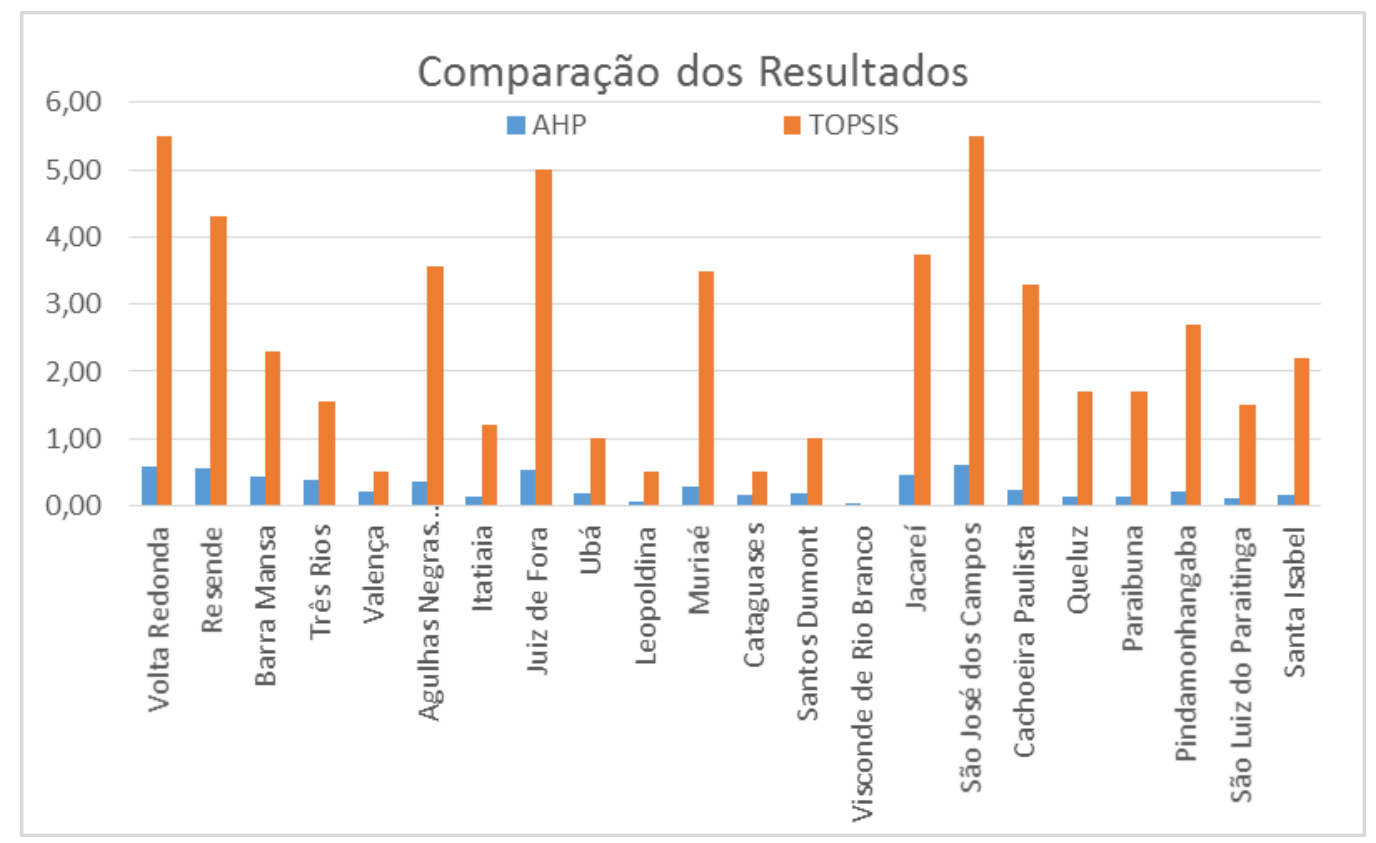

Figura 32 - Comparação Resultados por município - valores absolutos

Fonte: Autoria própria 


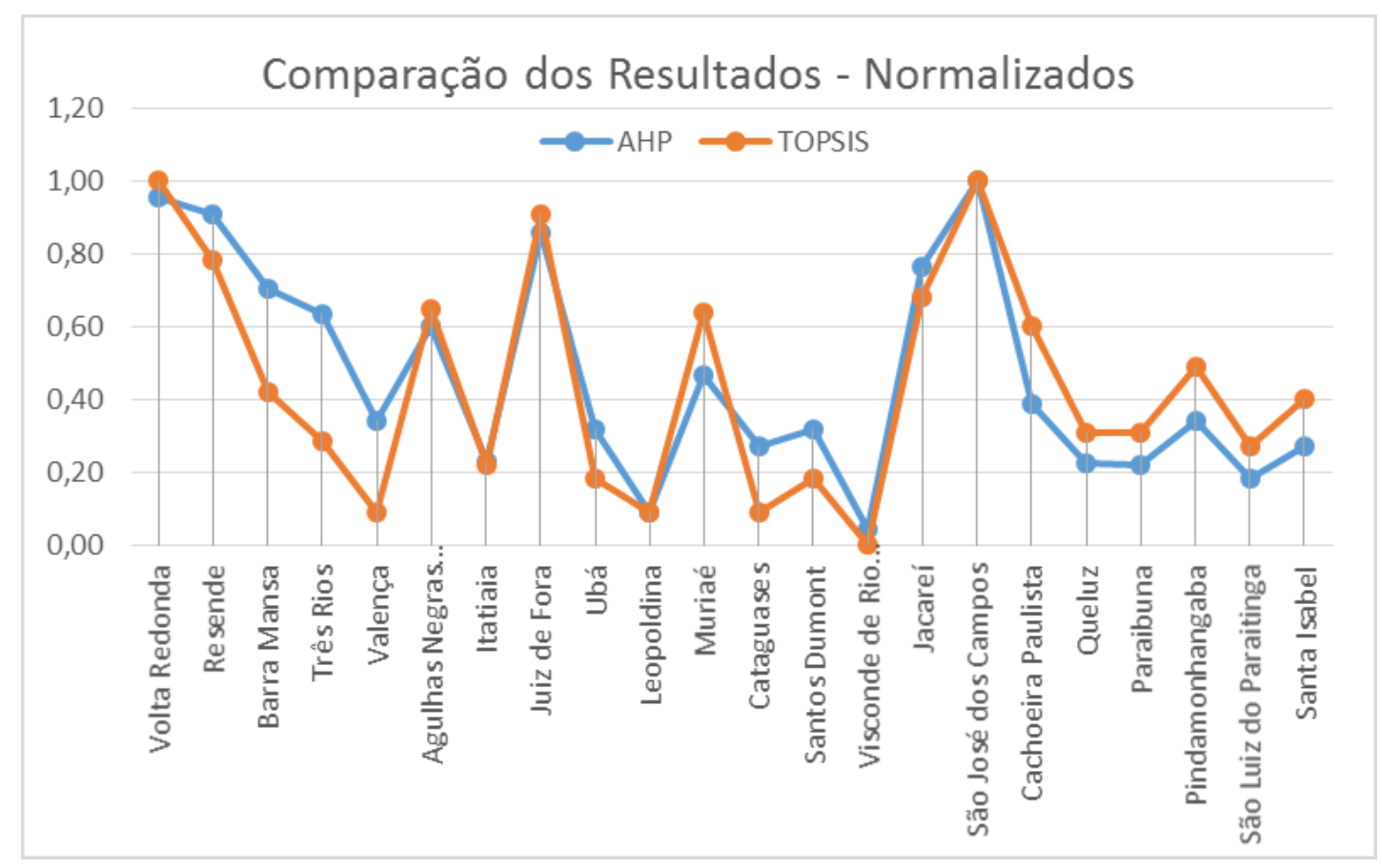

Figura 33 - Comparação Resultados por município - valores normalizados

Fonte: Autoria própria

No RJ, os resultados encontrados pelo AHP correspondentes aos municípios com maiores níveis de prioridade foram superiores ao valor médio do conjunto desses resultados em de cada estado. Todavia, nesse estado, além dos dois municípios selecionados, o município de Barra Mansa ficou em 3ํlugar seguido de Três Rios, ambos acima do valor médio tomado como referência. Aplicando-se o TOPSIS, apenas os municípios escolhidos excederam o valor médio correspondente.

Para o estado de SP, os valores obtidos na aplicação do TOPSIS excederam a média do conjunto desses resultados em três municípios: os dois escolhidos e Cachoeira Paulista, que ficou em $3^{\circ}$ lugar. No AHP apenas os dois municípios selecionados superaram o valor médio do conjunto de resultados correspondente. Nos municípios que se classificaram abaixo do $3^{\circ}$ lugar, no caso do AHP, observou-se uma disputa maior entre as preferências dos decisores, com valores distribuindo-se em uma faixa estreita, entre 0,21 a 0,14. No TOPSIS, por medir-se as distâncias da solução ideal e por não ser exposto a eventuais tendenciosidades dos decisores, a dispersão foi maior, variando de 2,70 a 1,50 (a amplitude chega a $80 \%$ do valor mínimo).

No estado de MG houve uma semelhança dos resultados de classificação AHP e TOPSIS: apenas os dois municípios escolhidos excederam o valor médio. (Tabela 16). 
Tabela 16 - Resultados Absolutos e Normalizados

\begin{tabular}{|c|c|c|c|c|c|c|c|c|}
\hline & & RESULTADOS & ABso & UTos & MORH. & ALI: & ZADOS & \\
\hline & UF & Projeto & AHP & TOPSIS & AHP & & TOPSIS & \\
\hline 1 & $R J$ & Volta Redonda & 0,58 & 5,50 & 0,95 & 1 & 1,00 & 1 \\
\hline 2 & RJ & Resende & 0,55 & 4,31 & 0,91 & 2 & 0,78 & 2 \\
\hline 3 & $\mathrm{RJ}$ & Barra Mansa & 0,43 & 2,30 & 0,70 & 3 & 0,42 & 4 \\
\hline 4 & $\mathrm{RJ}$ & Três Rios & 0,39 & 1,56 & 0,64 & 4 & 0,28 & 5 \\
\hline 5 & $\mathrm{RJ}$ & Valença & 0,21 & 0,50 & 0,34 & 6 & 0,09 & 7 \\
\hline 6 & RJ & Agulhas Negras (Resende) & 0,37 & 3,56 & 0,60 & 5 & 0,65 & 3 \\
\hline 7 & RJ & Itatiaia & 0,14 & 1,20 & 0,23 & 7 & 0,22 & 6 \\
\hline & & Média RJ & 0,38 & 2,70 & 0,62 & & 0,49 & \\
\hline & & Desvio padrão $\mathrm{RJ}$ & 0,16 & 1,81 & 0,27 & & 0,33 & \\
\hline 8 & MG & Juiz de Fora & 0,52 & 5,00 & 0,86 & 1 & 0,91 & 1 \\
\hline 9 & MG & Ubá & 0,19 & 1,00 & 0,32 & 3 & 0,18 & 3 \\
\hline 10 & MG & Leopoldina & 0,06 & 0,50 & 0,09 & 6 & 0,09 & 6 \\
\hline 11 & MG & Muriaé & 0,29 & 3,50 & 0,47 & 2 & 0,64 & 2 \\
\hline 12 & MG & Cataguases & 0,17 & 0,50 & 0,27 & 5 & 0,09 & 5 \\
\hline 13 & MG & Santos Dumont & 0,19 & 1,00 & 0,32 & 4 & 0,18 & 4 \\
\hline 14 & MG & Visconde de Rio Branco & 0,03 & 0,00 & 0,05 & 7 & 0,00 & 7 \\
\hline & & Média MG & 0,20 & 1,46 & 0,32 & & 0,27 & \\
\hline & & Desvio padrão MG & 0,15 & 1,51 & 0,24 & & 0,28 & \\
\hline 15 & SP & Jacareí & 0,47 & 3,74 & 0,76 & 2 & 0,68 & 2 \\
\hline 16 & SP & São José dos Campos & 0,61 & 5,50 & 1,00 & 1 & 1,00 & 1 \\
\hline 17 & SP & Cachoeira Paulista & 0,24 & 3,30 & 0,39 & 3 & 0,60 & 3 \\
\hline 18 & SP & Queluz & 0,14 & 1,70 & 0,23 & 4 & 0,31 & 6 \\
\hline 19 & SP & Paraibuna & 0,14 & 1,69 & 0,22 & 7 & 0,31 & 7 \\
\hline 20 & SP & Pindamonhangaba & 0,21 & 2,70 & 0,34 & 5 & 0,49 & 4 \\
\hline 21 & SP & São Luiz do Paraitinga & 0,11 & 1,50 & 0,18 & 6 & 0,27 & 8 \\
\hline 22 & SP & Santa Isabel & 0,17 & 2,20 & 0,27 & 8 & 0,40 & 5 \\
\hline & & Média SP & 0,26 & 2,79 & 0,42 & & 0,51 & \\
\hline & & Desvio padrão SP & 0,18 & 1,36 & 0,30 & & 0,25 & \\
\hline
\end{tabular}

Fonte: Autoria própria

Foi possível aplicar a metodologia TOPSIS na escolha das alternativas Gráfico abaixo (Figura 34 e 35), uma vez que não havia sido feito nenhum relatório de metodologia no projeto anterior, apenas listagem de exclusão das alternativas que ultrapassava os limites monetários do projeto pré-estabelecidos. Demonstrando-se como uma boa ferramenta como apoio na escolha final, retirando a subjetividade da escolha no final. 


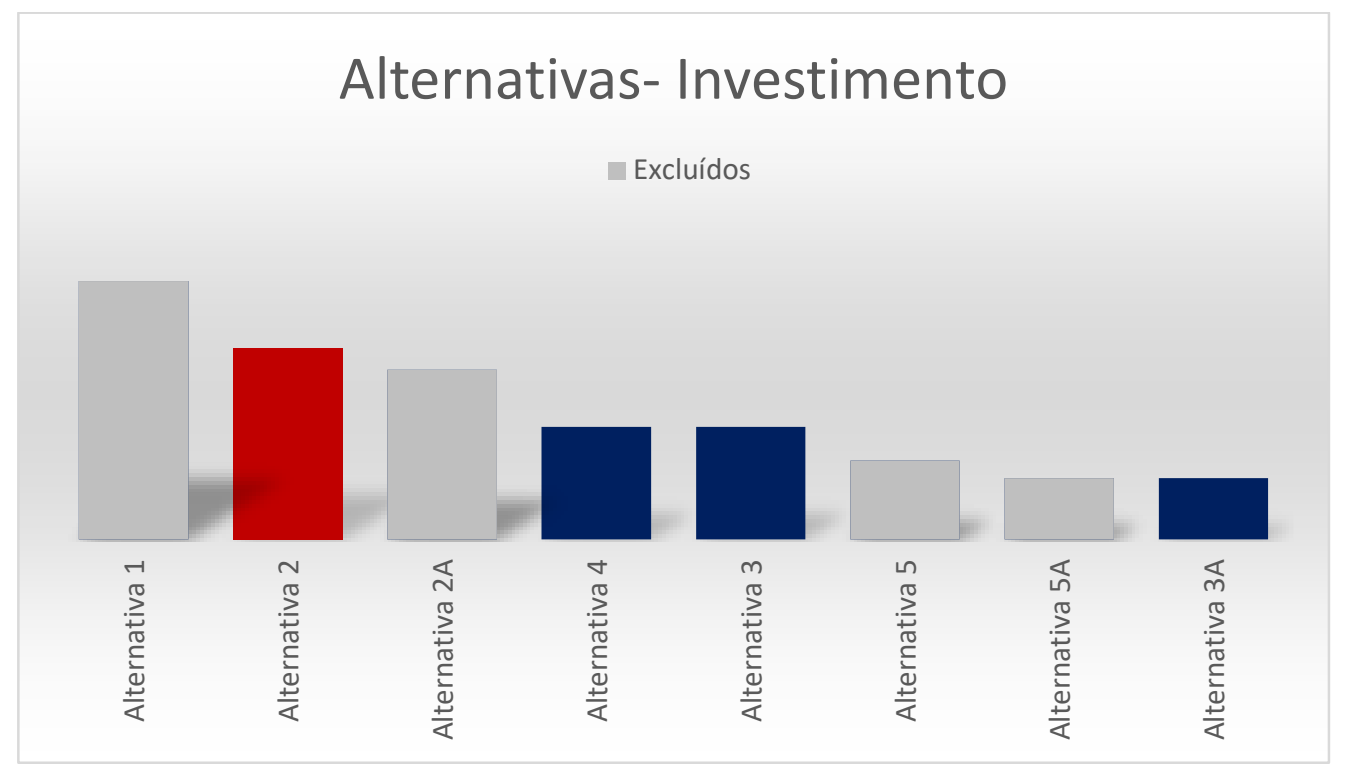

Figura 34 - Gráfico das Alternativas para investimento

Fonte: Autoria própria

Passo 5:

SIMILARIDADE RELATIVA

\begin{tabular}{|l|r|r|r|r|r|r|}
\hline \multicolumn{1}{|c|}{ Alternativas } & Saneamento & Drenagem & $\begin{array}{c}\text { Controle } \\
\text { de Erosão }\end{array}$ & Total & Ordem & OBS \\
\hline Alternativa 1 & 1,00000 & 1,00000 & 1,00000 & 3,00000 & 1 & aporte da união acima dos 20\% \\
\hline Alternativa 2 & 0,91426 & 0,51890 & 0,78838 & 2,22155 & 2 & \\
\hline Alternativa 2A & 0,47830 & 0,70391 & 0,78838 & 1,97059 & 3 & excedeu os 10\% de aporte / aporte da união acima do \\
\hline Alternativa 4 & - & 0,51890 & 0,78838 & 1,30729 & 4 & \\
\hline Alternativa 3 & 0,00056 & 0,51890 & 0,78838 & 1,30785 & 5 & \\
\hline Alternativa 5 & 0,91426 & - & - & 0,91426 & 6 & excedeu os 10\% de aporte / aporte da união acima do \\
\hline Alternativa 5A & - & 0,35837 & 0,35137 & 0,70973 & 7 & aporte da união acima dos 20\% \\
\hline Alternativa 3A & 0,00056 & 0,35837 & 0,35137 & 0,71030 & 8 & \\
\hline
\end{tabular}

Figura 35 - Aplicando TOPSIS na Alternativa

Fonte: Autoria própria

\section{CONCLUSÕES E TRABALHOS FUTUROS}

A arena de métodos multicritério de apoio à decisão continua sendo uma das áreas de maior atividade e atratividade em $\mathrm{Bl}$, como bem atestam os numerosos trabalhos publicados no Brasil e no mundo, que reportam novas aplicações, estudos comparativos sobre a robustez, precisão, sensibilidade adequação dos diferentes métodos concebidos em diferentes situações, bem como o desenvolvimento de softwares para contornar as dificuldades computacionais e organizar os resultados.

Nesse sentido, a revisão bibliográfica empreendida e a análise de alguns métodos e aplicações confirmam que, para fazer frente aos complexos problemas que vêm se apresentando, quer pela sua capacidade, quer pelos impactos socioambientais que acarretam 
e pela necessidade de alocar recursos físicos e financeiros - normalmente escassos - sejam aplicados métodos de decisão multicritério aos projetos que envolvem a conservação de recursos naturais, a melhoria da qualidade de vida humana e o desenvolvimento regional, de modo a atender, conjunta e simultaneamente, diversos critérios declarados relevantes na fase de estudos, ainda que às custas da otimização de critério exclusivamente econômico. Tais métodos permitem, com diferentes níveis de precisão, não apenas a efetiva consideração dos diversos critérios definidos como relevantes pelas equipes responsáveis por sua concepção e detalhamento, mas também a participação com que devem entrar no desenho da solução preferida.

Os estudos empreendidos nesta monografia permitem concluir que existem diversos métodos disponíveis para seleção e priorização de projetos. Embora grupados em três grandes categorias, o número de métodos já alcança a casa das dezenas, assim como o número de softwares específicos. A escolha do método deve ser feita pela conveniência do responsável pela condução do processo (disponibilidade de software, decisão institucional) mas principalmente pelas características do problema e seu contexto, nomeadamente:

$\Rightarrow$ O que se pretende: escolher, classificar ou priorizar;

$\Rightarrow$ Número de critérios relevantes que não podem ser descartados;

$\Rightarrow$ Número de alternativas elencadas;

$\Rightarrow$ Comparabilidade e grau de subjetividade de avaliação dos critérios escolhidos;

$\Rightarrow$ Maior ou menor participação social.

Nessa monografia foram trabalhados e comparados os resultados da aplicação dos métodos AHP e TOPSIS.

No Método AHP é necessário atribuir pesos aos critérios com ajuda de especialistas, demandando tempo: no estudo de caso submetido a avaliação "ex-post", isso implicou no preparo do questionário "Instrumento para aplicação do método AHP", no preenchimento pelos especialistas convidados pelo CEIVAP e na tabulação de resultados. Muitas vezes, entretanto, os decisores selecionados podem não ter o conhecimento técnico necessário para definir a importância de um critério sobre o outro. Nesses casos, deve-se estabelecer um nível mínimo de qualificação que deverá ser satisfeito pelos escolhidos para integrar o quadro de tomadores de decisão.

Não obstante, algumas vezes não se levará em conta apenas critérios técnicos. Muitos projetos dependem de aceitação social, o que implica também em adoção de critérios sociais e da participação de representantes da sociedade no processo decisório.

Nesse último aspecto, o método TOPSIS exibe uma independência da ponderação dos critérios, já que busca medir a distância que cada solução examinada guarda em relação a cada critério considerado em sua condição ideal, o que dispensa a atribuição de pesos por 
decisores convidados para calibrar a matriz e as ações preparatórias referidas no parágrafo anterior.

Ambos os métodos foram capazes (para o caso estudado, da Bacia do Paraíba do Sul) de selecionar e priorizar os municípios para receber os projetos. O método TOPSIS, como comentado acima, foi mais "fácil" por não ter o questionário a ser tabulado, mensurado e, em seguida, aplicado o peso dos critérios. Tendo em vista o que foi apresentado, o método que apresenta menor suscetibilidade de ter os resultados afetados por interferência de decisores, seria o TOPSIS.

Em resumo, o TOPSIS mostra mais versatilidade, agilidade e independência na sua aplicação com relação ao AHP, mas carece da participação social, requisito muito valorizado e decisivo, em alguns casos, para validação das conclusões e proteção contra ações judiciais de grupos de interesse que se sintam prejudicados, no caso de políticas públicas e de grandes empreendimentos/projetos.

A complexidade das situações que se apresentam hoje e se apresentarão no futuro reforçam essas conclusões. Cada vez mais, as decisões terão que visar múltiplos objetivos para atender as crescentes exigências de sustentabilidade econômico-financeira e socioambiental postas pela comunidade internacional para compatibilizar as necessidades de desenvolvimento com a capacidade de suporte do planeta.

Os estudos e os trabalhos realizados mostraram igualmente que não basta dominar um procedimento que agregue em um único critério de síntese os vários atributos considerados ou que se estabeleça graus de dominância entre alternativas examinadas e maneje rapidamente os cálculos matemáticos envolvidos. Reconhecendo que não há uma solução ótima e sim uma solução preferida pelos decisores, entendida não como a ideal mas a satisfatória, a solução de preferência, capaz de incluir todos os atributos e as diferentes visões dos decisores envolvidos, resultou claro para a autora - e constitui uma recomendação desta monografia - a importância e o cuidado que devem ser atribuídos à estruturação do problema, à identificação e enunciado das alternativas a considerar, à escolha do método a ser aplicado, à formalização e registro das manifestações dos decisores, ao monitoramento e à avaliação ex-post da implementação da decisão tomada assim como de todo o processo, com o monitoramento dos impactos gerados por meio de indicadores associados aos critérios adotados na escolha/ seleção/ classificação/priorização empreendida e de toda a consistência do processo.

A possibilidade de utilizar formulas para aplicação dos métodos AHP e TOPSIS em ambiente computacional Excel como, de fato, foi realizado nesta monografia, facilita grandemente o emprego futuro desses métodos em processos decisórios que considerem múltiplos critérios com participação social e cria oportunidades de ampliar a utilização desses 
métodos, antes limitado à possibilidade de acesso a softwares dispendiosos, como o Expert Choice, 1000Files ou Macbeth, entre outros.

A importância das várias etapas preparatórias para a tomada de decisão e a aplicação de "algoritmos" ou fórmulas de cálculo em ambiente Excel sinalizam no sentido de desenvolvimento de sistemas expert que possam dar suporte às várias etapas do processo decisório, não se limitando à resolução de equações matemáticas, mas também apoiando efetivamente cada etapa do processo. Porém enfatiza-se a qualidade da entrada da informação, é necessária uma boa coleta dos dados, a custos compatíveis com a complexidade do problema e um tempo requerido para a solução, garantindo assim um resultado satisfatório a todos os interessados.

Diante das facilidades computacionais de que se dispõe hoje, o desenvolvimento de tal sistema poderia, inclusive, oferecer a opção de escolha do método multicritério mais apropriado para o problema em função de suas características e objetivos perseguidos e conter diferentes sistemáticas de cálculo, conforme o método escolhido, e ainda a possibilidade do uso conjunto de diferentes métodos. Uma possibilidade seria o uso do TOPSIS em uma primeira avaliação que oriente o nivelamento dos decisores na aplicação de um método como o AHP, que assegura a participação social.

Finalmente, ainda em relação a estudos futuros deve-se ter em mente a análise feita por Mardani et al. (2015) onde se destaca a tendência da utilização de métodos híbridos. Estes se baseiam nos métodos já conhecidos, tais como TOPSIS, SAW, DEA, AHP, ANP, VIKOR, DEMATEL, DEA, PROMETHEE, ELECTRE e suas modificações, aplicando lógica fuzzy e a teoria de sistemas cinza (grey systems theory) e incluindo métodos MCDM mais recentemente desenvolvidos. Outra possibilidade é a aplicação de lógica fuzzy nas metodologias AHP e TOPSIS, que tem sido utilizada para lidar com incertezas na tomada de decisões. 


\section{REFERÊNCIAS BIBLIOGRÁFICAS}

- AHMADI, G. A. A.; TAGHIPOURIAN, M. J.; TAGHIPOURIAN, Y. The evaluation of instructors training performance by fuzzy MCDM - $2^{\text {nd }}$ International Conference of Teaching and Learning (ICTL/09) INTI University College, Malaysia, 2009. Disponível em: https://my.laureate.net/Faculty/docs/Faculty\%20Documents/INTI\%20Conferences/Parallel \%20Sessions\%204/4A/4A-02-P179\%20(Iran).pdf. Acessado em 13 de novembro de 2016

- ARAUJO, J. J.; AMARAL, T. M. Aplicação do método ELECTRE I para problemas de seleção envolvendo projetos de desenvolvimento de software livre. GEPROS. Gestão da Produção, Operações e Sistemas, Bauru, Ano 11, no 2, abr-jun/2016, p. 121-137. 2016. Disponível em: http://revista.feb.unesp.br/index.php/gepros/article/download/1425/718. Acessado em: 13 de novembro de 2016.

- ARULdOSS, M.; LAKSHMI, T. M.; VENKATESAN V. P. A Survey on Multi Criteria Decision Making Methods and Its Applications American Journal of Information Systems. 1(1), pages 31-43. 2013. Disponível em: http://pubs.sciepub.com/ajis/1/1/5/. Acessado em: 21 de novembro de 2016.

- $\quad$ BALL, S.; KORUKOĞLU , S. Operating system selection using fuzzy AHP and TOPSIS methods Mathematical and Computational Applications, Vol. 14, No. 2, pp. 119-130, 2009. Disponível em: http://www.mdpi.com/2297-8747/14/2/119 Acessado em: 20 de outubro de 2016.

- BEHZADIAN, M; OTAGHSARA, S. K.; YAZDANI, M; IGNATIUS, J. A state-of the-art survey of TOPSIS applications. Expert Systems with Applications 39 (2012) 1305113069. Disponível em: http://dx.doi.org/10.1016/j.eswa.2012.05.056. Acessado em: 1 de dezembro de 2016.

- BUNRUAMKAEW, K. How to do AHP analysis in Excel University of Tsukuba. 2012. Disponível em: http://giswin.geo.tsukuba.ac.jp/sis/gis seminar/How\%20to\%20do\%20AHP\%20analysis\%2 0in\%20Excel.pdf. Acessado em: 23 de outubro de 2016.

- CAMPOS, V. R. Modelo de Apoio à decisão multicritério para priorização de projetos de saneamento Tese Doutorado em Engenharia de produção Escola de engenharia de São Carlos/SP 2011. Disponível em: http://www.teses.usp.br/teses/disponiveis/18/18157/tde- 
08022012-104925/publico/VanessaRibeiroCampos.pdf. Acessado em: 27 de novembro de 2016.

- CATERINO, N.; IERVOLINO, I; MANFREDI, G.; COSENZA, E. A comparative analysis of decision making methods for the seismic retrofit of RC buildings - $14^{\text {th }}$ World Conference on Earthquake Engineering October 12-17, Beijing/ China. 2008. Disponível em: http://www.iitk.ac.in/nicee/wcee/article/14 09-01-0168.PDF. Acessado em: 23 de outubro de 2016.

- CHIAVENATO, I. Introdução à teoria geral da administração. 5a Edição, Rio de Janeiro: Campus. 1999.

- COSTA, H. Apoio Multicritério à Decisão em ambientes corporativos Helder Gomes Costa Grupo de pequisa: Auxílio multicritério à decisão (CNPq/UFF) MCDA Lab Apoio Relatório de Pesquisa em Engenharia de Produção, Niterói, RJ, Brasil: Programa de Engenharia de Produção da Universidade Federal Fluminense, v. 6, n. 3, pp. Disponível em: http://slideplayer.com.br/slide/1233027/. Acessado em: 23 de outubro de 2016.

- FREITAS, A. L. P.; MARINS, C. S. \& COZENDEY, M. I. A metodologia de multicritério como ferramenta para tomada de decisões gerenciais: um estudo de caso. In: $25^{\circ}$ Encontro Nacional de Engenharia de Produção (ENEGEP). Anais. Porto Alegre / RS. 2005. Disponível em: http://www.academia.edu/696348/A metodologia de multicrit\%C3\%A9rio como ferrame nta para a tomada de decis\%C3\%B5es gerenciais um estudo de caso. Acessado em: 21 outubro de 2016 .

- FREITAS, Andressa Marques de Pina. Descrição das Aplicações do Método AHP no Campo da Administração Através da Construção de Mapa Conceitual. - São Paulo, 2013. Trabalho de Conclusão de Curso - Universidade de São Paulo. Faculdade de Economia, Administração e Ciências Contábeis Orientadora: Professora Doutora Adriana Backx Noronha Viana.

- GOMES, L. F.; GOMES, C. F. S.; ALMEIDA A. T. Tomada de decisão gerencial: enfoque multicritério São Paulo: Atlas, 2002. 
- GOMES, L. F. A. M.; GONZÁLEZ-ARAYA, M. C.; CARIGNANO, C. Tomada de decisões em cenários complexos: introdução aos modelos discretos de apoio multicritério à decisão. São Paulo: Thomson, 2004.

- GUERREIRO, A. S. Análise da Eficiência de Empresas de Comércio Eletrônico usando Técnicas da Análise Envoltória de Dados Dissertação de Mestrado em Engenharia de Produção da PUC-Rio 2006. Disponível em: http://www.maxwell.vrac.pucrio.br/9973/9973 1.PDF. Acessado em: 21 novembro de 2016.

- HEIN, N.; DEGENHART, L.; VOGT, M.; KROENKE, A.; CAMPESTRINI, I. M. Método TOPSIS na avaliação das empresas listadas no IBrX-100: uma avaliação multicritério dos impactos ambientais $\mathrm{V}$ Congresso Brasileiro de Engenharia De Produção Ponta Grossa, PR, Brasil, 02 a 04 de Dezembro de 2015. Disponível em: https://www.google.com.br/url?sa=t\&rct=i\&q=\&esrc=s\&source=web\&cd=2\&cad=ria\&uact= 8\&ved=0ahUKEwji6qKnn8zQAhWMgZAKHa8JArMQFggeMAE\&url=http\%3A\%2F\%2Fww w.aprepro.org.br\%2Fconbrepro\%2F2015\%2Fdown.php\%3Fid\%3D1367\%26q\%3D1\&usg= AFQjCNGItDmEiPnYbYAEBV6YXZVgJS4dDw\&sig2=DA22SFTJd6JDKhxk3W1bbQ\&bvm =bv.139782543,d.Y2I. Acessado em: 28 de novembro de 2016.

- HELMANN, K. \& MARÇAL, R. Método multicritério de apoio à decisão na gestão da Manutenção: aplicação do método electre I na seleção de equipamentos críticos para processo Revista Gestão Industrial, ISSN 1808-0448 / v. 03, n. 01: p. 123-133, 2007. Disponível em: http://revista.feb.unesp.br/index.php/gepros/article/view/116/66. Acessado em: 21 outubro de 2016.

- HO, William Integrated analytic hierarchy process and its applications - A literature review, European Journal of Operational Research, 186, issue 1, p. 211-228. 2008. Disponível em: http://EconPapers.repec.org/RePEc:eee:ejores:v:186:y:2008:i:1:p:211228. Acessado em: 28 de novembro de 2016.

- JANNUZZI, P. M.; MIRANDA, W. L.; SILVA, D. S. G. Análise Multicritério e Tomada de Decisão em Políticas Públicas: Aspectos Metodológicos, Aplicativo Operacional e Aplicações Informática Pública ano 11 (1) 69 - 87, 2009. Disponível em: http://www.ip.pbh.gov.br/ANO11 N1 PDF/analise multicriterio e tomada de decisao e m Politicas Publicas.pdf. Acessado em: 23 de novembro de 2016. 
- KATAYAMA, K.; KOSHIISHI, T.; NARIHISA, H. Reinforcement Learning Agents with Primary Knowledge Designed by Analytic Hierarchy Process. Okayama University of Science, Okayama. $2005 . \quad$ Disponível em: http://citeseerx.ist.psu.edu/viewdoc/download?doi=10.1.1.98.6363\&rep=rep1\&type=pdf. Acessado em: 07 novembro 2016.

- KROHLING, R. M. ; SOUZA, T. T. M. Dois Exemplos da Aplicação da Técnica TOPSIS para Tomada de Decisão Revista de Sistemas de Informação da FSMA n. 8 (2011) pp. 31-35. Disponível em: http://www.fsma.edu.br/si/edicao8/FSMA_SI_2011_2_Principal_1.pdf. Acessado em 20 de novembro de 2016.

- LABORATÓRIO DE hIDROLOGIA - COPPE/UFRJ PPG-RE-026-R1 - Projeto Preparatório para o Gerenciamento dos Recursos Hídricos do Paraíba do Sul Critérios para a hierarquização das intervenções estruturais. Maio de 2000. Disponível em: http://www.hidro.ufrj.br/ppg/relatorios/ppg-re-26-r1.pdf. Acessado em: 10 outubro de 2016.

- LABORATÓRIO DE HIDROLOGIA - COPPE/UFRJ PPG-RE-030-R1 - Projeto Preparatório para o Gerenciamento dos Recursos Hídricos do Paraíba do Sul Aplicação dos critérios para a hierarquização das intervenções estruturais relativas aos projetos de esgotamento sanitário e apresentação da alternativa recomendada para 0 Projeto Inicial. Julho de 2000. Disponível em: http://www.hidro.ufrj.br/ppg/relatorios/ppg-re-30/introducao.pdf. Acessado em: 10 outubro de 2016.

- LABORATÓRIO DE HIDROLOGIA - COPPE/UFRJ PPG-RE-050-R0 - Projeto Preparatório para o gerenciamento dos recursos hídricos do Paraíba do Sul Relatório Final. Agosto de 2000. Disponível em: < http://www.hidro.ufrj.br/ppg/relatorios/ppg-re-50.pdf. Acessado em: 10 outubro de 2016.

- LIMA JUNIOR, F. R. Comparação entre os métodos fuzzy TOPSIS e fuzzy AHP no apoio a tomada de decisão para seleção de fornecedores. Dissertação de Mestrado Engenharia de Produção - Escola de Engenharia de São Carlos Universidade de São Paulo - São Carlos/SP. 2013.2 Disponível em: http://www.teses.usp.br/teses/disponiveis/18/18156/tde-12092013-103003/pt-br.php. Acessado em: 10 agosto de 2016. 
- LIMA JUNIOR, F. R.; CARPINETTI, L. C. R. Uma comparação entre os métodos TOPSIS e Fuzzy-TOPSIS no apoio à tomada de decisão multicritério para seleção de fornecedores. Gest. Prod., São Carlos, v. 22, n. 1, p. 17-34, 2015. Disponível em: http://www.scielo.br/scielo.php?script=sci arttext\&pid=S0104-530X2015000100017.

Acessado em: 10 novembro de 2016.

- MARDANI, Abbas; JUSOH, Ahmad; NOR, Khalil MD; KHALIFAH, Zainab; ZAKWAN, Norhayati and VALIPOUR, Alireza Multiple criteria decision-making techniques and their applications - a review of the literature from 2000 to 2014 . ECONOMIC RESEARCH-EKONOMSKA ISTRAŽIVANJA VOL. 28 , ISS. 1, 2015. Disponível em: http://www.tandfonline.com/doi/full/10.1080/1331677X.2015.1075139. Acessado em

- MEDEIROS JR, A. Seleção de Sistema Integrado de Gestão (ERP) Alinhado à Estratégica de Negócio. XXXIII ANPAD SP 19 a 23 de janeiro de 2009. Disponível em: http://www.anpad.org.br/admin/pdf/ADI2286.pdf. Acessado em 20 de novembro de 2016.

- MUSSOI, F. \& TEIVE, R. Uma abordagem multicritério para seleção do portfólio de projetos de melhorias e expansão do sistema de distribuição de energia elétrica. Anais do XIX Congresso Brasileiro de Automática, CBA 2 a 6 de setembro de 2012 Campina Grande. Disponível em: http://www.eletrica.ufpr.br/anais/cba/2012/Artigos/97722.pdf. Acessado em: 15 de outubro de 2016.

- NUNES JUNIOR, L. F. Tomada de decisão com múltiplos critérios - Pesquisa-ação sobre o método AHP em pequenas empresas. Dissertação de Mestrado em Gestão e Desenvolvimento Regional do Departamento de Economia, Contabilidade e Administração da Universidade de Taubaté/ SP 2006. Disponível em: http://ppga.com.br/mestrado/2006/nunesjr-luis_fernando.pdf. Acessado em: 27 de novembro de 2016.

- PERdigÃo, J. G. L.; FUlGÊNCIO, E. V.; SOUSA, S. A. C.; MAGALHÃES NETO, J. B.; DORNELAS, J. S. Processo decisório: um estudo comparativo da tomada de decisão em organizações de segmentos distintos. IX Simpósio de Excelência em Gestão em Tecnologia 2012. Disponível em: http://www.aedb.br/seget/arquivos/artigos12/7416262.pdf. Acessado em: 23 de novembro de 2016. 
- PEREIRA, S. L. Utilização do método multicritério PROMÉTHÉE para definição da ordem de desenvolvimento de programas de Indicadores de negócio. Faculdades Ibmec/RJ XXXVI - SBPO São João del Rei- MG 23 a 26/11/04. Disponível em: http://www.din.uem.br/sbpo/sbpo2004/pdf/arq0160.pdf. Acessado em: 23 de novembro de 2016.

- PONTES, I. Integração do modelo Topsis e fuzzy multi-objetivo para o problema de seleção de fornecedores. Trabalho do curso de Engenharia de Produção, Disciplina: Método Matemático Aplicado a Engenharia Da universidade Estácio de Sá 17 de novembro de 2012.

- RAFFO, J. G. DA G. O Processo Analítico Hierárquico e seu uso na modelagem do espaço geográfico. Revista do Departamento de Geografia - USP, v. Volume Esp, p. 2637, 2012. Disponível em: http://www.revistas.usp.br/rdg/article/view/53840/57803. Acessado em: 21 outubro de 2016.

- REZENDE, H. F. F. Seleção de sistema de informações gerenciais de projetos utilizando SAW e VIP analysis. Dissertação de Mestrado profissionalizante em Administração IBMEC-RJ, Fevereiro 2012. Disponível em: http://docplayer.com.br/16017910-Selecao-de-sistema-de-informacoes-gerenciais-deprojetos-utilizando-saw-e-vip-analysis.html. Acessado em: 23 de novembro de 2016.

- RODRIGUEZ, D; COSTA, H; CARMO, L. Métodos de auxílio multicritério à decisão aplicados a problemas de PCP: Mapeamento da produção em periódicos publicados no Brasil. Gestão e Produção, São Carlos, v. 20, n. 1, p. 134-146 2013. Disponível em: http://www.scielo.br/scielo.php?script=sci_arttext\&pid=S0104-530X2013000100010. Acessado em: 07 novembro 2016.

- SALOMON, V. A. P.; MONTEVECHI, J. A. B. A compilation of comparisons on the Analytic Hierachy Process and others multiple criteria decision making methods: some cases developed in Brasil. 60 ISAHP, Suíça. 2001. Disponível em: http://www.feg.unesp.br/ salomon/pesquisa/vapsjabm.pdf. Acessado em: 07 novembro 2016. 
- SALOMON, V. P.; MONTEVECHI, J. A. B.; PAMPLONA, E. O. Justificativas para aplicação do método de análise hierárquica. 19 ENEGEP, Rio de Janeiro. 1999. Disponível em:

http://www.iepg.unifei.edu.br/edson/download/Artahp99.pdf. Acessado em: 29 outubro 2016.

- SRDJEVIC B., Advanced decision support tools in agriculture and water management. International Conference on Sustainable Agriculture and European Integration Processes, Novi Sad, Serbia. 2004. Disponível em: http://citeseerx.ist.psu.edu/viewdoc/download;jsessionid=CF66B78DE86A77E6A8005318 EF7D5F64?doi=10.1.1.203.800\&rep=rep1\&type=pdf. Acessado em: 23 de novembro de 2016.

- THOR, J.; DING, S.; KAMARUDDIN, S. Comparison of multi criteria decision making methods from the maintenance alternative selection perspective. The International Journal Of Engineering And Science (IJES) - Volume 2 Issue 6 Pages 27-34. 2013. Disponível em: http://www.theijes.com/papers/v2-i6/Part.4/D0364027034.pdf. Acessado em: 23 de outubro de 2016.

- VIEIRA, B. K. G.; AMARAL, T. M. Aplicação de decisão multicritério no desempenho de funcionários a partir do método PROMETHEE II. XXXV ENCONTRO NACIONAL DE ENGENHARIA DE PRODUCAO Fortaleza, CE, Brasil, 13 a 16 de outubro de 2015. Disponível em: $\quad$ http://www.abepro.org.br/biblioteca/TN STP 211251 27010.pdf. Acessado em: 28 de novembro de 2016.

- VILAS-BOAS, C. L. (2016) Método multicritérios de análise de decisão (MMAD) na gestão de recursos hídricos. Dissertação de Mestrado em Economia - Gestão Econômica do Meio Ambiente na Universidade de Brasília / novembro 2006. Disponível em: http://www.cprm.gov.br/publique/media/vilas boas.pdf. Acessado em 23 de outubro de 2016.

- WERNKE, R.; BORNIA, A. C; A contabilidade gerencial e os métodos multicriteriais. Revista Contabilidade \& Finanças FIPECAFI - FEA - USP, São Paulo, FIPECAFI, v.14, n. 25, p. 60 - 71, janeiro/abril 2001. Disponível em: http://www.scielo.br/pdf/rcf/v12n25/v12n25a04.pdf. Acessado em 23 de outubro de 2016. 
- XIANG, W. N.; GROSS, M; FABOS, J. G.; MACDOUGALL, E. B. A fuzzy-group multicriteria decisionmaking model and its application to land-use planning. Environment and Planning B: Planning and Design, 1992, volume 19, pages 61-84. Disponível em: http://journals.sagepub.com/doi/pdf/10.1068/b190061. Acessado em: 20 de outubro de 2016.

- ZOLFAN, S.H.; MAKNOON, R; ZAVADSKAS, E. K. MADM and futures studies; a necessity. $9^{\text {th }}$ International Scientific Conference "Business and Management 2016", At Vilnius Gediminas Technical University, Vilnius, Lithuania. 2016 . Disponível em: https://www.researchgate.net/publication/303550221 MADM AND FUTURES STUDIES A NECESSITY. Acessado em: 22 de novembro de 2016. 